\title{
Towards Wireless Characterization of Solvated lons with Uncoated Resonant Sensors
}

sadaf charkhabi, Adam R. Carr, Jiahao Wu, Subhanwit Roy, Andee M. Beierle, Dustin K. Thomas, Leigh Ann M. Long, Michelle Soupir, Nathan M. Neihart, Nigel F. Reuel

Submitted date: 03/05/2020 - Posted date: 05/05/2020

Licence: CC BY-NC-ND 4.0

Citation information: charkhabi, sadaf; Carr, Adam R.; Wu, Jiahao; Roy, Subhanwit; Beierle, Andee M.; Thomas, Dustin K.; et al. (2019): Towards Wireless Characterization of Solvated lons with Uncoated Resonant Sensors. ChemRxiv. Preprint. https://doi.org/10.26434/chemrxiv.9595628.v2

Uncoated resonant sensors are presented here for wireless monitoring of solvated ions, with progress made toward monitoring nitrates in agricultural runoff. The sensor, an open-circuit Archimedean coil, is wirelessly interrogated by a portable vector network analyzer (VNA) that monitors the scattering parameter response to varying ionic concentrations. The sensor response is defined in terms of the resonant frequency and the peak-to-peak amplitude of the transmission scattering parameter profile $\left(\left|\mathrm{S}_{21}\right|\right)$. Potassium chloride $(\mathrm{KCl})$ solutions with concentrations in the range of $100 \mathrm{nM}-4.58 \mathrm{M}$ were tested on nine resonators having different length and pitch sizes to study the effect of sensor geometry on its response to ion concentration. The resonant sensors demonstrated an ion-specific response, caused by the variations in the relative permittivity of the solution, which was also a function of the resonator geometry. A lumped circuit model, which fit the experimental data well, confirms signal transduction via change in solution permittivity. Also, a ternary ionic mixture (composed of potassium nitrate $\left(\mathrm{KNO}_{3}\right)$, ammonium nitrate $\left(\mathrm{NH}_{4} \mathrm{NO}_{3}\right)$, and ammonium phosphate $\left.\left(\mathrm{NH}_{4} \mathrm{H}_{2} \mathrm{PO}_{4}\right)\right)$ response surface was constructed by testing 21 mixture variations on three different sensor geometries and the phase and magnitude of scattering parameters were monitored. It was determined that the orthogonal responses presented by resonant sensor arrays can be used for quantifying levels of target ions in ternary mixtures. Applications of these arrays include measuring the concentration of key ions in bioreactors, human sweat, and agricultural waters. Preliminary results are shown for calibration standards and real waterway samples in lowa, USA.

File list (2)

Ion Paper_v36.docx (7.52 MiB)

view on ChemRxiv - download file

Supplement_v9.docx (4.06 MiB)

view on ChemRxiv - download file 


\title{
Towards Wireless Characterization of Solvated lons with Uncoated Resonant Sensors
}

Sadaf Charkhabi ${ }^{\mathrm{a}}$, Adam R. Carr ${ }^{\mathrm{a}}$, Jiahao $\mathrm{Wu}^{\mathrm{a}}$, Subhanwit Roy ${ }^{\mathrm{b}}$, Andee M. Beierle ${ }^{\mathrm{a}}$, Dustin K. Thomas $^{\mathrm{a}}$, Leigh Ann M. Long ${ }^{\mathrm{c}}$, Michelle L. Soupir ${ }^{\mathrm{c}}$, Nathan M. Neihart ${ }^{\mathrm{b}}$, and Nigel F. Reuel ${ }^{\mathrm{a} *}$

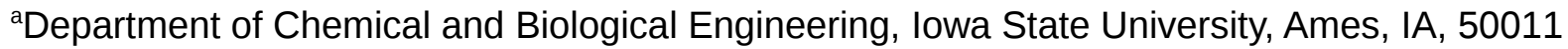

${ }^{\mathrm{b}}$ Department of Electrical and Computer Engineering, Iowa State University, Ames, IA, 50011

'Department of Agricultural and Biosystems Engineering, lowa State University, Ames, IA, 50011

*Corresponding Author - reuel@iastate.edu

\begin{abstract}
Uncoated resonant sensors are presented here for wireless monitoring of solvated ions, with progress made toward monitoring nitrates in agricultural runoff. The sensor, an open-circuit Archimedean coil, is wirelessly interrogated by a portable vector network analyzer (VNA) that monitors the scattering parameter response to varying ionic concentrations. The sensor response is defined in terms of the resonant frequency and the peak-to-peak amplitude of the transmission scattering parameter profile $\left(\left|\mathrm{S}_{21}\right|\right)$. Potassium chloride $(\mathrm{KCl})$ solutions with concentrations in the range of $100 \mathrm{nM}-4.58 \mathrm{M}$ were tested on nine resonators having different length and pitch sizes to study the effect of sensor geometry on its response to ion concentration. The resonant sensors demonstrated an ion-specific response, caused by the variations in the relative permittivity of the solution, which was also a function of the resonator geometry. A lumped circuit model, which fit the experimental data well, confirms signal transduction via change in solution permittivity. Also, a ternary ionic mixture (composed of potassium nitrate $\left(\mathrm{KNO}_{3}\right)$, ammonium nitrate $\left(\mathrm{NH}_{4} \mathrm{NO}_{3}\right)$, and ammonium phosphate $\left(\mathrm{NH}_{4} \mathrm{H}_{2} \mathrm{PO}_{4}\right)$ ) response surface was constructed by testing 21 mixture variations on three different sensor geometries and the phase and magnitude of scattering parameters were monitored. It was determined that the orthogonal responses presented by resonant sensor arrays can be used for quantifying levels of target ions in ternary mixtures. Applications of these arrays include measuring the concentration of key ions in bioreactors, human sweat, and agricultural waters. Preliminary results are shown for calibration standards and real waterway samples in lowa, USA.
\end{abstract}

KEYWORDS: Resonant sensor|Ion concentration|LCR sensor|Wireless |Resonant frequency 
Charged chemical species, ions, are the signaling logic of biological systems and ubiquitous in natural waterways, industrial processes, and energy systems. Detection of their presence and level is important for many processes, such as identifying harmful levels of nitrate in agricultural runoff water that can lead to downstream eutrophication and algae blooms. ${ }^{1,2}$ Since ions play such significant roles in many systems, there have been several methods developed for accurate measurement of ion concentration in solutions since the early $1900 \mathrm{~s}^{3}$ including, but not limited to, spectrophotometric methods ${ }^{4}$, photoluminescent probes ${ }^{5}$, ion chromatography ${ }^{6}$, and optical fiber sensors. ${ }^{7}$ Frequently used ion-selective membrane electrodes (ISME) ${ }^{8}$ measure the potential difference caused by the interactions between the targeted ion and the ionophore which is present in the selective membrane. ${ }^{9}$ The major challenges associated with these techniques are the need for bulky instruments and direct access to the solution (required sampling).

In recent years, there have been some novel advances to enable wireless ion concentration measurements to measure in situ without sampling. A common strategy is to couple a solidstate ISME to powered, integrated circuits (ICs) that enable wireless measurement (e.g. Bluetooth, cellular). ${ }^{10}$ In one embodiment the ISME is coupled to an RFID potentiometer (operating at the ISM $13.56 \mathrm{MHz}$ band); the RFID tag has an internal, electrically erasable, programmable read-only memory to store the sensor data and the sensor can be wirelessly accessed. ${ }^{11,12}$ Optical probes have also been developed to enable contact-free measurement, but require a transparent line of sight. ${ }^{13-15}$ Measuring ions, contact-free, from opaque closed systems (biological, manufacturing, and processing) without wireless communication ICs (typically powered) has not been demonstrated. A simple, passive, wireless system is critical for applications where the sensor is widely distributed to many measurement nodes (e.g. a farm field or large runoff and river system) or in applications that demand a disposable price point (e.g. single-use bioreactors ${ }^{16-22}$ or sweat analytic wearables ${ }^{23-27}$ ). Ion monitoring is needed to measure, model, and control these systems.

The focus of this paper is to demonstrate the use of passive, resonant sensors for the wireless measurement of ions. Resonant sensors, also known as LCR sensors, are inexpensive simple circuits containing an inductor $(\mathrm{L})$, capacitor $(\mathrm{C})$, and inherent system resistance $(\mathrm{R}) .{ }^{28}$ The sensor has a specific resonant response which will modulate by altering one or more of the above-mentioned circuit parameters. The applicability of these sensors in measuring physical (e.g. temperature, humidity, strain, and pressure $)^{29-32}$, chemical (e.g. $\left.\mathrm{pH}\right)^{33-39}$, and biological (e.g. bacterial growth, enzyme activity, and tissue characterization $)^{40-44}$ parameters have been reported. In terms of ions, the concentration of nitrate, sulfate, and phosphate ions was estimated in water sources via planar electromagnetic sensors. ${ }^{45-47}$ For instance, tethered LC resonators have been used to sense phosphate and nitrate in solutions by correlating the ion concentration to the transmission coefficient response behavior using a vector network analyzer. ${ }^{48}$ However, the sensor is not truly wireless, as it is directly connected to the VNA via coaxial cables. Hence, it is not appropriate for applications in which it is not possible to have direct access to the sensor.

To the best of our knowledge, a non-invasive, passive (no onboard power), wireless sensor capable of reporting real-time, ionic concentration in aqueous solutions has not been described. Herein we demonstrate the response of resonant sensors to a panel of ions that are relevant to environmental and agricultural applications. These sensors resonate at specific frequencies, which can be tuned by the resonator's geometry ${ }^{28}$, and herein we show how these resonant 
properties are modulated based on the type and amount of solvated ions. To describe this phenomenon, we also model the effect of ions using a lumped circuit model to validate the transduction mechanism proposed as a change in solution permittivity. To demonstrate utility of an uncoated resonant sensor, we show the response to nitrates in agricultural field runoff. Finally, we determine the effect of resonator geometry on ion-specific responses and show the limits of fingerprinting ternary mixtures of ionic compounds with an array of three resonators with orthogonal responses.

\section{RESULTS AND DISCUSSION}

\section{Resonator Fabrication and Measurement}

As explained in the previous works ${ }^{30,42}$, the resonators were rapidly fabricated in a standard laboratory without lithographic processes. In brief, the steps were: 1) depositing the spiralshaped positive mask on a copper-polyimide flexible substrate, 2) etching the sheet to remove the unmasked copper, and 3) rinsing the sample with acetone to remove the mask (Figure 1a). The resonator was then adhered to the base of a petri dish in order to prevent short-circuiting and the dish was securely positioned over a two-loop reader antenna connected to a vector network analyzer (VNA) (Figure 1b). The VNA measures the scattering parameter (S parameters) from the system (phase and magnitude data). The sensing medium containing the ionic compound(s) of interest was added to the dish and the coupled signal from the LC sensor and medium was measured by the VNA. The dielectric properties of the sensor environment were affected by the ions in solution which resulted in variations in the reported values for the Sparameters. By monitoring the magnitude of the transmission S-parameter signal $\left(\left|S_{21}\right|\right)$ over the frequency range of interest (10-100 MHz), we were able to extract two variables of the sigmoidal $\left|S_{21}\right|$ response (Figure $1 \mathrm{c}$ ): peak resonant frequency (I), and peak-to-peak amplitude (II). A custom algorithm is then used to detect the resonant (peak) and anti-resonant (trough) frequencies (red circles in Figure 1c). The peak-to-peak amplitude is the vertical distance of the peak to trough, as a measure of power $(\mathrm{dB})$ absorbed by the resonator. 


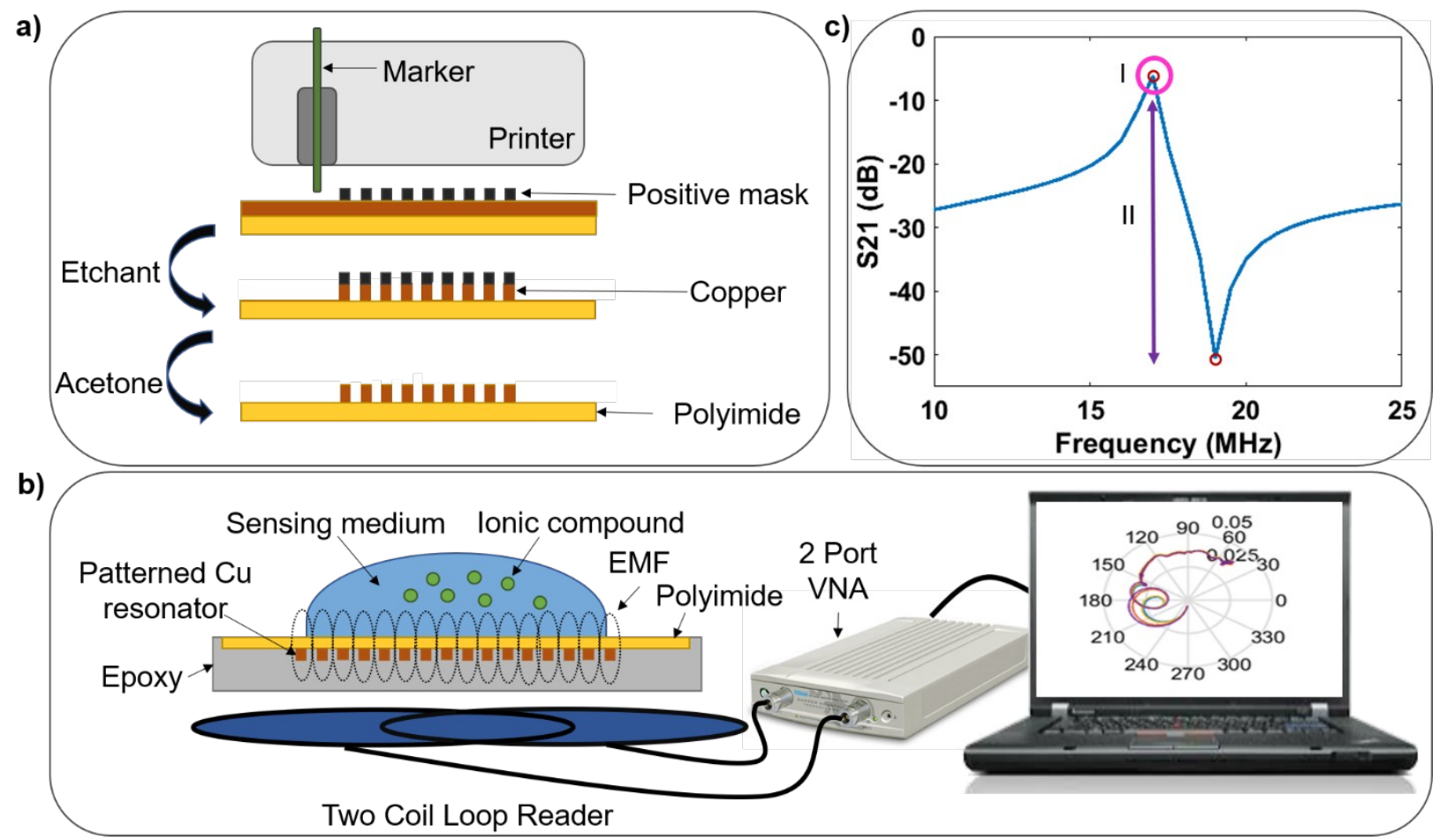

Figure 1. Fabrication and operating principles of resonant sensors. (a) Three-step process for prototyping resonant sensors from copper clad polyimide: positive masking, etching, and mask removal; (b) summary of the method for detection and measurement of ionic compounds in a solution using an external reader antenna connected to a vector network analyzer and monitoring the scattering parameter response; (c) example of the transmission magnitude response $\left(\left|S_{21}\right|\right)$ in which resonant frequency and peak amplitude are noted as I and II, respectively.

\section{Modeling of Resonator Response}

Next, the response of the resonant sensor and reader antenna system were described with a lumped element model (Figure 2a). Each non-concentric coil in the reader is modeled as a pair of coupled parallel LCR resonators where $L_{P}$ models the self-inductance of each coil, $C_{P}$ models the parasitic capacitance to ground, and $\mathrm{R}_{\mathrm{P}}$ models the conduction losses in the reader. The coupling between each coil is modeled through the mutual inductance, $M_{1}$. The values for $L_{P}, C_{P}$, $\mathrm{R}_{\mathrm{P}}$, and $\mathrm{M}_{1}$ were extracted from experimentally measured $\mathrm{S}$-parameters from our system (168.8 $\mathrm{nH}, 9.4 \mathrm{pF}, 27.3 \mathrm{k} \Omega$, and $-11.4 \mathrm{nH}$, respectively). The S-parameters were measured from 300 $\mathrm{kHz}$ to $100 \mathrm{MHz}$ using an Agilent 5071C 4-port network analyzer calibrated such that the reference plane was at the terminals of the reader. While more complicated models could be used for the reader, good agreement between the simulated and measured S-parameters were obtained with the model (Figure $2 \mathrm{c}$ and $\mathrm{d}$ ).

The resonator is a spiral (Figure $2 b$ ) of copper on a thin, flexible substrate, with its terminals left in an open circuit. The resonator has an outer diameter, $d_{\text {out }}$, an inner diameter, $d_{i n}, a$ pitch, $P$, and a set number of turns, N. Further, we define the average diameter and fill ratio to be:

$$
d_{\text {avg }}=\frac{1}{2}\left(d_{\text {out }}+d_{i}\right)
$$




$$
\rho=\frac{d_{\text {out }}-d_{i}}{d_{\text {out }}+d_{i}}
$$

Moreover, the material to which the resonator is exposed has a complex relative permittivity, $\varepsilon_{\mathrm{r}}$. In our setup, this is the aqueous solution with ions above the resonator. The resonator (Figure $2 b$ ) is modeled using a series LCR circuit (Figure 2a), where the inductor, $L_{\text {res, }}$ models the selfinductance of the resonator coil and $\mathrm{R}_{\text {res }}$ models the conduction losses in the metal. The capacitor, $\mathrm{C}_{\text {res}}$, models the parasitic capacitance seen across the terminals of the resonator and is dependent upon the material to which the resonator is exposed. Finally, the interaction between the resonator and the reader is modeled with the mutual inductances $M_{2 A}$ and $M_{2 B}$. The self-inductance of the resonator can be approximated using the following expression: ${ }^{49}$

$$
L_{r e s}=\frac{1}{2} \mu_{0} N^{2} d_{\text {avg }}\left(\ln \left(\frac{2.46}{\rho}\right)+0.2 \rho^{2}\right)
$$

Where $\mu_{0}$ is the permeability of free space $\left(1.257 \times 10^{-6} \mathrm{H} / \mathrm{m}\right), \mathrm{N} \quad$ is the number of turns, and $\mathrm{d}_{\mathrm{avg}}$ and $\rho$ are defined in (eq 1) and (eq 2), respectively. The value for the capacitor, $\mathrm{C}_{\text {res, }}$, is obtained from the self-resonant frequency, $f_{\mathrm{SR}}$, of the resonator:

$$
C_{r e s}=\left(4 \pi^{2} f_{S R}^{2} L_{r e s}\right)^{-1}
$$

The self-resonant frequency of the resonator will depend on the material to which the resonator is exposed through a change in the complex relative permittivity, $\varepsilon_{r}$. Using expressions adapted from ${ }^{50}$, we can approximate the self-resonant frequency as:

$$
f_{S R}=\frac{C}{2 l \sqrt{\varepsilon}}\left(0.24 N^{-0.46}+0.95\right)(1+\beta)
$$

where $c$ is the speed of light in free space, $\quad l$ is the total length of copper used to construct the resonator, $\varepsilon^{\prime}$ is the real component of the complex relative permittivity, and $\beta$ is expressed as:

$$
\beta=-\left((0.29+0.043 \rho)\left(\frac{d_{\text {i }}}{d_{\text {out }}}\right)+0.22\right)\left((\rho-0.5)\left(2.65\left(\frac{P}{d_{\text {out }}}\right)+0.03\right)+1\right)
$$

The series resistance of the resonator, $R_{\text {res }}$, is approximated from the resistivity of copper and the skin effect. ${ }^{51}$ It is assumed that the metal used to realize the resonator has a circular cross-section with an effective area expressed as:

$$
A_{e f f}=D \pi \sqrt{\frac{1.678 \times 10^{-8}}{\pi \mu_{0} f_{S R}}}
$$


where $D$ is the cross-sectional diameter of the copper trace. The result of (eq 7) can then be used to express the total $A C$ resistance of the resonator as:

$$
R_{\text {res }}=\frac{1.678 \times 10^{-8}}{A_{\text {eff }}} \cdot l
$$

To demonstrate the utility of this model, a resonator with $\mathrm{d}_{\text {in }}=1.5 \mathrm{~mm}, \mathrm{~d}_{\text {out }}=40 \mathrm{~mm}, \mathrm{P}=1 \mathrm{~mm}$, $\mathrm{N}=20$, and $l=1255 \mathrm{~mm}$ is considered. Equations (eq 3) - (eq 8) are evaluated for the cases where the resonator is exposed to air, DI water, and a $3 \mathrm{mM}$ solution of potassium chloride $(\mathrm{KCl})$. The static relative permittivity (relative permittivity at $\mathrm{DC}$ ) for air and DI water are $\varepsilon_{\mathrm{rA}}=1$ and $\varepsilon_{\mathrm{rW}}=80.4$, respectively. ${ }^{52}$ The static relative permittivity for the $\mathrm{KCl}$ solution was estimated to be $\varepsilon_{\mathrm{rkCl}}=78.8 .^{53}$ The resulting resonator model values are shown in Table S1. We also compared simulated S-parameters of the model to measured S-parameters for air and DI water (Figure 2e) and the $3 \mathrm{mM}$ solution of $\mathrm{KCl}$ (Figure 2f).

Using the model (Figure 2a), the simulated $\left|\mathrm{S}_{21}\right|$ matches well with experimental results for air and DI water (Figure 2e). There are, however, resonant peaks in the measured response at approximately $40 \mathrm{MHz}$ and $60 \mathrm{MHz}$ that are not captured by the simulation. These peaks are likely the result of higher-order interactions between the reader/resonator/solution system that were not captured in this model. Comparing the simulated and measured $\left|S_{21}\right|$ for the $\mathrm{KCl}$ solution, we see that the model accurately predicts the frequencies of the peaks and valleys, but the simulated magnitudes are several $\mathrm{dB}$ larger than the measured values. This is due to the method by which the resonator loss is modeled. The loss was modeled as just the AC loss in the conductors. There is possible additional loss due to the increased conductivity of the solution resulting in energy loss caused by the interaction between the electric fields and the ions in the solution.

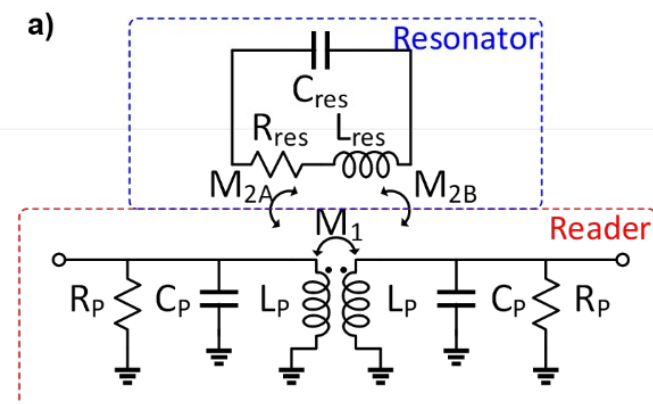

b)

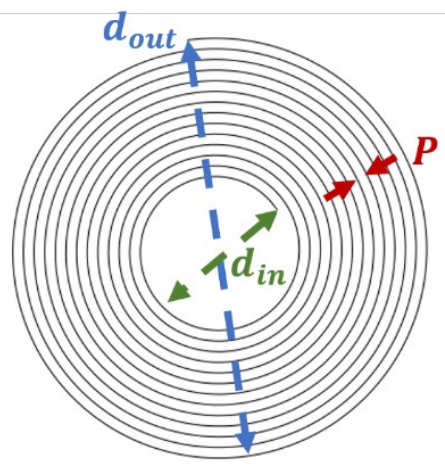

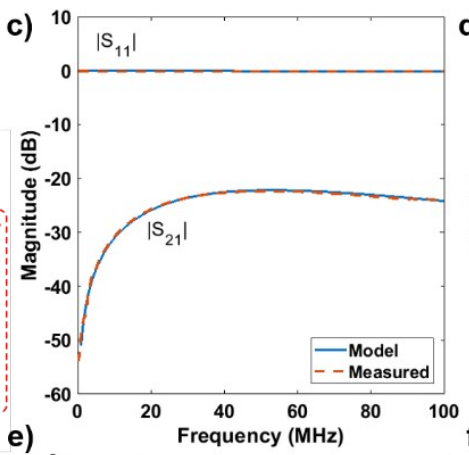

e)

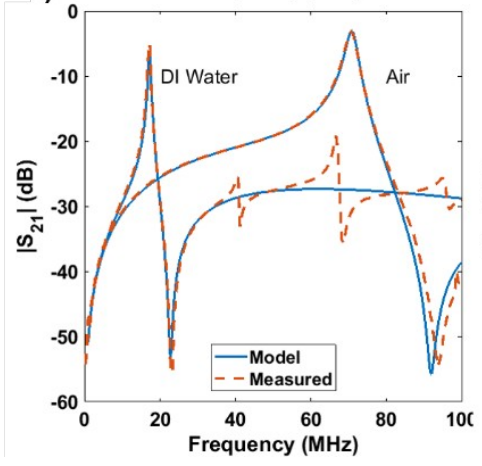

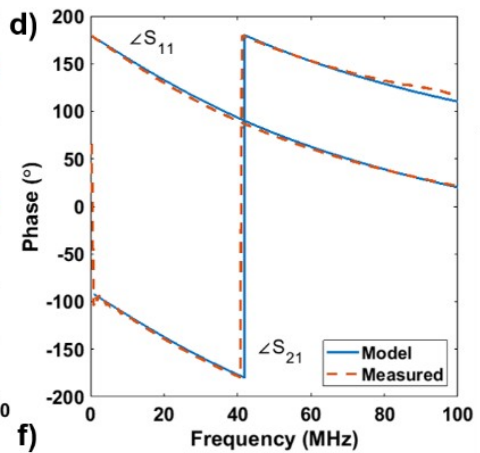

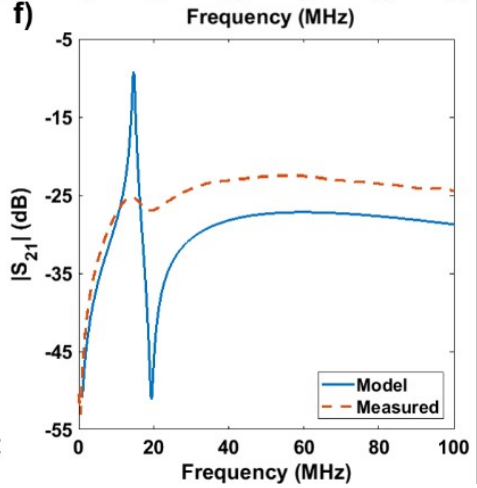


Figure 2. Modeled response of the resonant circuit. (a) Lumped circuit model of resonator and reader; (b) the Archimedean spiral resonator having three design parameters: inner diameter, outer diameter, and pitch size; simulated and measured (c) magnitude and (d) phase of $S_{21}$ and $S_{11}$ for the reader; (e) simulated and measured $\left|S_{21}\right|$ for the resonator exposed to air and DI water; (f) Simulated and measured | $\mathrm{S}_{21} \mid$ for $3 \mathrm{mM}$ of $\mathrm{KCl}$.

\section{Effects of Salt Concentration on Resonant Sensor Response}

In order to determine the effect of the ion concentration existing in an aqueous solution on the | $\mathrm{S}_{21} \mid$ response of the sensor, different concentrations of $\mathrm{KCl}$, ranging from $100 \mathrm{nM}$ to $1 \mathrm{M}$ as well as the solubility limit of $\mathrm{KCl}$ in $\mathrm{DI}$ water at room temperature $(4.58 \mathrm{M})^{54}$, were measured on a resonator with $\mathrm{d}_{\mathrm{in}}=1.5 \mathrm{~mm}, \mathrm{~d}_{\text {out }}=40 \mathrm{~mm}, \mathrm{P}=1 \mathrm{~mm}$. To initialize the experiment, deionized (DI) water was initially added to the petri dish $(50 \mathrm{ml})$ and the sensor setup was positioned at the center of the reader. Increasing concentrations of $\mathrm{KCl}$ were added to the solution while the total volume was kept constant in order to eliminate the effect of liquid volume on the sensor response. Using this method, 40 different concentrations of $\mathrm{KCl}$ were tested on the sensor (Table S2). By monitoring $\left|\mathrm{S}_{21}\right|$ (Code S3), it was observed that the resonant frequency and amplitude change as a function of ion concentration (Figure 3), however, not in a monotonic pattern as we expected.

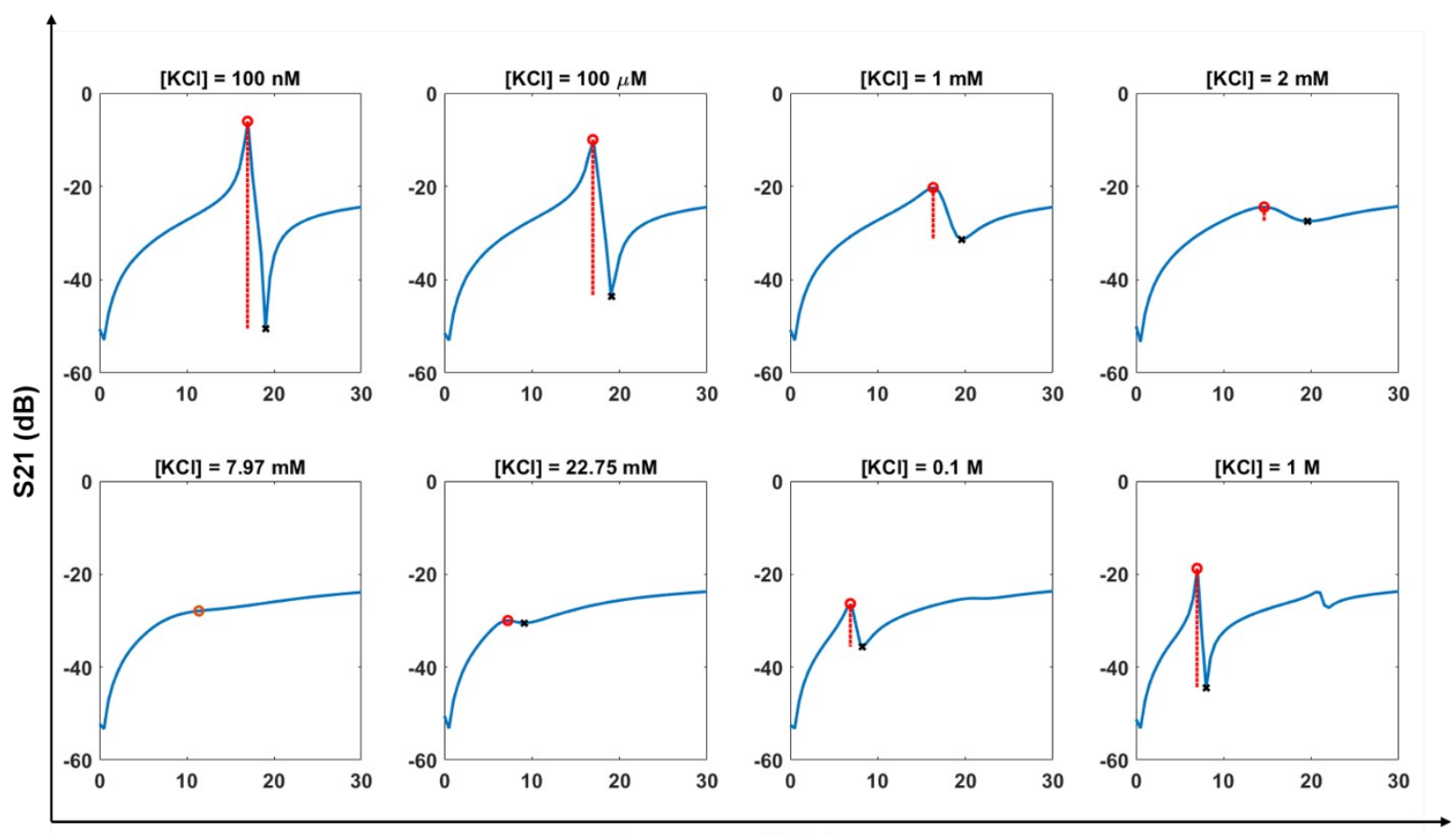

Frequency $(\mathrm{MHz})$

Figure 3. $\left|\mathrm{S}_{21}\right|(\mathrm{dB})$ response of $40 \mathrm{~mm}$ diameter, $1 \mathrm{~mm}$ pitch resonator to increasing concentration of $\mathrm{KCl}$. Red circle denotes resonant peak, black $x$ marks the anti-resonant trough, and the red dotted line shows peak amplitude.

The sensor response was more complex than anticipated (Video S4). The resonant peak initially appeared (16.96 MHz for this sensor) and did not change with concentration from 0 to $0.1 \mathrm{mM}$ $\mathrm{KCl}$ solution while the amplitude decreased. With further increase in the concentration of $\mathrm{KCl}$, the resonant frequency shifted to a lower frequency $(6.9 \mathrm{MHz})$ and it went through a transition 
point in where the peak was not detectable at $8 \mathrm{mM}$ (amplitude of zero). Above $20 \mathrm{mM}$, the peak-to-peak amplitude increased, and the resonant frequency continued to decrease up to 60 $\mathrm{mM}$ and reached a relatively stable level again at higher concentrations. At this phase, the resonant frequency increased $(0.174 \mathrm{MHz}$ for the sensor in Figure 3) as the concentration increased from $60 \mathrm{mM}$ to $4.58 \mathrm{M}$.

The sensor response observed here is in fair agreement with the previous experimental and circuit modeling studies as well as the physical principles of the electrolyte solutions, such as Debye-Falkenhagen theory and the kinetic polarization deficiency effect (detailed in S5). For instance, the drop in the resonant frequency with changing ionic concentration is caused by an increment in the relative permittivity of the aqueous $\mathrm{KCl}$ solution, which has been demonstrated by Hubbard et.al. ${ }^{55}$ Furthermore, the resonance feature behavior at concentrations around $8 \mathrm{mM}$ can be explained via circuit model developed by Elsherbiny et.al. In this model, the mismatch between the impedance of the spiral inductor and the solution impedance at certain concentrations causes poor power transfer from the spiral to the sample medium, which eventually results in full attenuation of the resonant signal. ${ }^{56}$

\section{Effect of Resonator Geometry on Sensor Response}

Next, we determined the effect of resonator geometry on these $\left|S_{21}\right|$ responses (plotted using MATLAB (Code S7)) caused by increasing $\mathrm{KCl}$ concentration. Nine resonators with variant pitch and length sizes were designed (Table S6) and the same concentrations of $\mathrm{KCl}$ from above were studied. Similar patterns for shifts in resonant frequency and peak amplitude were observed (Figure 4); however, the magnitudes of these measurements were dependent on the geometry of the sensor.

The initial resonant frequency $\left(f_{S R}\right)$, which did not go through major changes up to $1 \mathrm{mM}$, was observed to be dependent on the geometrical parameters (e.g. outer diameter, pitch size, number of turns, etc.) of the Archimedean spiral resonator. For resonators with similar length $(1255 \mathrm{~mm})$ and variant pitch sizes (1-2.5 mm), the measured self-resonant frequency was higher for a larger pitch size (Figure S8a) which is consistent with the previous findings. ${ }^{40}$ For the spirals with a similar pitch size $(1.2 \mathrm{~mm})$ and different length $(800-2764 \mathrm{~mm})$, the resonant frequency was inversely related to the length size (Figure S8b). As the length increases, both the outer diameter $\left(\mathrm{d}_{\text {out }}\right)$ and the number of turns $(\mathrm{N})$ increase, which would cause the inductance $\left(\mathrm{L}_{\mathrm{res}}\right)$ of the circuit to increase (Eq. 3). This causes a lower resonant frequency. For all geometries, the large decrease in resonant frequency was observed in the concentration range of $0.1 \mathrm{mM}-0.1 \mathrm{M}$; however, the absolute value of this shift was more dependent on the length of the resonator rather than the pitch size (Figure S9).

As mentioned earlier, the resonant frequency response to different concentrations of $\mathrm{KCl}$ can be explained through the electrical properties of ionic aqueous solutions theories. This trend is consistent through all the resonators; however, unexpectedly, the window in which the peak-topeak amplitude is almost zero (e.g. where the resonator/solution system is most lossy) is dependent on the pitch size and coil length. We attribute this to the surface area of the sensor, which has the highest value for the largest pitch size and the largest coil length. For a resonator with a larger surface area, the reader antenna is better shielded from the ionic solution. Therefore the $\left|S_{21}\right|$ signal is less sensitive to the energy loss in this transition zone. 
a)

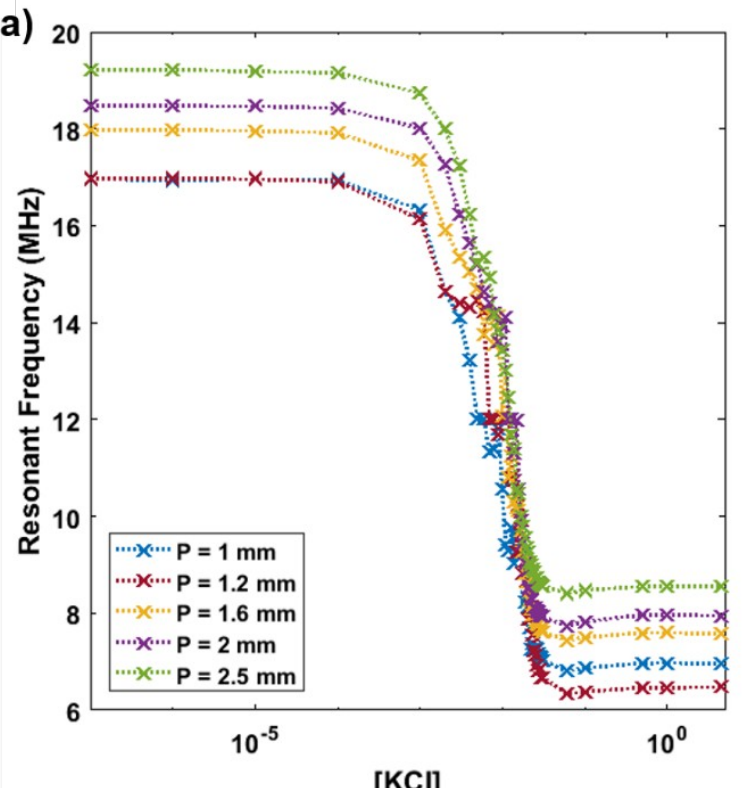

$[\mathrm{KCl}]$

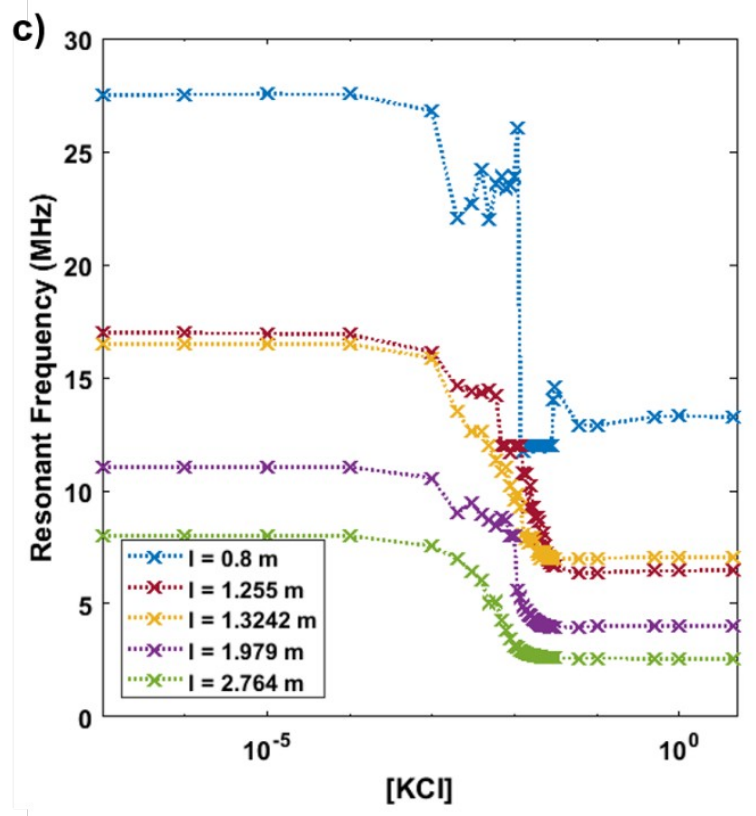

b)

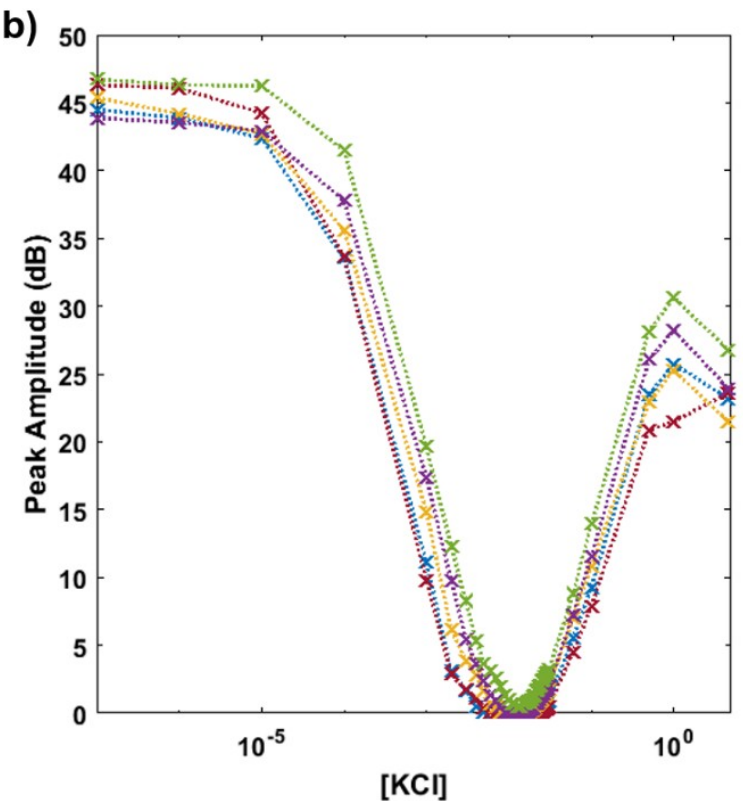

d)

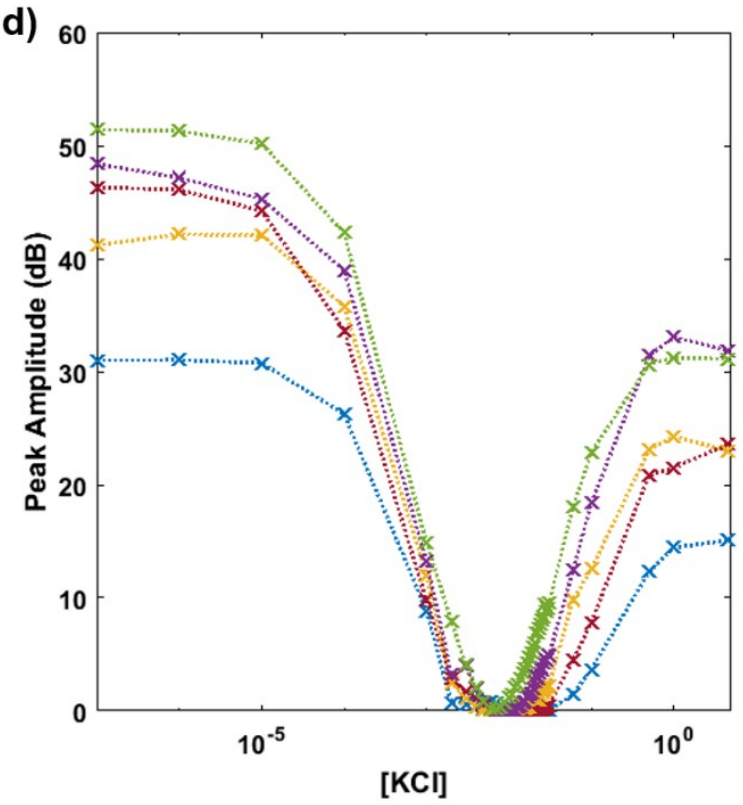

Figure 4. Effect of resonator geometry on $\left|\mathrm{S}_{21}\right|$ response to different concentrations of $\mathrm{KCl}$. The changes in resonant frequency and peak amplitude responses for resonators (a-c) with $1.26 \mathrm{~m}$ spiral length with varying pitch and (d-f) with constant $1.2 \mathrm{~mm}$ pitches and varying lengths (see Table S1).

\section{Effect of Ion Type on Sensor Response}

To further study the sensor response to ionic compounds, four salts were chosen to be tested on resonators to investigate if the LC sensors have an ion-specific response. The salt panel included potassium nitrate $\left(\mathrm{KNO}_{3}\right)$, ammonium nitrate $\left(\mathrm{NH}_{4} \mathrm{NO}_{3}\right)$, potassium phosphate $\left(\mathrm{KH}_{2} \mathrm{PO}_{4}\right)$, and ammonium phosphate $\left(\mathrm{NH}_{4} \mathrm{H}_{2} \mathrm{PO}_{4}\right)$, which were carefully selected to have matched cation and anion pairs. Also, since nitrate and phosphate are among most important anions in agriculture, they were chosen to demonstrate the potential application of this work. Since the length of the resonator had a more significant effect on the changes in the resonant 
frequency response to different $\mathrm{KCl}$ concentrations, three resonators with constant pitch size $(1.2 \mathrm{~mm})$ and different length $(0.8,1.26$, and $2.76 \mathrm{~m})$ were used for this test. The $\mathrm{S}_{21}$ sensor response for $100 \mu \mathrm{M}, 2 \mathrm{mM}, 30 \mathrm{mM}$, and $100 \mathrm{mM}$ for these salts are shown as polar plots (Figure 5). Polar plots (Code S10) are useful for these measurements as they show both the magnitude and phase of the $S_{21}$ signal simultaneously, rather than just the magnitude data (Figure 3 and 4) and subtle differences caused by geometric changes can be observed. In these polar plots, the radial gridlines represent the phase of $S_{21}$ and the concentric circles demonstrate the radio frequency (RF) voltage gain (RF output voltage/RF input voltage), which can be calculated using $\left|S_{21}\right|$ :

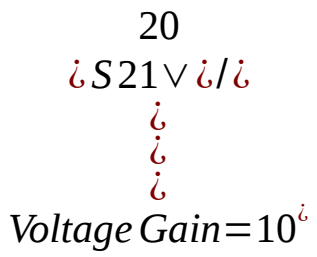

It was observed that the type of ion has a major effect on the sensor response for all concentrations of the ions and all geometries of the resonators (Video S11). The reason that the sensor is able to have a unique response to each of these salts is that they have different polarization behavior which leads to different dielectric properties. Furthermore, the Debye Falkenhagen expression is dependent on the mobility of ions and the type of salt. Therefore, the relative permittivity of aqueous solutions is dependent on the solvated salt. Even for a concentration in the transition range (30 mM here) in which the resonator behavior might look independent of the type of salt due to the collapse of the amplitude, there are small variations observed. In general, the $S_{21}$ signal response is more salt-dependent at very low $(<10 \mathrm{mM})$ and very high $(>100 \mathrm{mM})$ due to the higher amplitude at these regions. Nonetheless, the salts with similar anion $\left(\mathrm{KNO}_{3}-\mathrm{NH}_{4} \mathrm{NO}_{3}\right.$, and $\left.\mathrm{KH}_{2} \mathrm{PO}_{4}-\mathrm{NH}_{4} \mathrm{H}_{2} \mathrm{PO}_{4}\right)$ result in a more similar sensor response. We attribute this to the potassium and ammonium having identical ionic mobilities of 1 , while the ionic mobility for nitrate and phosphate are more unique, 0.972 and 0.45 , respectively. Therefore, $\mathrm{KNO}_{3}-\mathrm{NH}_{4} \mathrm{NO}_{3}$, and $\mathrm{KH}_{2} \mathrm{PO}_{4}-\mathrm{NH}_{4} \mathrm{H}_{2} \mathrm{PO}_{4}$ have similar electrical behavior in this system. Furthermore, it is of interest to note that the resonator having the smallest outer diameter has a more salt-specific response. We attribute this to the smaller shielding of the reader antenna associated with a smaller surface area of the Archimedean spiral resonator, which leads to a higher sensitivity of the sensor to the ionic solution and therefore, the variations between the sensor responses are easier to detect. 


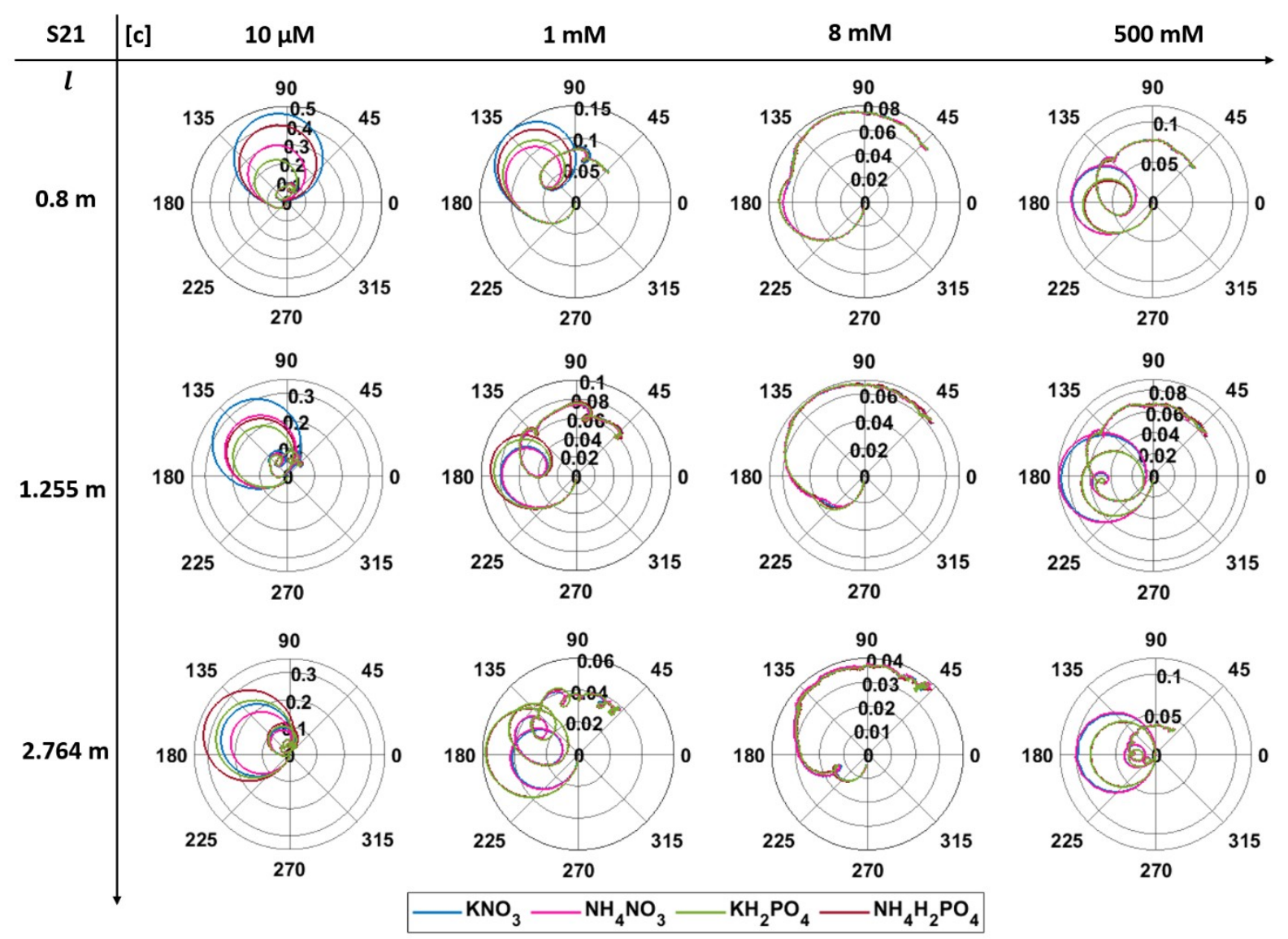

Figure 5. Polar plots showing magnitude and phase of transmission scattering signal $\left(\mathrm{S}_{21}\right)$ for potassium nitrate $\left(\mathrm{KNO}_{3}\right)$, ammonium nitrate $\left(\mathrm{NH}_{4} \mathrm{NO}_{3}\right)$, potassium phosphate $\left(\mathrm{KH}_{2} \mathrm{PO}_{4}\right)$, and ammonium phosphate $\left(\mathrm{NH}_{4} \mathrm{H}_{2} \mathrm{PO}_{4}\right)$. The test was conducted using three resonators with $1.2 \mathrm{~mm}$ pitch size and varying length in the $100 \mathrm{nM}-1 \mathrm{M}$ concentration range and the results are demonstrated here for four of these concentrations.

\section{Application of Resonant Sensors to Field Run-off of Nitrates}

To further explore the applicability of an uncoated resonator to transduce the relative ion level in a meaningful, real-world use case, we applied these sensors to agricultural field run-off. Subsurface drainage water samples were collected from research plots at the lowa State University Agricultural Engineering and Agronomy Research Farm in Boone, IA (Field 5), which receive either poultry manure or inorganic nitrogen fertilizer as a source of nitrogen, to measure the level of nitrate draining from the field. These were quantified in an established water testing lab using a cadmium reduction method, which reports the results as nitrogen concentration ([N]). We first benchmarked the resonant sensor $(\mathrm{I}=1.255 \mathrm{~m})$ with the calibration standards used by the established method. The standard solutions show a reduction in the peak to peak amplitude as the nitrogen concentration increases (Fig 6a, b). This response follows what we observed in the $\mathrm{KCl}$ tests (Fig $4 \mathrm{~b}$ and $\mathrm{d}$ ) in terms of the peak to peak amplitude decrease. The sensor response to the actual field samples (Fig 6c) and measured peak-to-peak amplitude (Figure 6d) also show a similar trend (observed when screening the same samples on the 0.8 and $2.764 \mathrm{~m}$ length resonators as well, Figure S12), albeit with more noise and at a different level of power transmission ( $3 \mathrm{~dB}$ vs. $30 \mathrm{~dB}$ ). We attribute this to the complexity of actual field 
samples that contain other background ions, biomass, and sediment, although in the case of these samples coming from the same water source, these background ions are more uniform. The complexity of field samples is further accentuated when attempting to correlate samples collected from different bodies of water (vastly differing background profiles). This was done for 18 samples collected across two different sites in lowa (Figure S13). These experiments highlight an inherent limitation to the uncoated resonant sensors: they are susceptible to a large amount of noise caused by changing levels of other ions in solution (or other particles that might affect the solution conductivity or permittivity). To overcome this limitation, selectivity could be improved by incorporating polymer-based ion selective membranes to filter the disturbing ions and particles. ${ }^{57,58}$ For example, high nitrate selectivity has been demonstrated by using rhodium(III) porphyrin and salophen as ionophores in a polymeric-based nitrate selective membrane. ${ }^{59}$ A possible alternative to these more elaborate coatings, would be to exploit the differences in response observed when the resonator geometry is changed.
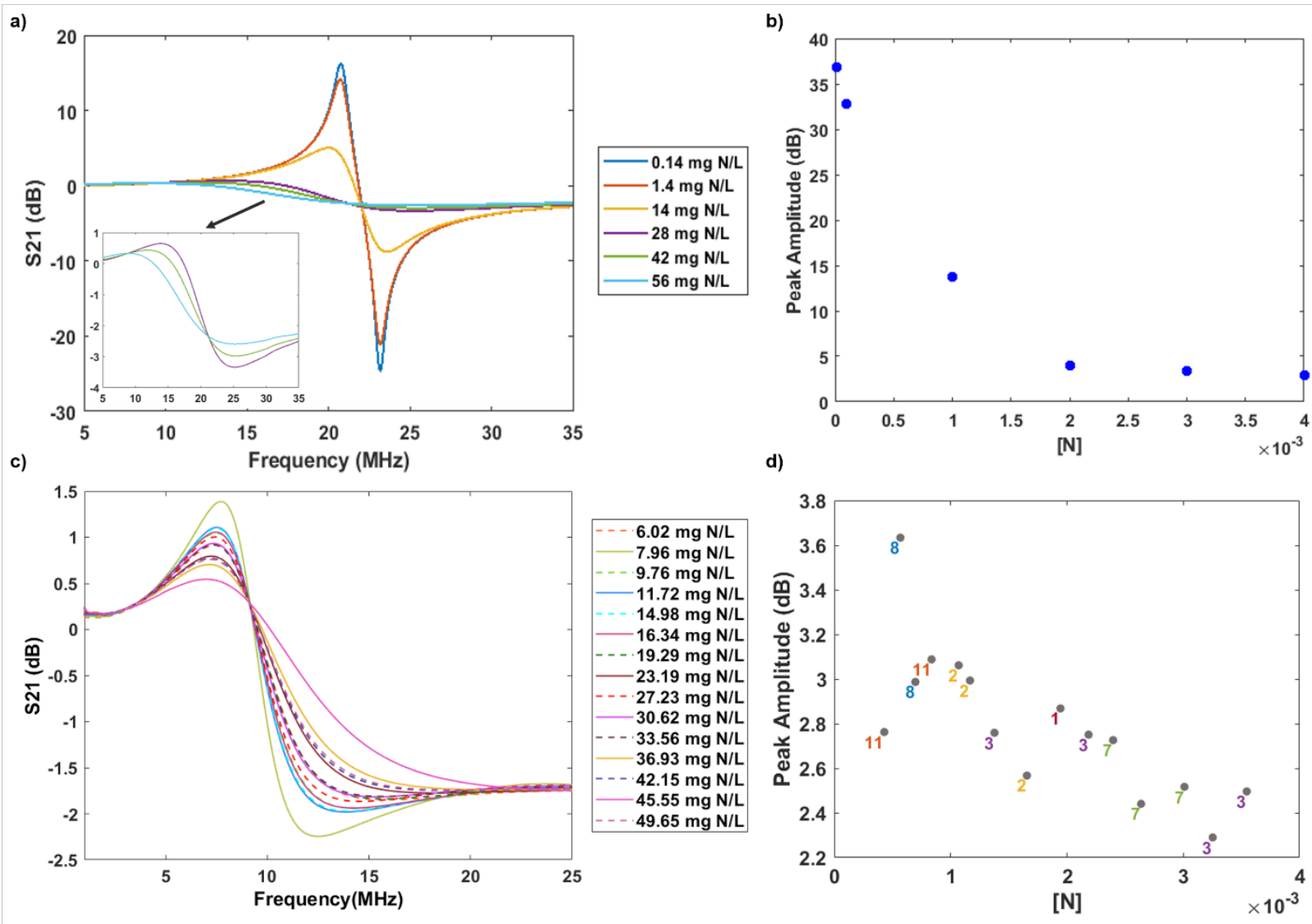

Figure 6. Field 5 nitrate and nitrite test. (a) The sensor S21 magnitude (dB) response for nitrate standard solutions $\left(\mathrm{KNO}_{3}\right)$ b) the calibration curve of the resonant sensor for the standard nitrate solutions (c) the sensor response for real waterway samples collected from lowa sources with accompanying nitrogen levels. (d) the peak-to-peak amplitude for the real sample vs. measured nitrogen levels. The subscripts represent the field plot number from which the sample was collected.

Measuring Ion Mixtures with Resonant Sensor Array 
Observing that the sensor response was dependent on the concentration, type of ion, and resonator geometry, we wanted to test if an array of resonators could provide orthogonal responses such that a mixture of ions could be better differentiated. We tested this idea by preparing 21 samples of $1 \mathrm{mM}$ solutions consisting of $\mathrm{KNO}_{3}, \mathrm{NH}_{4} \mathrm{NO}_{3}$, and $\mathrm{NH}_{4} \mathrm{H}_{2} \mathrm{PO}_{4}$ (Table $\mathrm{S} 14)$. The total ion concentration was kept constant at $1 \mathrm{mM}$ in order to eliminate the effect of the concentration of the solution on the sensor response. Each individual salt component had a concentration ranging from 0 to $1 \mathrm{mM}$. As mentioned earlier, changing the length of the Archimedean spiral resonator has a more significant effect on the resonant frequency shifts observed for different concentration values. Therefore, the three resonators used for this experiment had a $1.2 \mathrm{~mm}$ pitch size and $0.8,1.225$, and $2.764 \mathrm{~m}$ spiral length. The three parameters captured and plotted in ternary response diagrams (Code S15) were $\left|S_{11}\right|,\left|S_{21}\right|$, and

$\angle \mathrm{S}_{21}$ (Figure 7). For $\left|\mathrm{S}_{21}\right|$, the magnitude was defined as the peak-to-peak amplitude as described earlier (Figure S16 b). For the non-sigmoidal response of $\left|S_{11}\right|$ and $\angle S_{21}$ however, the results were reported in reference to the control solution (50 $\mathrm{ml} \mathrm{DI}$ water) (Figure S16a and c).

The ternary diagrams show that the resonator array responds with some orthogonality to different ion mixtures even though the total concentration of the solution is constant. The sensor response is dependent on the geometry of the resonator; however, the general trend (pattern of the ternary plot) of the response is consistent between different sensor sizes. Moreover, since $\mathrm{KNO}_{3}$ and $\mathrm{NH}_{4} \mathrm{NO}_{3}$ are electrically similar (having cations with similar mobilities and identical anions), there is a relatively large region observed in the ternary plot in which modifying the concentration of $\mathrm{KNO}_{3}$ and $\mathrm{NH}_{4} \mathrm{NO}_{3}$ does not cause a change on the scattering parameters; however, a major variation in the sensor response was observed by changing the $\mathrm{NH}_{4} \mathrm{H}_{2} \mathrm{PO}_{4}$ concentration which we attribute to the sensor being more responsive to anion in this case due to the similar mobility of cations present in the solution $\left(\mathrm{K}^{+}\right.$and $\left.\mathrm{NH}_{4}^{+}\right)$. The ternary test was repeated in order to study the reproducibility of the sensor response and was found to be consistent (Figure S17). 


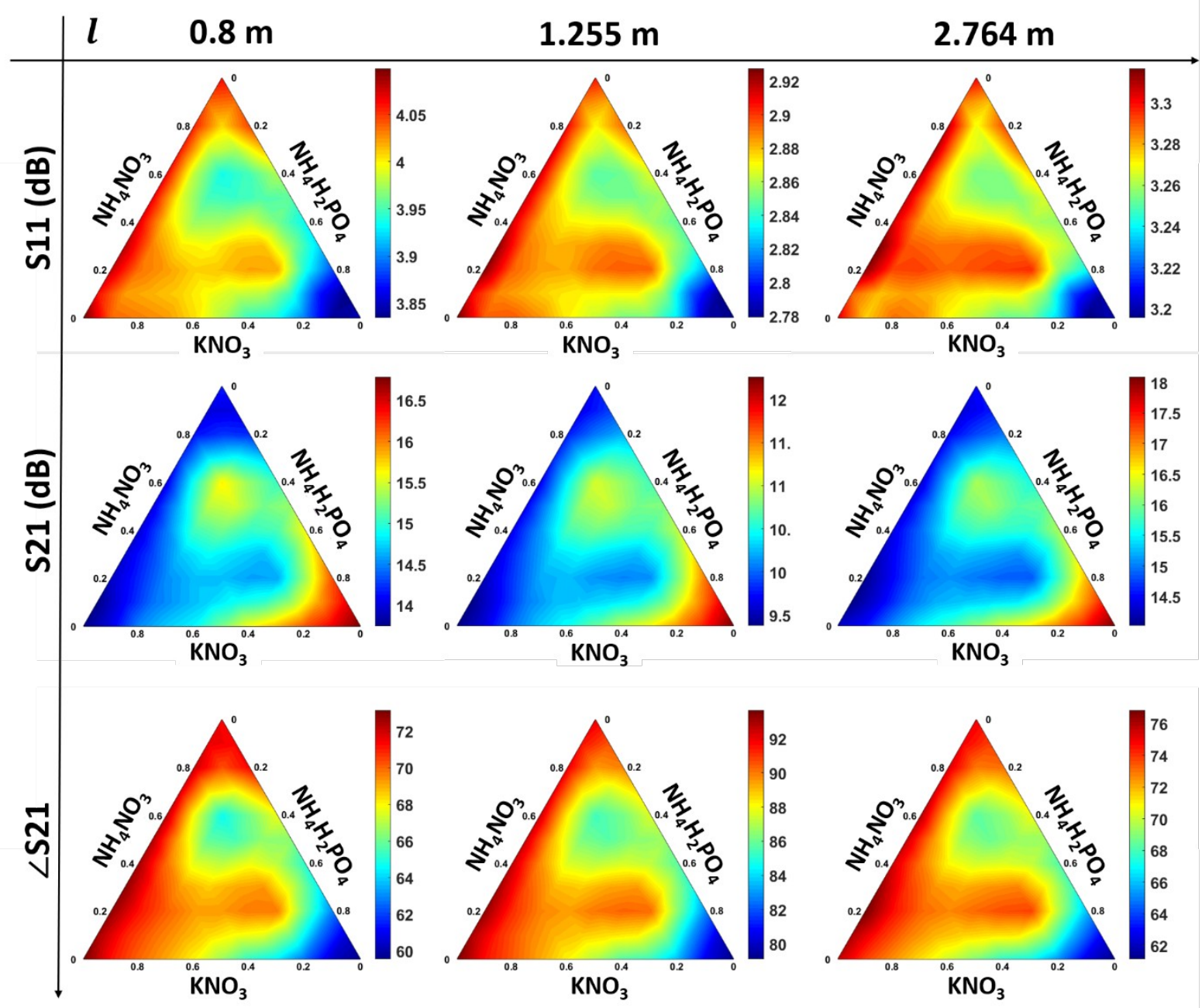

Figure 7. The sensor response in terms of the magnitude of $S_{11}$ (reflection signal) and magnitude and phase of $S_{21}$ (transmission signal) to $1 \mathrm{mM}$ solutions of various mixtures of $\mathrm{KNO}_{3}, \mathrm{NH}_{4} \mathrm{NO}_{3}$, and $\mathrm{NH}_{4} \mathrm{H}_{2} \mathrm{PO}_{4}$. The resonators used for this study were similar in pitch sizes $(1.2 \mathrm{~mm})$ and different in length size.

For all the sensor geometries and sensor response parameters, we observe four distinct regions observed in the ternary plots (Figure 8a). As a final step, we tested the ability of the resonant sensor to be used for determining the concentrations of individual salts in a solution containing unknown concentrations of $\mathrm{KNO}_{3}, \mathrm{NH}_{4} \mathrm{NO}_{3}$, and $\mathrm{NH}_{4} \mathrm{H}_{2} \mathrm{PO}_{4}$. For this purpose, four $1 \mathrm{mM}$ mixtures having unknown concentrations of the above-mentioned salts were prepared (Table S18) and their $\left|S_{11}\right|,\left|S_{21}\right|$, and $\angle S_{21}$ were measured via the same three resonators used in the previous ternary mixture tests. We developed an algorithm (Code S19) to generate prediction regions of concentrations for the samples with unknown salt mixture, based on the ternary plots demonstrated in Figure 7 . The algorithm takes data collected from the unknown salt mixture and rank orders it with interpolated data from the ternary plots of the 21 known salt mixtures. The top percent (different for different regions based off of the size of the region) of points from this rank ordering are then plotted with the unknown point (Code S19). It was observed that this algorithm is capable of predicting the dominant region to which the mixture 
belongs when the mixture is not on the borders between these regions (Figure 8d); however, at present, we were not able to predict the exact values of the salt concentrations in the solution (Figure 8). This can be attributed to the quantity of the solutions (21 samples) used to create the interpolation map, this might not be sufficient for the predictions. Furthermore, we have only used three response parameters as the sensor response while we can extract eight scattering parameters $\left(\left|\mathrm{S}_{11}\right|(\mathrm{dB}), \quad \angle \mathrm{S}_{11},\left|\mathrm{~S}_{21}\right|(\mathrm{dB}), \quad \angle \mathrm{S}_{21},\left|\mathrm{~S}_{12}\right|(\mathrm{dB}), \quad \angle \mathrm{S}_{12},\left|\mathrm{~S}_{22}\right|(\mathrm{dB})\right.$, and $\angle$ $\mathrm{S}_{22}$ ) for each sensor to make a prediction with higher accuracy. Also, using a larger array of sensors (e.g. a panel of 10 sensors with different lengths) would give better approximation of the unknown concentrations. In summary, it appears some amount of differentiation of complex samples can be afforded by an array of uncoated sensors, however in some cases it may be better to employ alternative means of selectivity.

b)

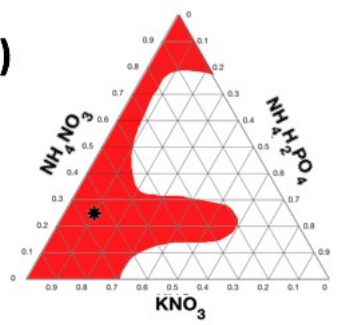

d)

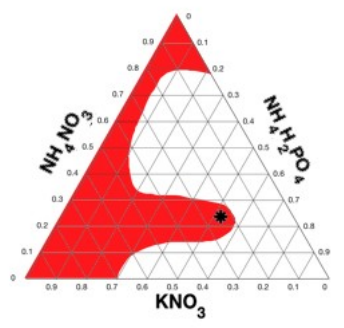

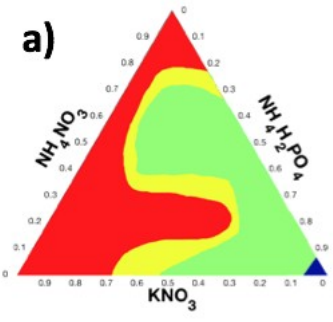

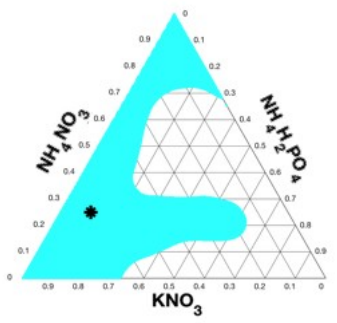

c)
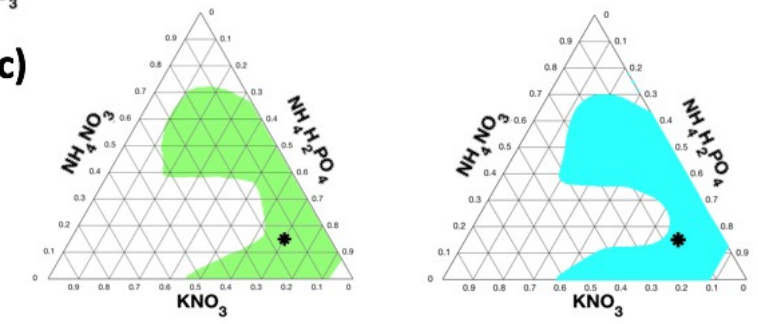

e)
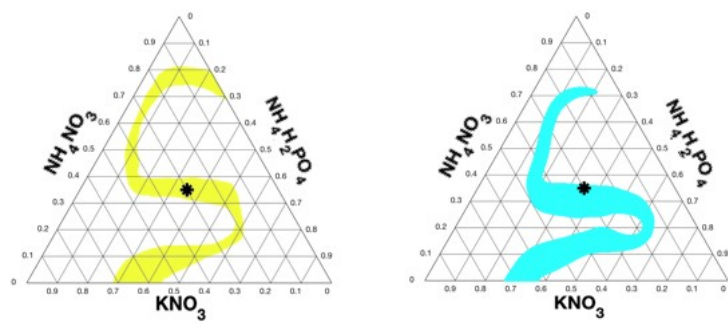

Figure 8. Ternary mixture with unknown ionic concentration. (a) Concentration regions of ternary plots; (b), (c), (d), (e) Prediction region from (a) on left (red, yellow, green) and region predicted from ion predictor algorithm on right (cyan) for $1 \mathrm{mM}$ aqueous solutions containing different combinations of $\mathrm{KNO}_{3}$, $\mathrm{NH}_{4} \mathrm{NO}_{3}$, and $\mathrm{NH}_{4} \mathrm{H}_{2} \mathrm{PO}_{4}$ concentrations.

\section{CONCLUSION}

In this paper, we have demonstrated the fabrication of flexible and wireless resonant sensors to be used for the detection and quantification of ions in an aqueous solution. In this setup, the scattering parameter responses are captured using an external reader antenna connected to a portable vector network analyzer, which are further analyzed to extract the resonant frequency and peak-to-peak amplitude as the sensor response. We have also modeled the sensor and reader setup with a lumped-element model, which closely matched the experimental data for air, $\mathrm{DI}$ water, and $\mathrm{KCl}$ media. Furthermore, $\mathrm{KCl}$ solutions, having a concentration range of $0-1 \mathrm{M}$ as well as at its solubility limit, were tested on the wireless resonant sensor and the sensor showed 
a clear response to changes in the concentration. This response is supported by lumpedelement circuit modeling and a combination of Debye - Falkenhagen theory, Sack's effect, and desaturation effect. This response was similar for sensors with different geometrical features. Repeating the same test for $\mathrm{KNO}_{3}, \mathrm{NH}_{4} \mathrm{NO}_{3}, \mathrm{KH}_{2} \mathrm{PO}_{4}$, and $\mathrm{NH}_{4} \mathrm{H}_{2} \mathrm{PO}_{4}$, the sensor showed a saltspecific response, which was more dependent on the anion. The resonant sensor was applied to agricultural runoff, measuring nitrate levels in samples from a field fertilized by poultry manure. The uncoated resonant sensor is capable of recapitulating the level of nitrates in real samples (same trend that is observed with clean standards), however, with a large degree of noise which is attributed to changing levels of background ions, sediments, etc. The resonant sensor was then challenged in the presence of multiple salts and showed four clear concentration regions for all the responses. Finally, we were able to successfully predict the general concentration region of an unknown solution using an array of three resonators with different length sizes. This is the first demonstration of using an array of uncoated resonant sensors to attempt fingerprinting of ions in solution.

Future work includes improving the sensor selectivity and fabrication. We can potentially improve the sensitivity and selectivity of the sensor by using a larger array of resonators ( $>3$ that were employed in this work) as well as attempting to leverage the ion-selective membranes (e.g. valinomycin for potassium $)^{60}$ as a coating on the resonator. Furthermore, the ability of the sensor array to accurately predict unknown ion concentrations can be fulfilled by testing more than 21 reference sample solutions, using more than three resonators, and extracting more than three scattering parameter features. This type of sensors has potential applications in industries for which measuring and detecting ions at low concentrations $(<100 \mathrm{mM})$ is substantial such as biomedical and agricultural. Using this method, the time-consuming process of collecting samples and conducting laboratory tests can be replaced with in situ scanning of the passive sensors, which provides us with the real-time results. This will especially become relevant when using other scalable fabrication methods, such as screen printing to make low-cost, single-use resonator arrays.

\section{EXPERIMENTAL SECTION}

Fabrication of resonators and reading process. The spiral resonators were designed using Rhino 5 software and then transferred as a mask on copper coated polyimide via a Silhouette Curio $\mathrm{XY}$ plotter coupled to an ultrafine point permanent marker. The masked copper is placed in an etchant solution of $30 \mathrm{ml} \mathrm{H}_{2} \mathrm{O}_{2}$ and $15 \mathrm{ml} \mathrm{HCl}^{40}$ The indelible ink was released from the sample by rinsing the sheet with acetone. As the final step, the resonator was inverted and sealed with epoxy to protect the coils from shorting. A coplanar two-loop reader antenna was connected to a vector network analyzer (VNA) to interrogate the resonator. The phase and the magnitude data of $S_{21}$ and $S_{11}$ were automatically recorded by a laptop using MATLAB. The resonant frequency and peak-to-peak amplitude of the resonant peak were determined with custom algorithms (Code S3).

Ion concentration test procedure. To test the effect of ion concentration on the scattering parameter response, increasing concentrations of potassium chloride $(\mathrm{KCl})$, potassium nitrate $\left(\mathrm{KNO}_{3}\right)$, monopotassium phosphate $\left(\mathrm{KH}_{2} \mathrm{PO} 4\right)$, ammonium phosphate $\left(\mathrm{NH}_{4} \mathrm{H}_{2} \mathrm{PO}_{4}\right)$, and ammonium nitrate $\left(\mathrm{NH}_{4} \mathrm{NO}_{3}\right)$ were added to the resonator petri dish while the total liquid volume was kept constant at $50 \mathrm{ml}$. For this purpose, a panel of 40 different concentrations of the abovementioned salts, ranging from $100 \mathrm{nM}$ to their solubility limits in DI water at room temperature were tested on resonators with different geometries (Table S2). 
Field Sample Test. The field runoff samples were collected from the Black Hawk Lake (BHL) watershed in west central lowa, and the Field 5 plots at the lowa State University Agricultural Engineering and Agronomy Research Farm in Boone, IA. The BHL samples were either instream samples from smaller subwatersheds $(8,11$, and 12) in the BHL watershed, or subsurface drainage tile samples (12 and 36 inches in diameter) from subwatershed 8 . These samples were collected during three types of conditions: 1) grab sample: the samples were collected regardless of the flow conditions; 2) storm event sample: the storm event is defined as an increase in base flow by more than $50 \%$. These samples were collected via an automated water sampler (ISCO 6712); 3) weekly flow-weighted sample: which are the base flow samples (no storm event samples included) and were also collected automatically using an ISCO 6712. Regarding the Field 5 plots, research has been performed on the effect of using poultry manure as fertilizer on crop yields, soil properties, and water quality for approximately 20 years. There are 14 field plots at the Agricultural Engineering and Agronomy Research Farm that receive different amounts of poultry manure or inorganic nitrogen fertilizer. All Field 5 samples are grab samples from subsurface tile drains.

All samples from BHL and Field 5 were preserved by using sulfuric acid in order to drop the $\mathrm{pH}$ of the samples to $<2$, and then were kept at $4^{\circ} \mathrm{C}$ until analyzing for nitrate and nitrite level. The water quality research laboratory measured the nitrate and nitrite level of the samples in terms of nitrogen concentration ([N]) via a Seal Analytical (Mequon, WI) AQ2 discrete autoanalyzer using the conventional colorimetric cadmium reduction method. The samples were then tested on the resonant sensor having outer diameter of $40 \mathrm{~mm}$, inner diameter of $1.2 \mathrm{~mm}$ and pitch size of $1 \mathrm{~mm}$ at room temperature. The standard nitrate solutions $(0.15-56.0 \mathrm{mg} \mathrm{N} / \mathrm{L})$ were also tested on the resonant sensor. Furthermore, the phosphate level (one of the important background ions) of the samples was also measured with a modified ascorbic acid method. The BHL samples were filtered $(<0.45 \mu \mathrm{m})$ prior to analysis for phosphate (and are reported as 'dissolved reactive phosphorus'). Field 5 samples were not filtered, but visible sediment was allowed to settle prior to analysis.

Ion mixture test. In order to study the ability of resonant sensors to have a specific response for different mixtures of ions, 21 samples containing different concentrations of $\mathrm{KNO}_{3}$, $\mathrm{NH}_{4} \mathrm{H}_{2} \mathrm{PO}_{4}$, and $\mathrm{NH}_{4} \mathrm{NO}_{3}$ were prepared which spanned the design space and allowed for the construction of ternary plots. The total concentration of each sample was kept at $1 \mathrm{mM}$ and the volume was $25 \mathrm{ml}$. These samples were tested on three resonators with constant pitch size (1.2 $\mathrm{mm}$ ) and $0.8 \mathrm{~m}, 1.255 \mathrm{~m}$, and $2.764 \mathrm{~m}$ lengths and the magnitude and phase response of the $\mathrm{S}_{21}$ as well as the magnitude of the $S_{11}$ were captured. Initially, the resonator of interest was fixed on the reader and then each sample was placed in the petri dish containing the resonator. After capturing the signal, the sample was removed, the sensor was completely cleaned without being moved, and the next sample was tested.

Unknown sample test. For each concentration region in the ion mixture ternary results, we prepared a sample called "mystery solution" or "unknown solution" in order to determine the concentrations of $\mathrm{KNO}_{3}, \mathrm{NH}_{4} \mathrm{H}_{2} \mathrm{PO}_{4}$, and $\mathrm{NH}_{4} \mathrm{NO}_{3}$ in the results of the ternary mixture test. The concentration information of these samples can be found in Table S18. A linear interpolation was performed between the 21 points of the lon mixture test using 150 majors in the "alchemyst/ternplotf" code for all data collected from three resonators with constant pitch size $(1.2 \mathrm{~mm})$ and $0.8 \mathrm{~m}, 1.255 \mathrm{~m}$, and $2.764 \mathrm{~m}$ lengths and the magnitude and phase response of the 
$\mathrm{S}_{21}$ as well as the magnitude of the $\mathrm{S}_{11}$. The data collected from the "unknown solutions" were thank ranked ordered to the closest fit using least squared errors method.

\section{ASSOCIATED CONTENT}

\section{Appendix A. Supplementary data}

Supplementary data associated with this article can be found, in the online version, at ...

\section{ACKNOWLEDGMENTS}

Funding for this research was provided in part by NSF Industrial Innovation and Partnerships under award 1827578 and lowa State University startup funds. The authors also thank DuPont for capital equipment donation.

\section{REFERENCES}

(1) Schindler, D. W.; Vallentyne, J. R. The Algal Bowl: Overfertilization of the World's Freshwaters and Estuaries; University of Alberta Press Edmonton, 2008.

(2) Callisto, M.; Molozzi, J.; Barbosa, J. L. E. Eutrophication of Lakes BT - Eutrophication: Causes, Consequences and Control: Volume 2. In; Ansari, A. A.; Gill, S. S., Eds.; Springer Netherlands: Dordrecht, 2014; pp. 55-71.

(3) Buck, R. P.; Lindner, E. Peer Reviewed: Tracing the History of Selective Ion Sensors, 2001.

(4) Narayana, B.; Sunil, K. A Spectrophotometric Method for the Determination of Nitrite and Nitrate. Eurasian J. Anal. Chem. 2009, 4, 204-214.

(5) Bai, J.; Zhang, L.; Liang, R.; Qiu, J. Graphene Quantum Dots Combined with Europium Ions as Photoluminescent Probes for Phosphate Sensing. Chem. Eur. J. 2013, 19, 3822 3826.

(6) Dudwadkar, A.; Shenoy, N.; Joshi, J. M.; Kumar, S. D.; Rao, H.; Reddy, A. V. R. Application of Ion Chromatography for the Determination of Nitrate in Process Streams of Thermal Denitration Plant. Sep. Sci. Technol. 2013, 48, 2425-2430.

(7) Ensafi, A. A.; Amini, M. Highly Selective Optical Nitrite Sensor for Food Analysis Based on Lauth's Violet-triacetyl Cellulose Membrane Film. Food Chem. 2012, 132, 1600-1606.

(8) Ceresa, A.; Bakker, E.; Hattendorf, B.; Günther, D.; Pretsch, E. Potentiometric Polymeric Membrane Electrodes for Measurement of Environmental Samples at Trace Levels: New Requirements for Selectivities and Measuring Protocols, and Comparison with ICPMS. Anal. Chem. 2001, 73, 343-351.

(9) Pungor, E.; Horvai, G. A Practical Guide to Instrumental Analysis; Taylor \& Francis, 1994.

(10) Brennan Jr, T. M.; Ernst, J. M.; Day, C. M.; Bullock, D. M.; Krogmeier, J. V; Martchouk, M. Influence of Vertical Sensor Placement on Data Collection Efficiency from Bluetooth MAC Address Collection Devices. J. Transp. Eng. 2010, 136, 1104-1109.

(11) Kassal, P.; Steinberg, I. M.; Steinberg, M. D. Wireless Smart Tag with Potentiometric Input for Ultra Low-Power Chemical Sensing. Sensors actuators B Chem. 2013, 184, 254-259. 
(12) Novell, M.; Guinovart, T.; Steinberg, I. M.; Steinberg, M.; Rius, F. X.; Andrade, F. J. A Novel Miniaturized Radiofrequency Potentiometer Tag Using Ion-Selective Electrodes for Wireless Ion Sensing. Analyst 2013, 138, 5250-5257.

(13) Kermis, H. R.; Kostov, Y.; Harms, P.; Rao, G. Dual Excitation Ratiometric Fluorescent PH Sensor for Noninvasive Bioprocess Monitoring: Development and Application. Biotechnol. Prog. 2002, 18, 1047-1053.

(14) Hirata, T.; Terai, T.; Yamamura, H.; Shimonishi, M.; Komatsu, T.; Hanaoka, K.; Ueno, T.; Imaizumi, Y.; Nagano, T.; Urano, Y. Protein-Coupled Fluorescent Probe to Visualize Potassium Ion Transition on Cellular Membranes. Anal. Chem. 2016, 88, 2693-2700.

(15) Steinberg, I. M.; Steinberg, M. D. Radio-Frequency Tag with Optoelectronic Interface for Distributed Wireless Chemical and Biological Sensor Applications. Sensors Actuators B Chem. 2009, 138, 120-125.

(16) Kusterer, A.; Krause, C.; Kaufmann, K.; Arnold, M.; Weuster-Botz, D. Fully Automated Single-Use Stirred-Tank Bioreactors for Parallel Microbial Cultivations. Bioprocess Biosyst. Eng. 2008, 31, 207-215.

(17) Biechele, P.; Busse, C.; Solle, D.; Scheper, T.; Reardon, K. Sensor Systems for Bioprocess Monitoring. Eng. Life Sci. 2015, 15, 469-488.

(18) Bluma, A.; Höpfner, T.; Prediger, A.; Glindkamp, A.; Beutel, S.; Scheper, T. Process Analytical Sensors and Image-based Techniques for Single-use Bioreactors. Eng. Life Sci. 2011, 11, 550-553.

(19) Hillig, F.; Pilarek, M.; Junne, S.; Neubauer, P. Cultivation of Marine Microorganisms in Single-Use Systems. In Disposable Bioreactors II; Springer, 2013; pp. 179-206.

(20) Nurhayati, R. W.; Ojima, Y.; Dohda, T.; Kino-Oka, M. Large-scale Culture of a Megakaryocytic Progenitor Cell Line with a Single-use Bioreactor System. Biotechnol. Prog. 2018, 34, 362-369.

(21) Ahmed, S.; Chauhan, V. M.; Ghaemmaghami, A. M.; Aylott, J. W. New Generation of Bioreactors That Advance Extracellular Matrix Modelling and Tissue Engineering. Biotechnol. Lett. 2018, 1-25.

(22) Kessler, M.; Hoper, J. Ion-Selective Electrode Device for Polarographic Measurement of Oxygen, 1981.

(23) Schazmann, B.; Morris, D.; Slater, C.; Beirne, S.; Fay, C.; Reuveny, R.; Moyna, N.; Diamond, D. A Wearable Electrochemical Sensor for the Real-Time Measurement of Sweat Sodium Concentration. Anal. Methods 2010, 2, 342-348.

(24) Curto, V. F.; Coyle, S.; Byrne, R.; Angelov, N.; Diamond, D.; Benito-Lopez, F. Concept and Development of an Autonomous Wearable Micro-Fluidic Platform for Real Time PH Sweat Analysis. Sensors Actuators B Chem. 2012, 175, 263-270.

(25) Wilhelm, A.; Wilhelm, A.; Emaminejad, S. Emerging Wearable Technologies for Personalized Health and Performance Monitoring. In Proc.SPIE; 2018; Vol. 10639.

(26) Coyle, S.; Diamond, D. Medical Applications of Smart Textiles. In Advances in Smart Medical Textiles; Elsevier, 2016; pp. 215-237.

Coyle, S.; Morris, D.; Lau, K.-T.; Diamond, D.; Taccini, N.; Costanzo, D.; Salvo, P.; Di 
Francesco, F.; Trivella, M. G.; Porchet, J.-A. Textile Sensors to Measure Sweat PH and Sweat-Rate during Exercise. In 2009 3rd International Conference on Pervasive Computing Technologies for Healthcare; IEEE, 2009; pp. 1-6.

(28) Charkhabi, S. Resonant Sensors for Passive, Real-Time, and Wireless Characterization of Biological Analytes. 2018.

(29) Li, C.; Tan, Q.; Zhang, W.; Member, S.; Xue, C.; Xiong, J. An Embedded Passive Resonant Sensor Using Frequency Diversity Technology for High- Temperature Wireless Measurement. 2015, 15, 1055-1060.

(30) Charkhabi, S.; Chan, Y. J.; Hwang, D.; Frey, S. T.; Bartlett, M. D.; Reuel, N. F. KirigamiEnabled, Passive Resonant Sensors for Wireless Deformation Monitoring. Adv. Mater. Technol. 2019.

(31) Ren, Q. Y.; Wang, L. F.; Huang, J. Q.; Zhang, C.; Huang, Q. A. Simultaneous Remote Sensing of Temperature and Humidity by LC-Type Passive Wireless Sensors. J. Microelectromechanical Syst. 2015, 24, 1117-1123.

(32) Jia, Y.; Sun, K.; Agosto, F. J.; Quiñones, M. T. Design and Characterization of a Passive Wireless Strain Sensor. Meas. Sci. Technol. 2006, 17, 2869-2876.

(33) García-Cantón, J.; Merlos, A.; Baldi, A. A Wireless LC Chemical Sensor Based on a High Quality Factor EIS Capacitor. Sensors Actuators, B Chem. 2007, 126, 648-654.

(34) Cai, Q. Y.; Grimes, C. A. A Remote Query Magnetoelastic PH Sensor. Sensors Actuators B Chem. 2000, 71, 112-117.

(35) Lei, M.; Baldi, A.; Pan, T.; Gu, Y.; Siegel, R. A.; Ziaie, B. A Hydrogel-Based Wireless Chemical Sensor. In 17th IEEE International Conference on Micro Electro Mechanical Systems. Maastricht MEMS 2004 Technical Digest; IEEE, 2004; pp. 391-394.

(36) Potyrailo, R. A.; Burns, A.; Surman, C.; Lee, D. J.; McGinniss, E. Multivariable Passive RFID Vapor Sensors: Roll-to-Roll Fabrication on a Flexible Substrate. Analyst 2012, 137, 2777-2781.

(37) Fiddes, L. K.; Yan, N. RFID Tags for Wireless Electrochemical Detection of Volatile Chemicals. Sensors Actuators B Chem. 2013, 186, 817-823.

(38) Kassal, P.; Steinberg, M. D.; Steinberg, I. M. Wireless Chemical Sensors and Biosensors: A Review. Sensors Actuators B Chem. 2018, 266, 228-245.

(39) Potyrailo, R. A.; Mouquin, H.; Morris, W. G. Position-Independent Chemical Quantitation with Passive 13.56-MHz Radio Frequency Identification (RFID) Sensors. Talanta 2008, $75,624-628$.

(40) Charkhabi, S.; Beierle, A.; McDaniel, M. D.; Reuel, N. F. Resonant Sensors for Low-Cost, Contact-Free Measurement of Hydrolytic Enzyme Activity in Closed Systems. ACS Sensors 2018.

(41) Ong, K. G.; Bitler, J. S.; Grimes, C. A.; Puckett, L. G.; Bachas, L. G. Remote Query Resonant-Circuit Sensors for Monitoring of Bacteria Growth: Application to Food Quality Control. Sensors 2002, 2, 219-232.

(42) Charkhabi, S.; Beierle, A.; Reuel, N. Short Wave Radio Frequency Resonators for Transducing Protein and Cell Surface Interactions in Closed Systems. In ABSTRACTS 
OF PAPERS OF THE AMERICAN CHEMICAL SOCIETY; AMER CHEMICAL SOC 1155 16TH ST, NW, WASHINGTON, DC 20036 USA, 2018; Vol. 255.

(43) Yvanoff, M.; Venkataraman, J. A Feasibility Study of Tissue Characterization Using LC Sensors. IEEE Trans. Antennas Propag. 2009, 57, 885-893.

(44) Potyrailo, R. A.; Nagraj, N.; Tang, Z.; Mondello, F. J.; Surman, C.; Morris, W. Battery-Free Radio Frequency Identification (RFID) Sensors for Food Quality and Safety. J. Agric. Food Chem. 2012, 60, 8535-8543.

(45) Nor, A. S. M.; Faramarzi, M.; Yunus, M. A. M.; Ibrahim, S. Nitrate and Sulfate Estimations in Water Sources Using a Planar Electromagnetic Sensor Array and Artificial Neural Network Method. IEEE Sens. J. 2014, 15, 497-504.

(46) Yunus, M. A. M.; Mukhopadhyay, S. C. Novel Planar Electromagnetic Sensors for Detection of Nitrates and Contamination in Natural Water Sources. IEEE Sens. J. 2010, $11,1440-1447$.

(47) Gorji, A.; Bowler, N. Dielectric Measurement of Low-Concentration Aqueous Solutions: Assessment of Uncertainty and Ion-Specific Responses. Meas. Sci. Technol. 2018, 29, 85801.

(48) Harnsoongnoen, S.; Wanthong, A.; Charoen-In, U.; Siritaratiwat, A. Microwave Sensor for Nitrate and Phosphate Concentration Sensing. IEEE Sens. J. 2019, 19, 2950-2955.

(49) Mohan, S. S.; Hershenson, M.; Boyd, S. P.; Lee, T. H. Simple Accurate Expressions for Planar Spiral Inductances. 1999, 34, 1419-1424.

(50) Hooker, J. W.; Ramaswamy, V.; Member, S.; Arora, R. K.; Member, L. S.; Edison, A. S.; Withers, R. S.; Nast, R. E.; Brey, W. W.; Application, A. An Empirical Expression to Predict the Resonant Frequencies of Archimedean Spirals. 2015, 63, 2107-2114.

(51) Tsuchiya, A.; Onodera, H. Gradient Resistivity Method for Numerical Evaluation of Anomalous Skin Effect. In 2011 IEEE 15th Workshop on Signal Propagation on Interconnects (SPI); IEEE, 2011; pp. 139-142.

(52) Topp, G. C. State of the Art of Measuring Soil Water Content. Hydrol. Process. 2003, 17, 2993-2996.

(53) Chen, T.; Hefter, G.; Buchner, R. Dielectric Spectroscopy of Aqueous Solutions of KCl and CsCl. J. Phys. Chem. A 2003, 107, 4025-4031.

(54) Pinho, S. P.; Macedo, E. A. Solubility of $\mathrm{NaCl}, \mathrm{NaBr}$, and $\mathrm{KCl}$ in Water, Methanol, Ethanol, and Their Mixed Solvents. J. Chem. Eng. Data 2005, 50, 29-32.

(55) Hubbard, J. B.; Onsager, L.; Van Beek, W. M.; Mandel, M. Kinetic Polarization Deficiency in Electrolyte Solutions. Proc. Natl. Acad. Sci. 1977, 74, 401-404.

(56) Elsherbiny, O.; Roy, S.; Charkhabi, S.; Carr, A. R.; Beierle, A. M.; Reuel, N. F.; Neihart, N. M. Physically Inspired Circuit Model for Systematic Analysis of Resonant Ion Sensor.

(57) Tang, W.; Ping, J.; Fan, K.; Wang, Y.; Luo, X.; Ying, Y.; Wu, J.; Zhou, Q. All-Solid-State Nitrate-Selective Electrode and Its Application in Drinking Water. Electrochim. Acta 2012, 81, 186-190.

(58) Huber, C.; Klimant, I.; Krause, C.; Werner, T.; Wolfbeis, O. S. Nitrate-Selective Optical Sensor Applying a Lipophilic Fluorescent Potential-Sensitive Dye. Anal. Chim. Acta 2001, 
449, 81-93.

(59) Pietrzak, M.; Meyerhoff, M. E. Polymeric Membrane Electrodes with High Nitrite Selectivity Based on Rhodium (III) Porphyrins and Salophens as Ionophores. Anal. Chem. 2009, 81, 3637-3644.

(60) Eyal, E.; Rechnitz, G. A. Mechanistic Studies on the Valinomycin-Based Potassium Electrode. Anal. Chem. 1971, 43, 1090-1093. 


\section{Towards Wireless Characterization of Solvated Ions with Uncoated Resonant Sensors}

Sadaf Charkhabi ${ }^{\mathrm{a}}$, Adam R. Carr ${ }^{\mathrm{a}}$, Jiahao $\mathrm{Wu}^{\mathrm{a}}$, Subhanwit Roy ${ }^{\mathrm{b}}$, Andee M. Beierle ${ }^{\mathrm{a}}$, Dustin K. Thomas $^{a}$, Leigh Ann M. Long ${ }^{c}$, Michelle L. Soupir ${ }^{c}$, Nathan M. Neihart ${ }^{b}$, and Nigel F. Reuel ${ }^{a \star}$

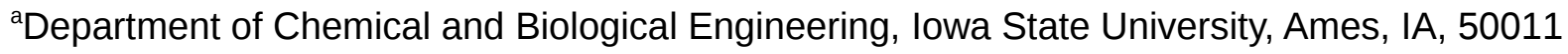

${ }^{\mathrm{b}}$ Department of Electrical and Computer Engineering, Iowa State University, Ames, IA, 50011

${ }^{\circ}$ Department of Agricultural and Biosystems Engineering, lowa State University, Ames, IA, 50011

*Corresponding Author - reuel@iastate.edu

\section{Contents}

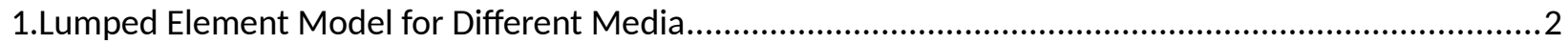

2.Table of Salt Concentrations Tested on Resonant Sensors....................................................................

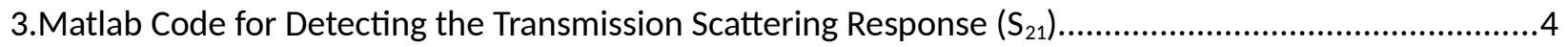

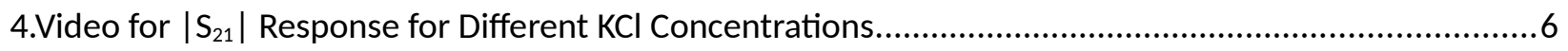

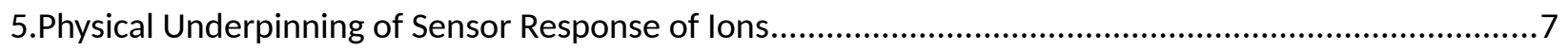

6.Table of Sensors with Different Geometries...................................................................................... 12

7.MATLAB Code for Plotting Geometry-Dependence Response ............................................................13

8.Effect of Pitch Size and the Spiral Length on the Initial Self-Resonant Frequency..................................16

9.The Dependency of Resonant Frequency Shift on Resonator Parameters..........................................17

10.MATLAB Code for Polar Plots of Salt Comparison Data..................................................................18

11.Polar Plot Video for Different Salts with100 nM to 1M Concentration................................................20

12.Reproducibility of Sensor Response to Field 5 Samples.................................................................21

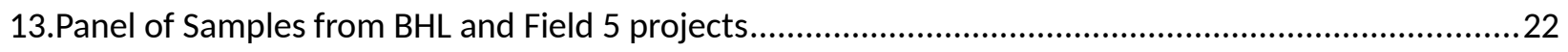

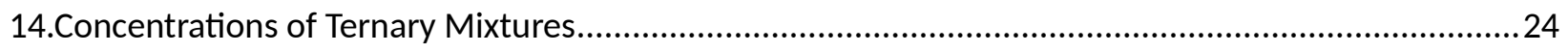

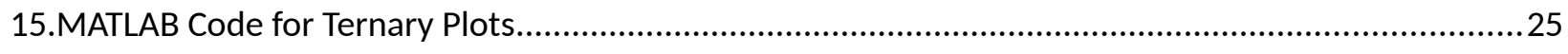

16.Definition of Scattering Parameters Used in Ternary Plots..............................................................31

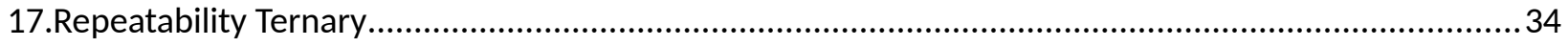

18.Concentrations of Solutions with Known (1-21) Unknown Mixture of Salts......................................35

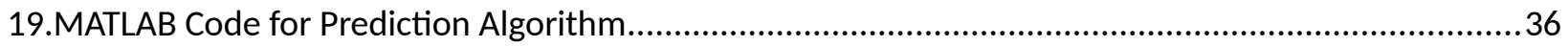

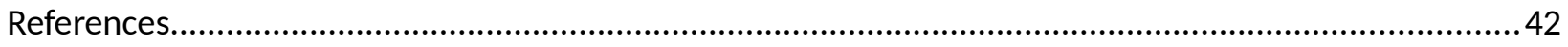




\section{Lumped Element Model for Different Media}

Lumped element model of the resonator with $\mathrm{d}_{\text {in }}=1.5 \mathrm{~mm}, \mathrm{~d}_{\text {out }}=40 \mathrm{~mm}, \mathrm{P}=1 \mathrm{~mm}, \mathrm{~N}=20$, and $\mathrm{I}=1255 \mathrm{~mm}$, and two-loop reader was created. Using equations 3-8, the electrical parameters of the resonator were estimated for three different media: free space, DI water, and $3 \mathrm{mM} \mathrm{KCl}$. The inductance of the resonator was assumed to be constant $(5.98 \mu \mathrm{H})$ for these media as it is only dependent on the geometrical parameters of the resonator. The capacitance of the resonator, however, varies by changing the media the resonator is exposed to. The reason is that the capacitance is dependent on the relative dielectric permittivity, which is $1,80.4$, and 78.75 for free space, DI water, and $3 \mathrm{mM} \mathrm{KCl}$, respectively. The frequency at which the sensor resonates is different for the above-mentioned media since it is dependent on the capacitance.

The resistance of the resonator is also dependent on the medium in contact with the sensor, which can be attributed to the skin effect of the conductor. The skin effect is defined as the propensity of the altering electric current $(\mathrm{AC})$ to be distributed in a way that the density of current has the highest value close to the conductor. The altering current results in changes in the magnetic field, which induce eddy currents and cause the skin effect. In other words, the electric current flows mostly between the surface of the conductor and the "skin depth". The skin depth is inversely related to the frequency. Therefore, as the resonant frequency increase, the skin depth decrease, which causes a reduction in the effective cross-section of the conductor, and subsequently, an increment in the resistance; However, the resistance was assumed to be constant to simplify the model.

Table S1. The electrical values for the resonator exposed to different media.

\begin{tabular}{|c|c|c|c|}
\hline & \multicolumn{3}{|c|}{ Media } \\
\cline { 2 - 4 } & Free Space & DI Water & 3 mMol/L KCl \\
\hline $\begin{array}{c}\text { Relative Dielectric Constant, } \\
\epsilon_{r}\end{array}$ & 1 & 80.4 & 78.75 \\
\hline Resonant Frequency, $f_{0}$ & $69.5 \mathrm{MHz}$ & $17.2 \mathrm{MHz}$ & $14.5 \mathrm{MHz}$ \\
\hline$C_{\text {res }}$ & $0.877 \mathrm{pF}$ & $14.29 \mathrm{pF}$ & $20.14 \mathrm{pF}$ \\
\hline$R_{\text {res }}$ & $32.8 \Omega$ & $14.3 \Omega$ & $13.1 \Omega$ \\
\hline
\end{tabular}




\section{Table of Salt Concentrations Tested on Resonant Sensors}

To test the effect of ion concentration on the scattering parameter response, a resonator was adhered to the bottom of a petri dish such that the conductive copper trace was facing down and was isolated from the solution via the Polyimide layer, containing 50ml deionized water (DI water). Then, the dependence of resonant sensor response on the ionic concentration of the aqueous systems was studied by adding increasing concentrations of salt to the petri dish. For this purpose, a panel of 40 different concentrations of $\mathrm{KCl}$, ranging from $100 \mathrm{nM}$ to its solubility limit in DI water at room temperature $(4.587 \mathrm{M})$ were tested on the resonator. The total volume was kept constant at $50 \mathrm{ml}$ in order to remove the effect of liquid volume on the scattering response. The negative control for these tests is $50 \mathrm{ml} \mathrm{DI}$ water.

As an example, for testing solutions with different concentrations of $\mathrm{KCl}$ ranging from $10^{-6} \mathrm{M}$ to the salt's solubility limit, $20 \mathrm{ml}$ of $10^{-2} \mathrm{M} \mathrm{KCl}$ was initially prepared. Afterward, $10 \mathrm{ml}$ of this solution was diluted with $90 \mathrm{ml} \mathrm{DI}$ water and vortexed to make $10^{-3} \mathrm{M} \mathrm{KCl}$ and this serial dilution (10-fold dilution) continued until the concentration of the last batch was $10^{-5} \mathrm{M}$. By utilizing these solutions, the sensor response for low concentrations of $\mathrm{KCl}\left(10^{-6}-10^{-3} \mathrm{M}\right)$ were recorded. For the middle range concentrations $\left(2^{\star} 10^{-3}-3^{*} 10^{-2} \mathrm{M}\right), 50 \mu \mathrm{l}$ of $1 \mathrm{M} \mathrm{KCl}$ solution was added to the petri dish, and the trace was recorded. This step was repeated 30 times. For the higher concentrations, $5 \mathrm{ml}$ of $0.325 \mathrm{M}$ and $0.46 \mathrm{M} \mathrm{KCl}$ were respectively added to have final concentrations of $0.06 \mathrm{M}$ and $0.1 \mathrm{M}$ tested on the sensor. By using $25 \mathrm{ml}$ of $0.9 \mathrm{M}$ and $1.5 \mathrm{M}$ $\mathrm{KCl}, 0.5 \mathrm{M}$ and $1 \mathrm{M} \mathrm{KCl}$ solutions were also tested. The highest concentration for the $\mathrm{KCl}$ was its solubility limit which was tested by removing all the solution presented in the petri dish and adding $50 \mathrm{ml}$ of $4.587 \mathrm{M} \mathrm{KCl}$.

\begin{tabular}{|c|c|c|c|c|c|c|c|}
\hline Sample \# & {$[\mathbf{C}] \mathbf{( M )}$} & Sample \# & {$[\mathbf{C}](\mathbf{M})$} & Sample \# & {$[\mathbf{C}] \mathbf{( M )}$} & Sample \# & {$[\mathbf{C}](\mathbf{M})$} \\
\hline 1 & $1.00 \mathrm{E}-07$ & 11 & 0.006979 & 21 & 0.016865 & 31 & 0.026652 \\
\hline 2 & $1.00 \mathrm{E}-06$ & 12 & 0.007972 & 22 & 0.017848 & 32 & 0.027625 \\
\hline 3 & $1.00 \mathrm{E}-05$ & 13 & 0.008964 & 23 & 0.01883 & 33 & 0.028598 \\
\hline 4 & $1.00 \mathrm{E}-04$ & 14 & 0.009955 & 24 & 0.019811 & 34 & 0.029569 \\
\hline 5 & $1.00 \mathrm{E}-03$ & 15 & 0.010945 & 25 & 0.020791 & 35 & 0.030539 \\
\hline 6 & 0.001999 & 16 & 0.011934 & 26 & 0.021771 & 36 & 0.06 \\
\hline 7 & 0.002997 & 17 & 0.012922 & 27 & 0.022749 & 37 & 0.1 \\
\hline 8 & 0.003994 & 18 & 0.013909 & 28 & 0.023726 & 38 & 0.5 \\
\hline 9 & 0.00499 & 19 & 0.014895 & 29 & 0.024702 & 39 & 1 \\
\hline 10 & 0.005985 & 20 & 0.015881 & 30 & 0.025678 & 40 & 4.587 \\
\hline
\end{tabular}

Table S2. concentrations of $\mathrm{KCl}$ tested on resonant sensors 


\section{Matlab Code for Detecting the Transmission Scattering Response $\left(\mathbf{S}_{21}\right)$}

A two-loop reader antenna was developed to serve as the signal communication device. Each loop had a diameter of $54 \mathrm{~mm}$ and they were positioned in a 3D-printed plastic cast with 26.7 $\mathrm{mm}$ overlap. The coils were mutually grounded to eliminate the effect of cable movement and connected to S5048 two-port vector network analyzer (VNA) from Copper Mountain Technologies via RF-shielded BNC cables. For all tests in this paper, the center of the spiral resonator was aligned with the center of the coil overlap of the reader antenna. The phase and the magnitude data of $S_{21}$ and $S_{11}$ were automatically recorded by connecting the VNA to a Lenovo laptop using MATLAB. The resonant frequency and the Peak-to-peak amplitude of the resonance peak in scattering parameter responses were captured using MATLAB. The resonance feature observed in the magnitude of transmission scattering parameter response,

$\left|S_{21}\right|$, has a peak and trough. The frequency and the magnitude value for these two point were captured using the following Matlab code (Code S3):

function S21fit_v1

\% Coded by Nigel F. Reuel on 10.5.2017

$\%$ This code automates the peak fitting and finds the peak even if it is

$\%$ very small (using splines and derivatives)

$\%$ v1 - no looping through folders and all files, just uses single files to

$\%$ test

$\%$

$\% \mathrm{D}=$ csvread('0.csv'); \% AIR

$\% \mathrm{D}=$ csvread('1.csv'); \% Water

$\% \mathrm{D}=$ csvread('7.csv'); \% Small peak

$\% \mathrm{D}=$ csvread('21.csv'); \% No peak

$\mathrm{D}=$ csvread('40.csv'); \% big peak again

$\%$ plot(D(:,1),D(:,2))

$\%$ Use spline command to increase number of data points for numerical

$\%$ derivatives

$\mathrm{X}=\mathrm{D}(:, 1) / 10^{\wedge} 6 ; \% \mathrm{MHz}$

$x \min =\min (X)$;

$\operatorname{xmax}=\max (X)$;

$\mathrm{Y}=\mathrm{D}(:, 2) ; \%$ log magnitude $(\mathrm{dB})$

$\mathrm{np}=1000000$

$x q=$ linspace $(x \min , x \max , n p)$;

$y q=\operatorname{spline}(X, Y, x q)$;

$\%$ Now use forward finite differences to get slope

step $=((x \max -\mathrm{xmin}) / \mathrm{np})$;

slopevec $=\operatorname{diff}(y q) /$ step;

$\%$ Plot both and you can see that the min and max are now ZEROS

$\%$ value...

Flags $=\operatorname{zeros}(1, \mathrm{np}-1)$

\%plot(xq(1:np-1),slopevec)

\%hold on

for $\mathrm{i}=1$ :np-2

check $=\operatorname{sign}(\operatorname{slopevec}(1, \mathrm{i}))+\operatorname{sign}(\operatorname{slopevec}(1, \mathrm{i}+1)) ; \%$ NOTE: sign is 1 if positive, -1 if

negative) 


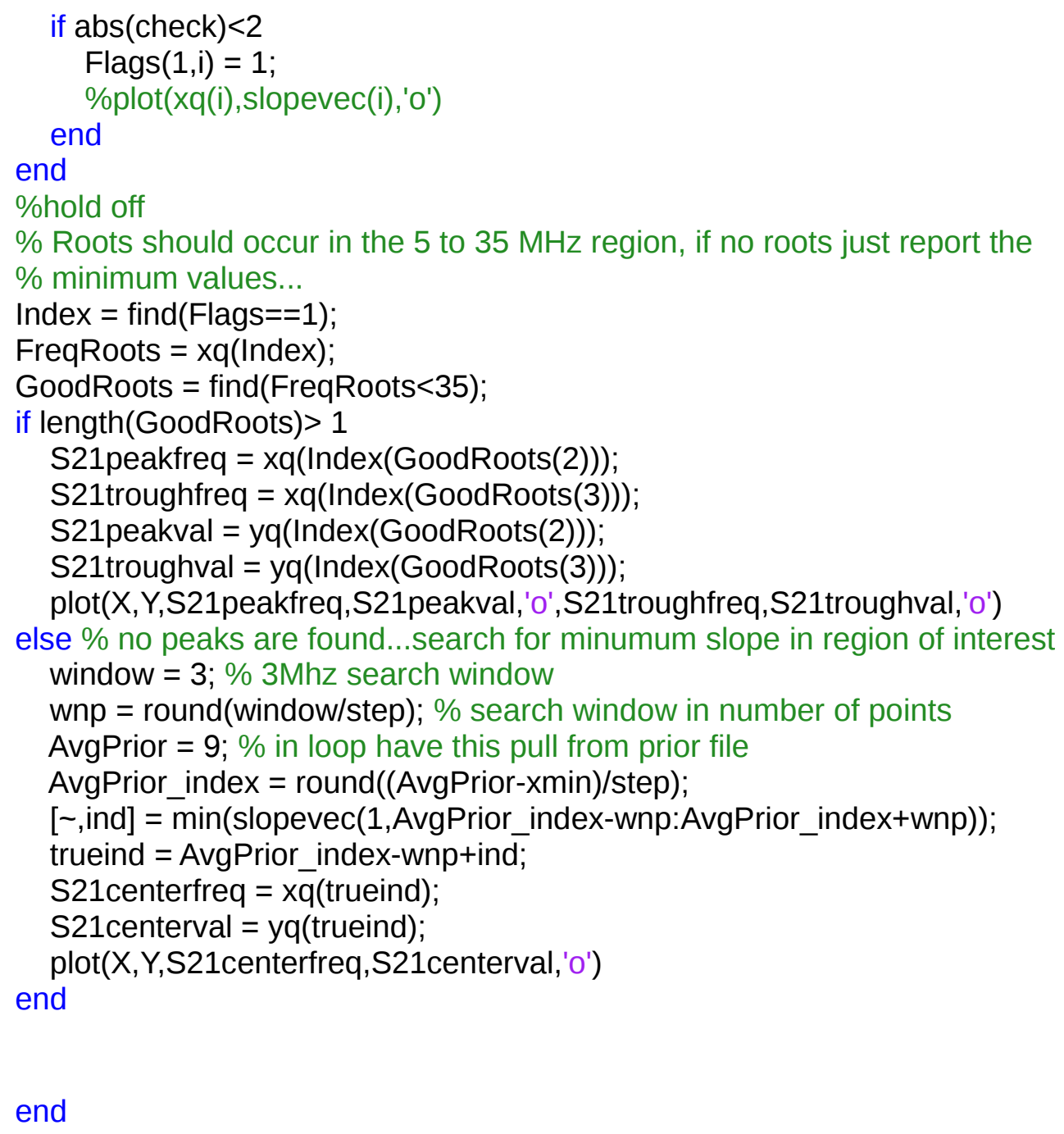




\section{Video for $\left|\mathrm{S}_{21}\right|$ Response for Different $\mathrm{KCl}$ Concentrations}

The magnitude of transmission scattering parameter $\left(\left|\mathrm{S}_{21}\right|\right)$ was captured over $0-100 \mathrm{MHz}$ for $\mathrm{KCl}$ solutions with varying concentrations, ranging from zero to $4.58 \mathrm{M}$ (Video S4). The red circles in the video represent the resonant peak. 


\section{Physical Underpinning of Sensor Response of lons}

Based on the lumped-element circuit model mentioned in the manuscript, there are three main circuit parameters affecting the system resonance: inductance (L), capacitance (C), and resistance $(R)$. The resonant frequency is solely dependent on the real component of the complex relative permittivity $\left(\varepsilon^{\prime}\right)$, as all other terms, such as the inductance $\left(L_{\text {res }}\right)$ of the sensor and number of turns $(\mathrm{N})$ are dictated by the resonator design and assumed to be constant. ${ }^{1}$ Hence, any shift observed in the resonant frequency is due to changes in the permittivity caused by modifying the ionic concentration of the solution above the resonator.

The permittivity of real materials is frequency-dependent, as molecules within the material exhibit a phase lag and damping to the imposed, external electromagnetic field. These components of phase and damping are presented mathematically as a complex number defined as: ${ }^{2}$

$$
\varepsilon_{r}=\varepsilon^{\prime}-j \varepsilon^{\prime \prime}
$$

Where $\varepsilon^{\prime} \quad$ is the real component of permittivity, which represents the polarization of the sample under the influence of an external electric field and is related to the lag between the phase of the applied electric field and the electric flux density. $\varepsilon^{\prime} '$ is the imaginary component which measures damping or dispersion of energy by the dielectric. The imaginary component can also be expressed related to both the conductivity and frequency: ${ }^{3}$

$$
\varepsilon^{\prime \prime}=\varepsilon_{d}^{\prime \prime}(f)+\frac{\sigma}{2 \pi f \varepsilon_{0}}
$$

where $\varepsilon_{d}^{\prime \prime}(f)$ represents the dipolar loss, $\sigma$ is the DC conductivity, and $\varepsilon_{0}$ is the absolute permittivity of free space. Typically, for the solutions and ions of interest in this work, $\varepsilon_{d}^{\prime \prime}(f)$ is constant with concentration and becomes negligible at low frequencies. ${ }^{4}$

In general, it is believed that higher salt concentration would increase the conductivity of the solution; however, the collisions of the ions with other particles present in the solution (e.g. water molecules, other ions, contaminations, etc.) constrain the ion movement. ${ }^{5}$ Hence, although all saline solutions are electrically conductive, their conductivity is a function of the amount of charge carried by the ions as well as how quickly their energy might disperse as heat.

At very low concentrations of $\mathrm{KCl}\left(<10^{-4} \mathrm{M}\right)$, there is not a significant dependence of permittivity on the concentration, as the solution is very dilute. Thus, the resonant frequency does not change (standard deviation of the measured resonant frequency for low concentrations of $\mathrm{KCl}$ is 0.008). For the concentration range of $0.1 \mathrm{mM}$ to $60 \mathrm{mM}$, however, there is an observed, dramatic decrease in the resonant frequency; this is a function of changes in the relative permittivity of the medium in proximity and coupled to the resonator. Conversely, we observe a small increase in resonant frequency at higher concentrations, which would indicate a decrease in the relative permittivity for the higher salt levels. 
There have been many efforts to study the behavior of permittivity as the salt concentration of a solution changes; however, we find varying results and reasoning in these different studies. A major challenge associated with measuring the relative permittivity of ionic solutions is due to their relatively large conductivities. ${ }^{6}$ In one theory it is concluded that for concentrations below $1 \mathrm{M}$ of a salt-water solution (e.g. potassium chloride, cesium chloride, and sodium chloride), the relative permittivity decreases with salt concentration. ${ }^{7,8}$ This dielectric decrement phenomenon is attributed to the local electric field which is created by individual ions that inhibit the externally applied field. ${ }^{9}$ The water molecules have the propensity to align with the local electric fields generated by ions and a hydration shell is created around the ion. Therefore, the water molecules are less responsive to the externally applied field and the dielectric permittivity decreases. In another theory proposed by Little $^{6}$, it is hypothesized that each ion in the solution is surrounded by spherical shells of the solvent molecules. Furthermore, it is assumed that the relative permittivity does not change within the ordered region of the shell system. Also, the shell structure for both potassium and chloride are assumed to be similar since their mobilities in aqueous solutions are the same. As the $\mathrm{K}^{+}$and $\mathrm{Cl}^{-}$approach each other and their outer shells come into contact (separation between the charges is $20^{\circ} \mathrm{A}$ ), a bridge of the directed solvent molecule will form which links the ions. Using these hypotheses, the total change in relative permittivity for dilute solutions is a parabolic function of $\mathrm{KCl}$ concentration governed by the following equation:

$$
\delta \varepsilon=34 \times 10^{3}[c]^{2}-\left[370+6 n_{4}\right][c]
$$

In which $\mathrm{n}_{4}$ is the number of effective molecules in the fourth shell, which is the outer shell since $\mathrm{n}_{5}$ is assumed to be zero. The coefficients for $[\mathrm{c}]^{2}$ and $[\mathrm{c}]$ are specified by the generation of dipole linkages and the shell structures, respectively. Therefore, the relative permittivity for potassium chloride would decrease to a minimum value with increasing the concentration but eventually increase to values higher than the value at zero concentration $(\sim 80)$. This general form is also confirmed via force method by Fürth ${ }^{10}$ for sodium chloride and by Pechhold ${ }^{11}$ for potassium, sodium, lithium, and hydrogen chloride. In another study conducted by Fürth regarding the relative permittivity of conducting liquids at low frequencies, increasing the concentration of the solution in the range of $2.5-10 \mathrm{mM}$ caused an increase in the relative permittivity from 80.2 to $83 .^{12}$

Another important theory about the relative permittivity of very dilute solutions $(<25 \mathrm{mM})$ was proposed through the Debye - Falkenhagen equation (eq S5. 8 - 11) ${ }^{13,14}$ which can be simplified as:

$$
\varepsilon_{w}-\varepsilon_{r w}=A \sqrt{\gamma^{i}}
$$

In which $\varepsilon_{w}$ is the relative permittivity of the solution at low frequencies (1-2 KHz), $\varepsilon_{\mathrm{rw}}$ is the relative permittivity of the solvent ( 80.4 for water), $A$ is a constant which is dependent on the properties of the salt, such as ion mobilities, valency type, etc. $(A=3.76$ for $\mathrm{KCl})$ (Table S. 5). $\mathrm{Y}^{*}$ represents the equivalent concentration and is defined as a function of the number of positive and negative ions for each molecule $\left(\mathrm{u}_{\mathrm{i}}\right)$, the valency of the ion $\left(\mathrm{z}_{\mathrm{i}}\right)$ and concentration of the solution ([c]): 


$$
y^{i}=v_{i} z_{i}[c]
$$

Although this study was validated for very low frequencies, the Debye and Falkenhagen theory was confirmed for frequencies up to $100 \mathrm{MHz}$, which is the frequency range in which our study was performed. Based on this equation, the relative permittivity should rapidly increase with concentration; however, it has been demonstrated that the agreement between the theoretical relative permittivity predicted by Debye - Falkenhagen and the experimental relative permittivity observed by Dunning and Shutt holds up to $2 \mathrm{mM} .{ }^{15}$ Based on these experimental data, for each salt, the relative permittivity of the aqueous solution can be calculated for concentrations less than $25 \mathrm{mM}$ using (eq S5-6):

$$
\varepsilon_{s}-\varepsilon_{r w}=A \sqrt{\gamma^{i}}-\varepsilon_{0} K \gamma^{i}+\varepsilon_{0} K \gamma^{i 2}
$$

In which $\varepsilon_{s}$ is the relative permittivity of the solution, $\mathrm{ky}^{*}$ is correspondent to the Sack's factor ${ }^{16}$ and $\mathrm{K}$ is proportional to the square root of valencies of ions $\left(\sum z_{i}^{1 / 2}\right)$ and its value is 0.74 for $\mathrm{KCl} . \mathrm{Ky}^{\text {t2 }}$ factor is explained in terms of the desaturation effect (the number of saturation holes does not increase as rapidly as the concentration) and has a value of 16 for $\mathrm{KCl}$. Hence, calculating the relative permittivity of $\mathrm{KCl}$ in terms of the concentration of the solution is possible using (eq S5-7).

$$
\varepsilon_{s}-\varepsilon_{r w}=3.76 \sqrt{\gamma^{i}}-0.74 \varepsilon_{0} \gamma^{i}+16 \varepsilon_{0} \gamma^{i 2}
$$

This equation has the capability to explain the decrease response of the resonant frequency (increase in the relative permittivity) for dilute solutions of $\mathrm{KCl}$; however, the concentration range for which we observe this trend $(0.1 \mathrm{mM}-60 \mathrm{mM}$ ) is larger than the one given by (eq S5-7) (up to $2 \mathrm{mM}$ ). The reason could be the same complexity we have observed in comparing previous studies, namely, generating a satisfactory equation to describe the behavior of relative permittivity for a large range of concentration is extremely challenging due to the high conductivity of the solution. Therefore, although explaining the effect of concentration on relative permittivity in terms of three separated phenomena of Debye-Falkenhagen (rise), Sack's factor (decrease), and desaturation (increase) helps with predicting the general trend, it is not able to fully predict the concentration ranges for which each theory holds.

Another phenomenon observed in the resonant frequency response is the small but not insignificant increase in the resonant frequency for the $\mathrm{KCl}$ concentration higher than $60 \mathrm{mM}$ (standard deviation $=0.05$ ), because of a decrease in the relative permittivity at high concentrations. This is attributed to the dipole saturation of the hydration shells around ions, which means the orientation polarizability of water molecules close to the ions decrease. This pattern has been observed before for high concentrations (e.g. $1 \mathrm{M}$ ) of strong electrolyte solutions, such as $\mathrm{KCl}, \mathrm{KNO}_{3}, \mathrm{NaCl}$, etc. ${ }^{17}$ Since the relative permittivity of the aqueous solution is determined by the polarization, it slightly decreases with increasing the concentration due to the dielectric saturation $(>60 \mathrm{mM}) \cdot{ }^{18}$ Although the above-mentioned theories all confirm the dielectric saturation of water in the vicinity of ions in the solution, discrepancies are observed regarding the concentration after which the saturation effect is not negligible. In the Dunning and Shutt theory, this critical concentration for $\mathrm{KCl}$ is about $5 \mathrm{mM}^{15}$, which is different from our experimental results $(60 \mathrm{mM})$, likely due to the applicability of the available models. 
Another important parameter extracted from the $\left|S_{21}\right|$ signal for all concentrations of $\mathrm{KCl}$ is the peak-to-peak amplitude. As mentioned earlier, as the concentration of $\mathrm{KCl}$ solution increases from $100 \mathrm{nM}$ to $\sim 10 \mathrm{mM}$, the peak-to-peak amplitude rapidly decreases, until it is not detectable anymore (peak-to-peak amplitude $\sim 0$ for concentration in the range of $10-17 \mathrm{mM}$ ). However, for concentrations higher than $17 \mathrm{mM}$, the peak-to-peak amplitude increases with concentration. Since the inductance of the resonator is assumed to be dependent on the physical parameters (e.g. length) of the spiral, it remains constant for all concentrations of $\mathrm{KCl}$. Therefore, the changes in the peak-to-peak amplitude are attributed to the variations in the conductivity of the aqueous solution. ${ }^{19,20}$ In order to describe the peak disappearance, first, it should be noted that with monitoring $\left|S_{21}\right|$ signal, we are in fact measuring the transmitted energy from one loop of the reader to the other. A disappearance in amplitude means that the energy sent by the VNA is being fully absorbed by the sensor/solution system. In other words, for $\mathrm{KCl}$ solutions with $10-$ $17 \mathrm{mM}$ concentration, there is a high energy loss due to an optimal impedance match and coupling to the sensor/solution system. This energy absorption is caused by the interaction between the electric field and ions in solution at these specific concentrations. The amplitude is zero through a range of concentrations. After this transition $(\mathrm{KCl}$ concentration $>17 \mathrm{mM})$, the energy loss to the sensor/solution system is again reduced and the transmission energy is again picked up by the second coil of the reader, and the resonant peak becomes detectable again.

One of the theories regarding the dependence of dielectric constant of ionic solutions on the salt concentration is Debye-Falkenhagen:

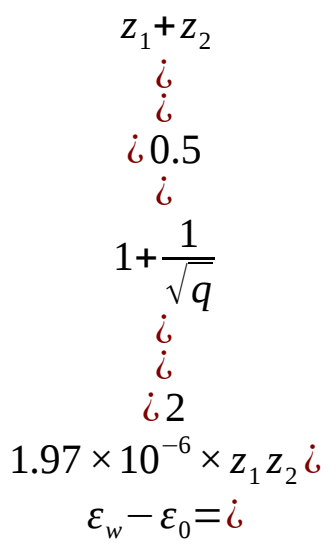

where $\varepsilon_{w}$ is the dielectric constant of the solution at low frequencies (1-2 KHz), $\varepsilon_{0}$ is the dielectric constant of the solvent ( 80.4 for water), $z_{1}$ and $z_{2}$ are the valencies of the ions, and $T$ is the temperature $(293.15 \mathrm{~K}) \cdot \mathrm{Y}^{*}$ is a measure of concentration defined as:

$$
\gamma^{i}=v_{i} z_{i} C
$$

Where $\mathrm{U}_{\mathrm{i}}, \mathrm{z}_{\mathrm{i}}$, and $\mathrm{C}$ are the number of positive and negative ions for each molecule, the valency of the ion, and concentration of the solution, respectively. $q$ is defined as: 


$$
q=\frac{z_{1} z_{2}}{z_{1}+z_{2}} \frac{l_{1}+l_{2}}{z_{2} l_{1}+z_{1} l_{2}}
$$

In which $I_{1}$ and $I_{2}$ are the relative mobilities of ions in the solution. Eq S8 can also be written as:

$$
\varepsilon_{w}-\varepsilon_{0}=A \sqrt{\gamma^{i}}
$$

And $A$ is a constant which can be calculated for different salts. Using the mobility values from (1), the salt constant (A) is calculated for $\mathrm{KCl}, \mathrm{KNO}_{3}, \mathrm{NH}_{4} \mathrm{NO}_{3}, \mathrm{KH}_{2} \mathrm{PO}_{4}$, and $\mathrm{NH}_{4} \mathrm{H}_{2} \mathrm{PO}_{4}$ :

Table S5. The Debye - Falkenhagen coefficient for different salts.

\begin{tabular}{|c|c|c|c|c|c|c|}
\hline Salt & Abs $\left(\mathbf{z}_{\mathbf{1}}\right)$ & $\mathbf{A b s}\left(\mathbf{z}_{\mathbf{2}}\right)$ & $\mathbf{I}_{\mathbf{1}}$ & $\mathbf{I}_{\mathbf{2}}$ & $\mathbf{q}$ & $\mathbf{A}$ \\
\hline $\mathrm{KCl}$ & 1 & 1 & 1 & 1.039 & 0.5 & 3.755 \\
\hline $\mathrm{KNO}_{3}$ & 1 & 1 & 1 & 0.972 & 0.5 & 3.755 \\
\hline $\mathrm{NH}_{4} \mathrm{NO}_{3}$ & 1 & 1 & 1 & 0.972 & 0.5 & 3.755 \\
\hline $\mathrm{KH}_{2} \mathrm{PO}_{4}$ & 1 & 1 & 1 & 0.45 & 0.5 & 3.755 \\
\hline $\mathrm{NH}_{4} \mathrm{H}_{2} \mathrm{PO}_{4}$ & 1 & 1 & 1 & 0.45 & 0.5 & 3.755 \\
\hline
\end{tabular}

Therefore, for salts with similar valencies, the Debye - Falkenhagen coefficient is independent of the type of salt. 


\begin{tabular}{|c|c|c|c|c|c|}
\hline $\begin{array}{l}\text { 6. Table } \\
\text { with }\end{array}$ & Specification & $\begin{array}{l}\text { Outer Diameter } \\
(\mathbf{m m})\end{array}$ & $\begin{array}{l}\text { Pitch } \\
(\mathrm{mm})\end{array}$ & $\begin{array}{c}\text { Length } \\
(\mathrm{mm})\end{array}$ & $\begin{array}{l}\text { of Sensors } \\
\text { Different } \\
\text { Geometries }\end{array}$ \\
\hline \multirow{10}{*}{$\begin{array}{l}\text { There are two } \\
\text { parameters for } \\
\text { spiral } \\
\text { length of the } \\
\text { pitch size. } \\
\text { inner diameter } \\
\text { constant for all } \\
\text { designs, the } \\
\text { spiral could be } \\
\text { the outer }\end{array}$} & \multirow{5}{*}{ Constant Length } & 40 & 1 & 1255 & \multirow{10}{*}{$\begin{array}{l}\text { major design } \\
\text { Archimedean } \\
\text { resonators: } \\
\text { spiral, and } \\
\text { Because the } \\
\text { was kept } \\
\text { resonator } \\
\text { length of the } \\
\text { controlled by } \\
\text { diameter. In }\end{array}$} \\
\hline & & 43.81 & 1.2 & 1255 & \\
\hline & & 50.59 & 1.6 & 1255 & \\
\hline & & 56.54 & 2 & 1255 & \\
\hline & & 63.21 & 2.5 & 1255 & \\
\hline & \multirow{5}{*}{ Constant Pitch } & 35 & 1.2 & 800 & \\
\hline & & 43.81 & 1.2 & 1255 & \\
\hline & & 45 & 1.2 & 1324 & \\
\hline & & 55 & 1.2 & 1979 & \\
\hline & & 65 & 1.2 & 2764 & \\
\hline
\end{tabular}

Table S6. Resonator geometries used for $\mathrm{KCl}$ test 
7. MATLAB Code for Plotting Geometry-Dependence Response

The following MATLAB code (Code S7) was used to loop through all folders containing the S21 data for different geometries of resonators in response to varying concentrations of $\mathrm{KCl}$. This test was conducted in order to study the effect of geometry on the resonant sensor ionic response.

function S21fit_v3b

$\%$ Coded by Nigel F. Reuel on 10.5.2017

$\%$ This code automates the peak fitting and finds the peak even if it is $\%$ very small (using splines and derivatives)

$\%$ v1 - no looping through folders and all files, just uses single files to

$\%$ test

$\%$ v2 - test looping in file

$\%$ v3 - loop through all files and all folders!

$\%$ v3b - Plot just the data you need for the Neihart grant

$\%$ Loop through folders

for $\mathrm{ii}=1 \%$ This is the $40 \mathrm{~mm} \mathrm{D}$ and $1 \mathrm{~mm}$ pitch folder

$\%$ Loop through files:

$\%$ Create file to store data:

Dstore = zeros $(40,6)$;

$\%$ Count picture spot

$\mathrm{cp}=1$;

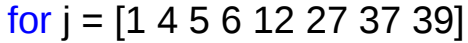

filename = fullfile(int2str(ii), [int2str(j),'.csv']);

$\mathrm{D}=\operatorname{csvread}($ filename); 


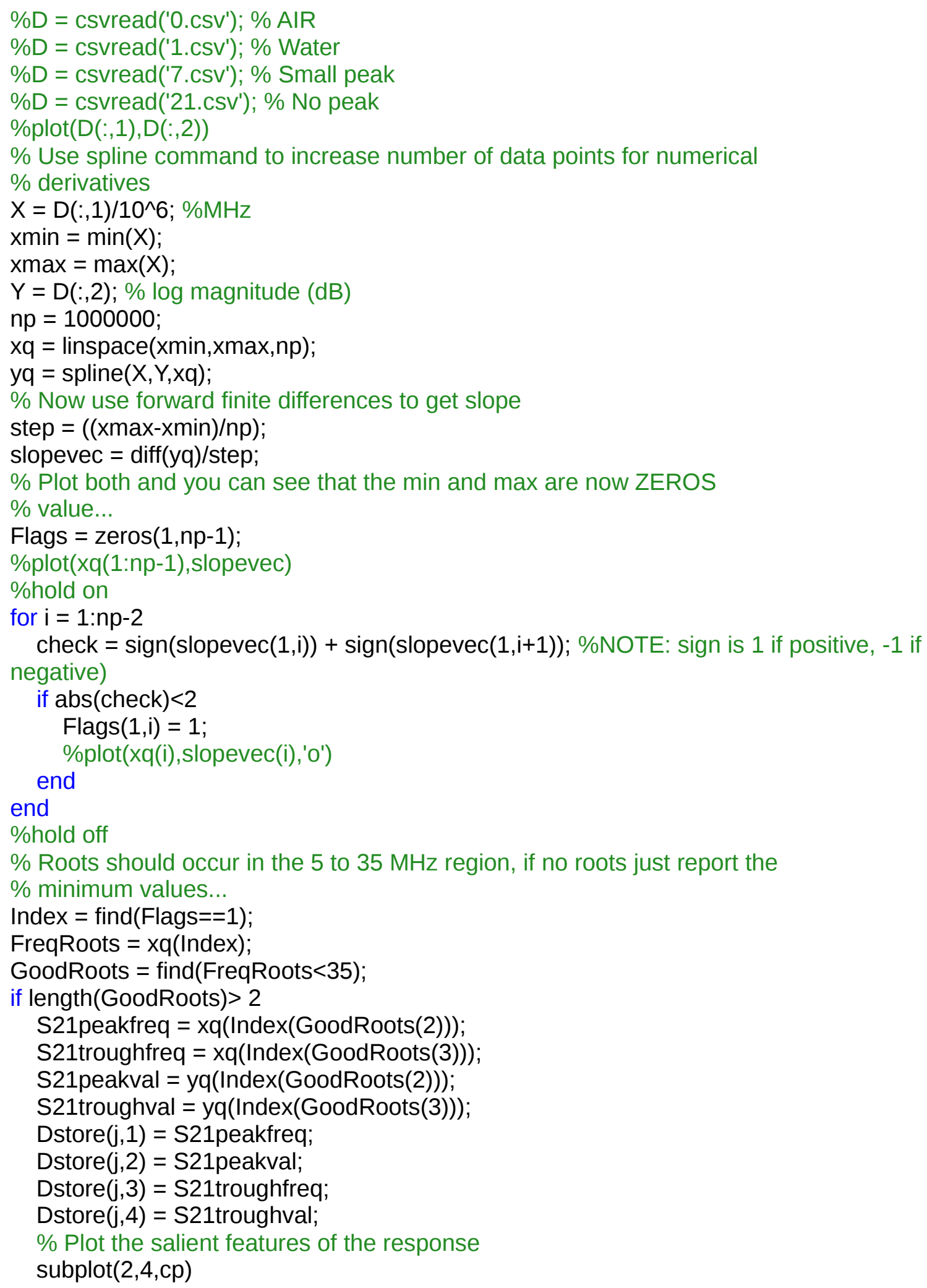


\%xlabel('Frequency (MHz)','FontWeight', 'bold','FontName','Arial', 'FontSize',14);

\%ylabel('S21(dB)','FontWeight', 'bold','FontName','Arial', 'FontSize',14);

set(gca,'fontsize',14,'FontWeight', 'bold')

hold on

plot([S21peakfreq S21peakfreq],[S21peakval S21troughval],':r')

\% xlabel('Frequency (MHz)','FontWeight', 'bold','FontName','Arial', 'FontSize',14);

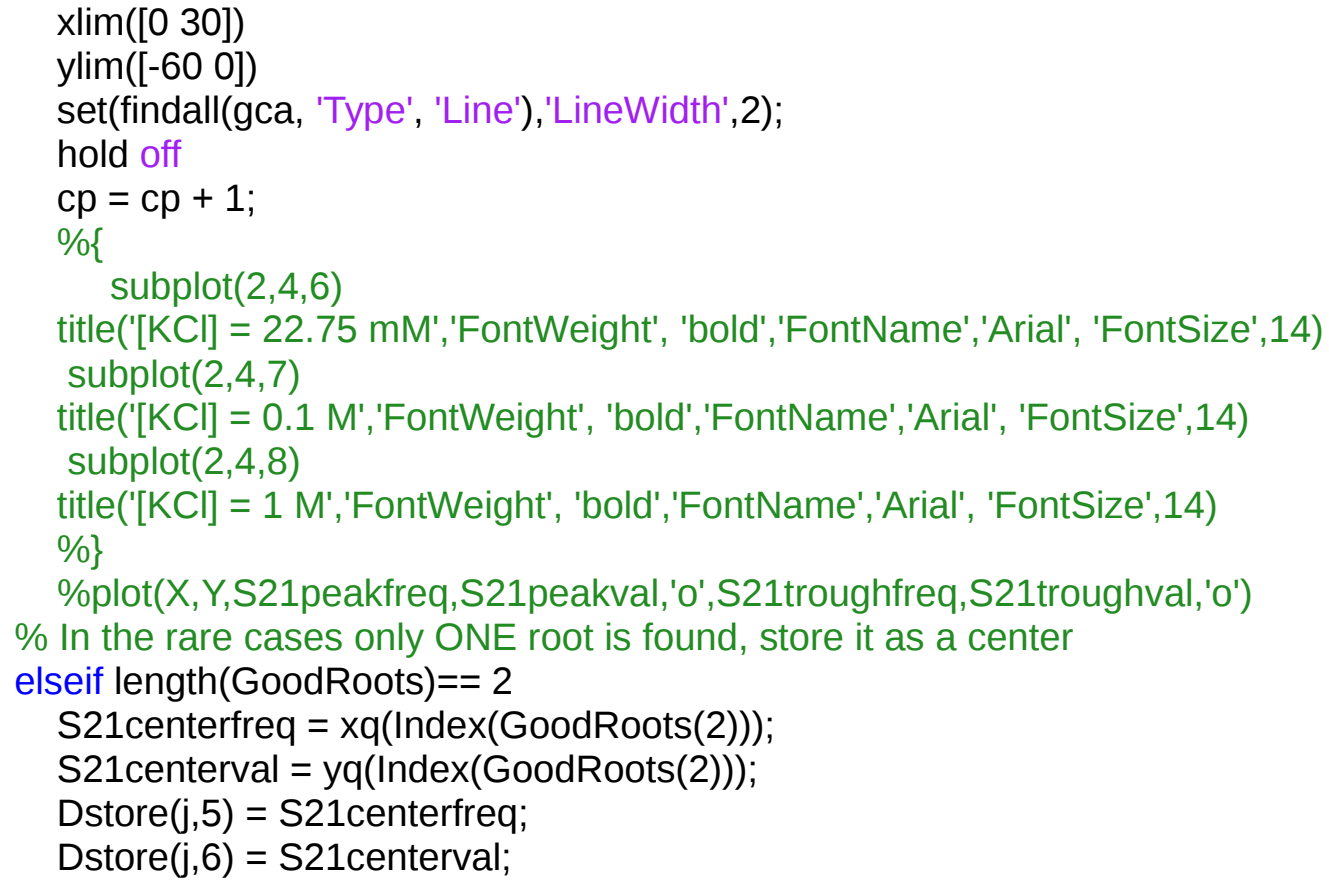

else $\%$ no peaks are found...search for minumum slope in region of interest window $=3 ; \% 3 \mathrm{Mhz}$ search window wnp = round(window/step); \% search window in number of points

AvgPrior $=9$; $\%$ in loop have this pull from prior file

AvgPrior_index = round ((AvgPrior-xmin)/step); [ , ind $]=$ min(slopevec(1,AvgPrior_index-wnp:AvgPrior_index+wnp));

trueind $=$ AvgPrior index-wnp+ind;

S21centerfreq $=x \bar{q}$ (trueind);

S21centerval = yq(trueind);

Dstore $(\mathrm{j}, 5)=\mathrm{S} 21$ centerfreq;

Dstore(j,6) = S21centerval;

$\%$ Plot the salient features of the response

subplot $(2,4, \mathrm{cp})$

$\operatorname{plot}(\mathrm{X}, \mathrm{Y}, \mathrm{S} 21$ centerfreq,S21centerval,'o')

$\%$ xlabel('Frequency (MHz)','FontWeight', 'bold','FontName','Arial', 'FontSize',14);

\% ylabel('S21(dB)','FontWeight', 'bold','FontName','Arial', 'FontSize',14);

set(findall(gca, 'Type', 'Line'),'LineWidth',2);

$\mathrm{x} \lim \left(\left[\begin{array}{l}0 \\ 0\end{array} 0\right]\right)$

$y \lim ([-600])$

set(gca,'fontsize',14,'FontWeight', 'bold')

$c p=c p+1$;

$\%\{$ 


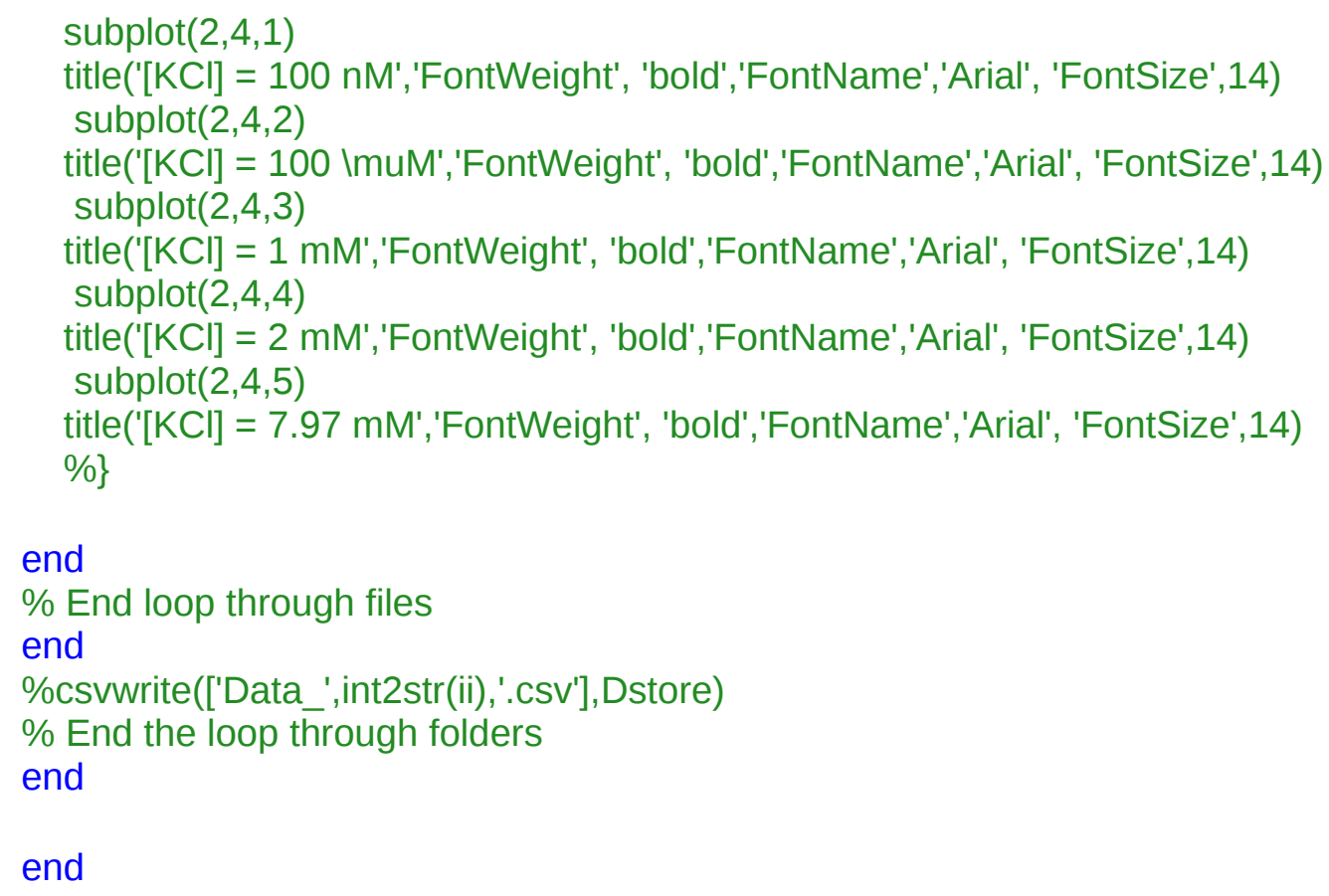

8. Effect of Pitch Size and the Spiral Length on the Initial Self-Resonant Frequency

For a resonant sensor exposed to air $\left(\varepsilon_{0}=1\right)$, the self-resonant frequency is governed by the physical parameters of the Archimedean spiral resonator. We designed two panels of resonators to study the effect of sensor geometry on its ion-specific response. The first panel had a constant length $(1255 \mathrm{~mm})$ and variant pitch sizes, ranging from $1-2.5 \mathrm{~mm}$. For the second panel of resonators, the pitch size did not vary among the resonators $(1.2 \mathrm{~mm})$ but the length ranged from $800-2764 \mathrm{~mm}$. The resonant frequency of the sensors exposed to air was dependent on both pitch size (Fig S8a) and spiral length (Fig S8b) through a quadratic function, having a direct relationship with the pitch size (higher pitch size lead to higher resonant frequency) and an inverse relationship with the length (the resonant frequency drops as the length increases). 

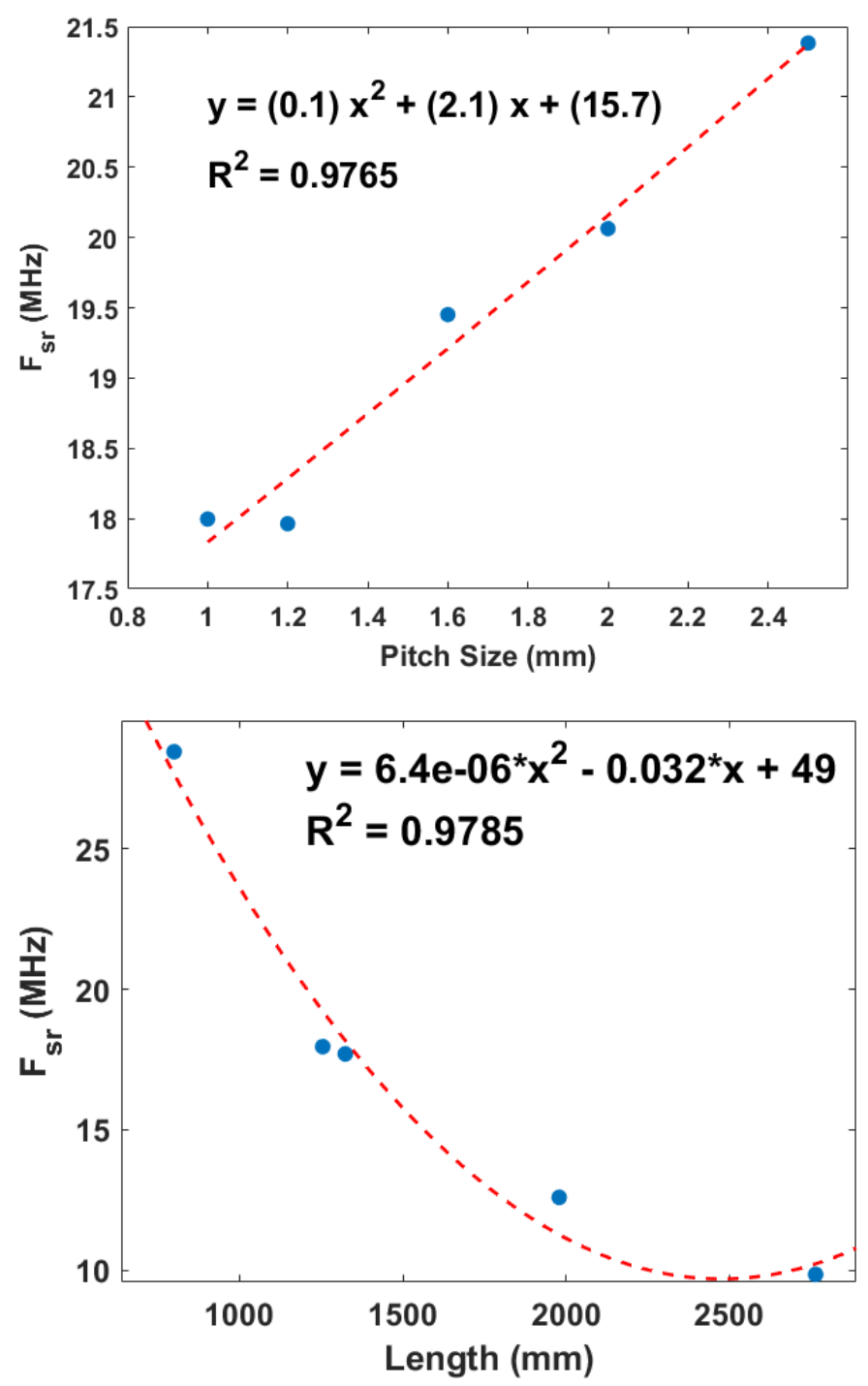

Fig S8. Effect of a) pitch size and b) spiral length on the self-resonant frequency of Archimedean spiral resonant sensors.

\section{The Dependency of Resonant Frequency Shift on Resonator Parameters}

With increasing the concentration of $\mathrm{KCl}$ solution, the resonant frequency dropped rapidly for a specific range of salinity $(1 \mathrm{mM}-0.1 \mathrm{M})$; However, this frequency shift was more dependent on the length of the resonator rather than its pitch size. In other words, as the length of the resonator changed, a bigger variation in the amount of the frequency shift was observed (Fig S9). 
a)

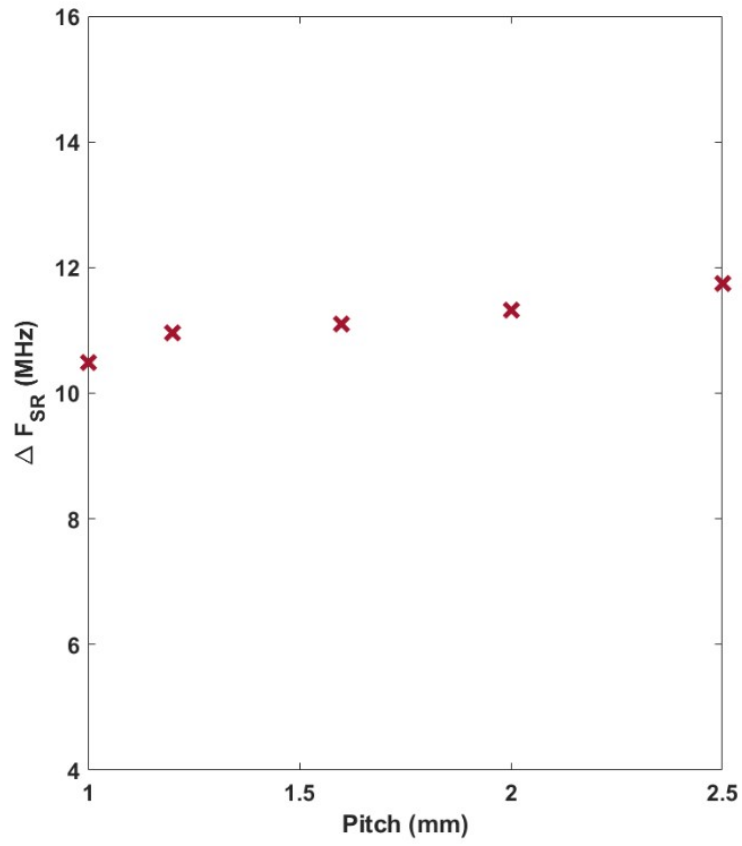

b)

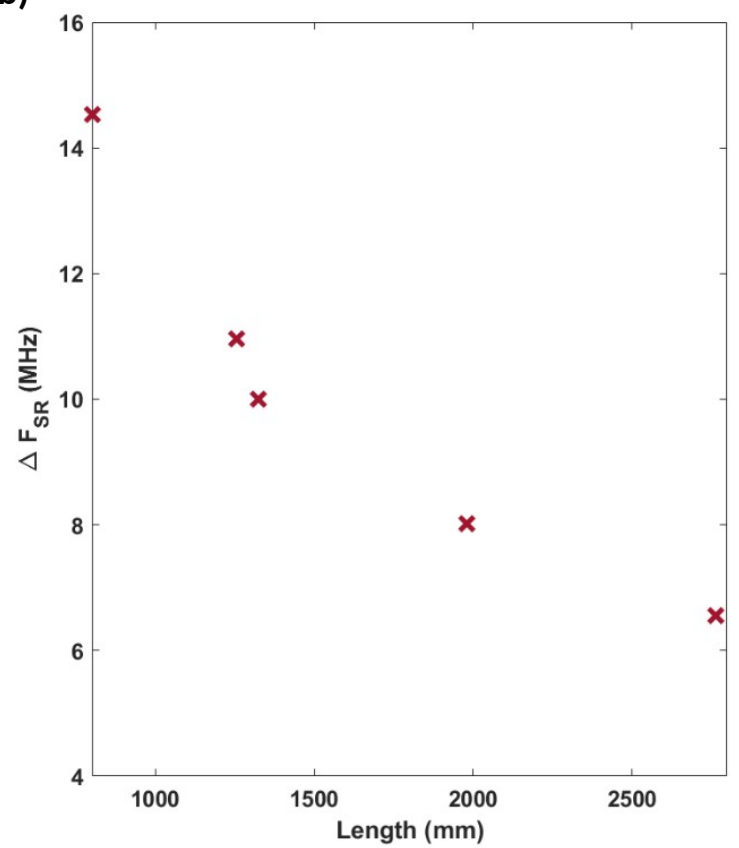

Figure S9. Effect of a) pitch size and b) spiral length on the frequency shift as a function of changing the $\mathrm{KCl}$ concentration.

In order to study the effect of ionic compound on the sensor response, $\mathrm{KNO}_{3}, \mathrm{NH}_{4} \mathrm{NO}_{3}, \mathrm{KH}_{2} \mathrm{PO}_{4}$, and $\mathrm{NH}_{4} \mathrm{H}_{2} \mathrm{PO}_{4}$, which are monovalent strong electrolytes salts with paired anion and cation, were tested on resonators (with $0.8,1.26$, and $2.76 \mathrm{~m}$ spiral length) over a concentration range of $100 \mathrm{~nm}-1 \mathrm{M}$. The $S_{21}$ responses for these salts were compared at different concentrations. The following MATLAB code (Code S10) was used to generate polar plots in order to show the phase and magnitude of $S_{21}$ at the same time. 


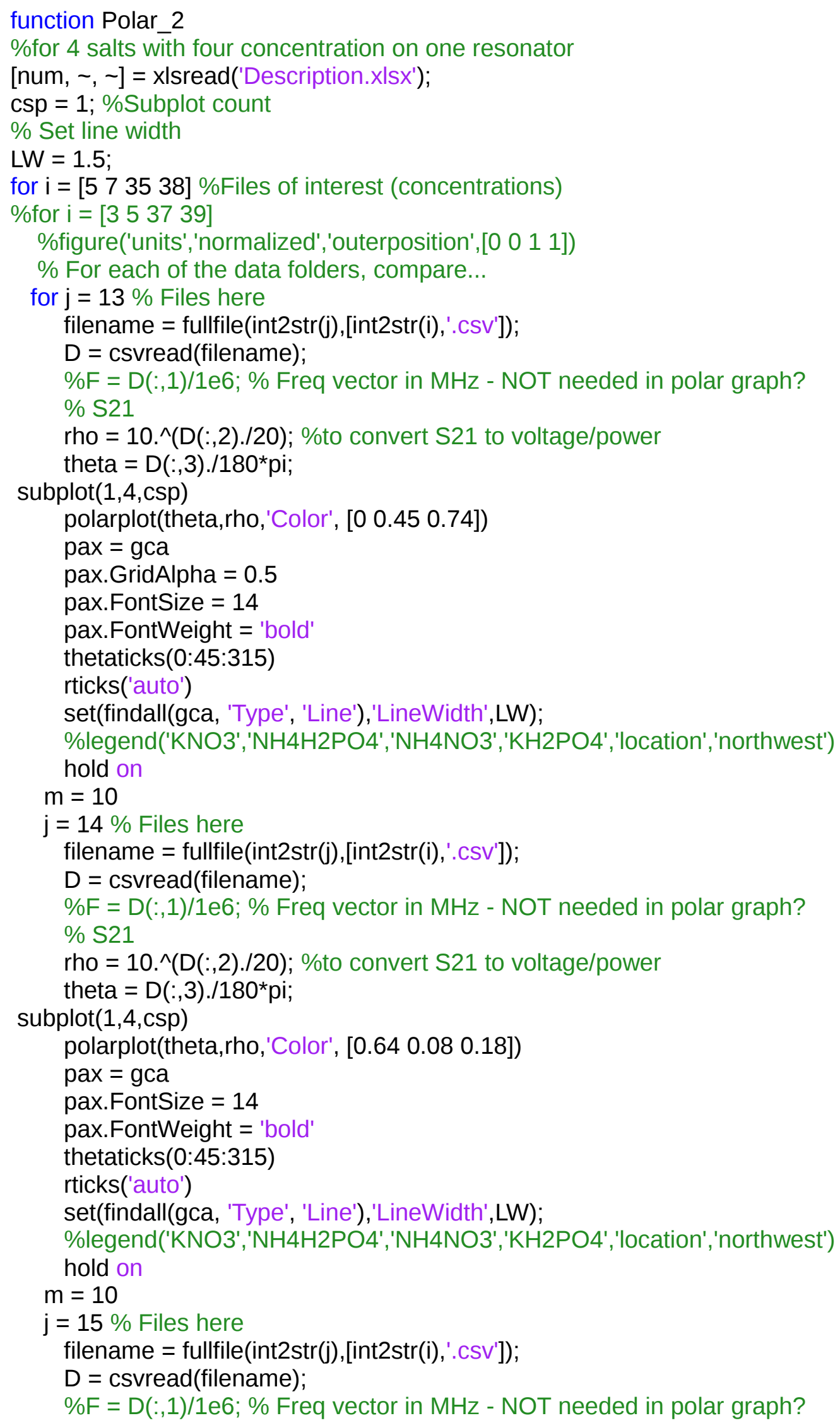




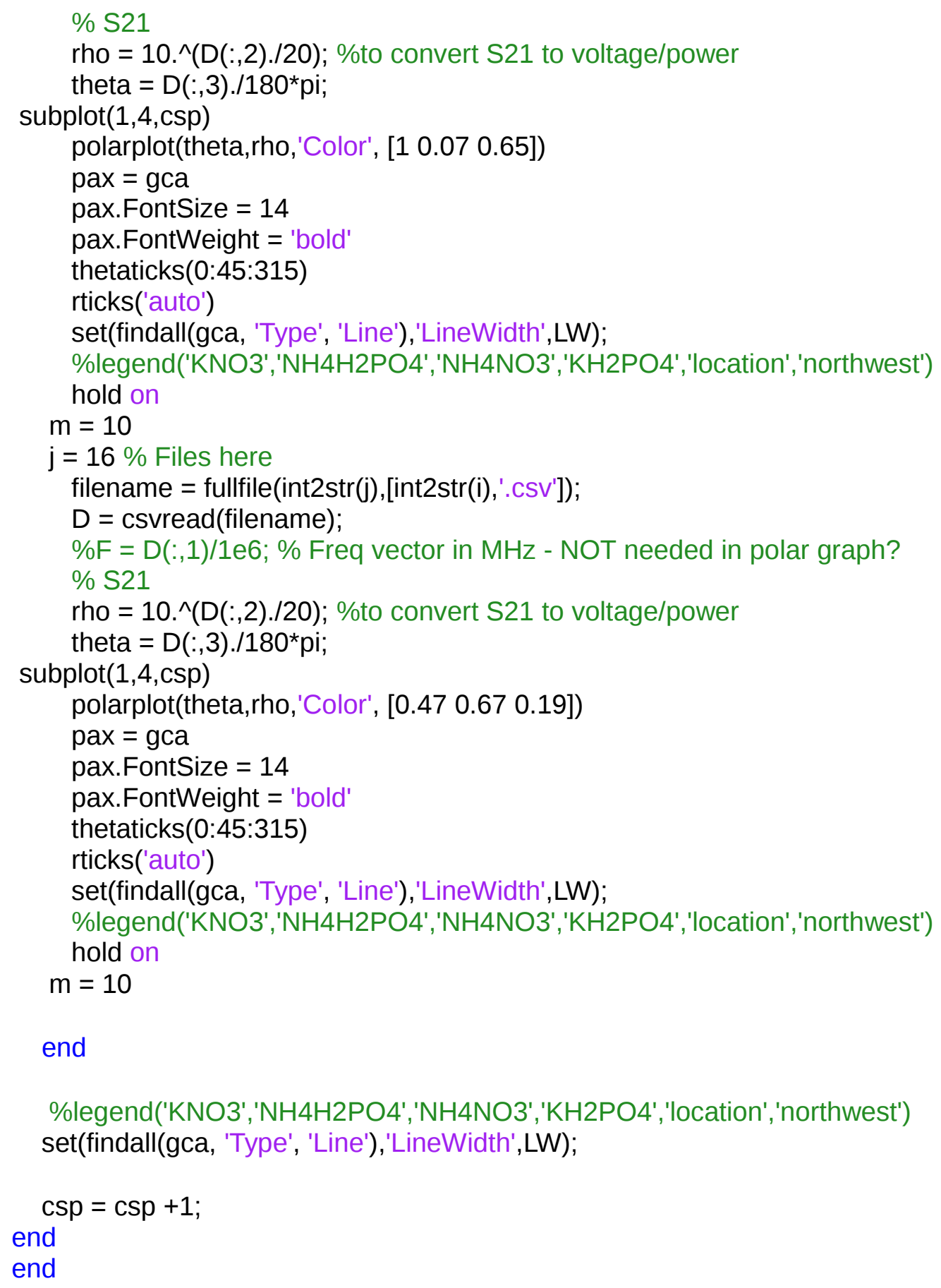

11. Polar Plot Video for Different Salts with100 nM to $1 \mathrm{M}$ Concentration

As mentioned earlier, $\mathrm{KNO}_{3}, \mathrm{NH}_{4} \mathrm{NO}_{3}, \mathrm{KH}_{2} \mathrm{PO}_{4}$, and $\mathrm{NH}_{4} \mathrm{H}_{2} \mathrm{PO}_{4}$, were tested on three resonators with different spiral lengths of $0.8,1.26,2.76 \mathrm{~m}$. The concentration range for this test was 100nM - $1 \mathrm{M}$; however, only four of these concentrations were plotted in Fig. 5 for simplicity. Video S11 represents the polar plots for all concentrations and all three resonators. 
12. Reproducibility of Sensor Response to Field 5 Samples

The samples collected from different field plots at the Agricultural Engineering/Agronomy Research Farm which receive varying amounts of poultry manure or inorganic $\mathrm{N}$ fertilizer were tested on three resonators having similar pitch and varying copper length. This test was conducted to study the reproducibility of sensor response to the nitrogen concentration using resonators with different geometrical features. It was observed that the sensor response has 
similar trend for all resonators and as expected, the peak-to-peak amplitude values are higher for a larger sensor.
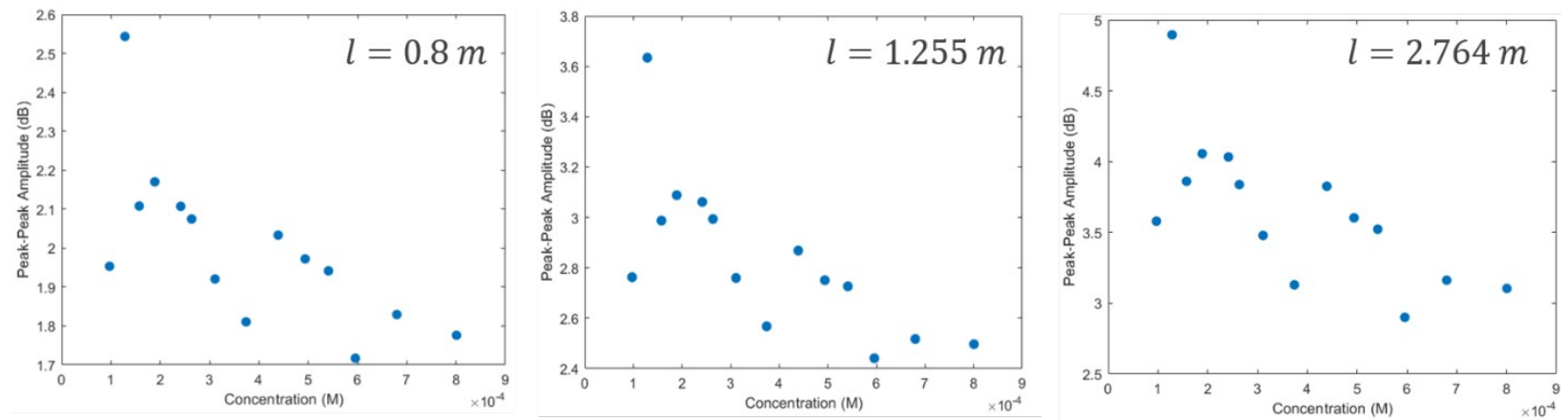

Fig S12. Effect of copper length on the sensor response to the level of nitrogen in the samples collected from Field 5.

13. Panel of Samples from BHL and Field 5 projects

A panel of samples having a nitrate concentration range of $0.05-3.54 \mathrm{mM}$ collected from both Black Hawk Lake and Field 5 (sample information can be found in Table S13) was tested on the resonant sensor with an outer diameter of $40 \mathrm{~mm}$ (Figure S13). The sensor response in terms of the peak amplitude cannot be fully attributed to the nitrogen level of these samples since there are other parameters affecting the scattering parameters. For instance, the samples were either 
in-stream samples collected from varying subwatersheds or subsurface samples. Moreover, some samples were collected during storm events, while others were collected regardless of the flow conditions. The sample collection method was also not consistent among the samples of this panel, as some were collected automatically, and some were grab samples. All the abovementioned inconsistencies between the samples lead to different levels of background ions (e.g. phosphate), biomass, and sediment which makes it impossible to extract a signal which is only proportional to the level of nitrogen from an uncoated resonant sensor.

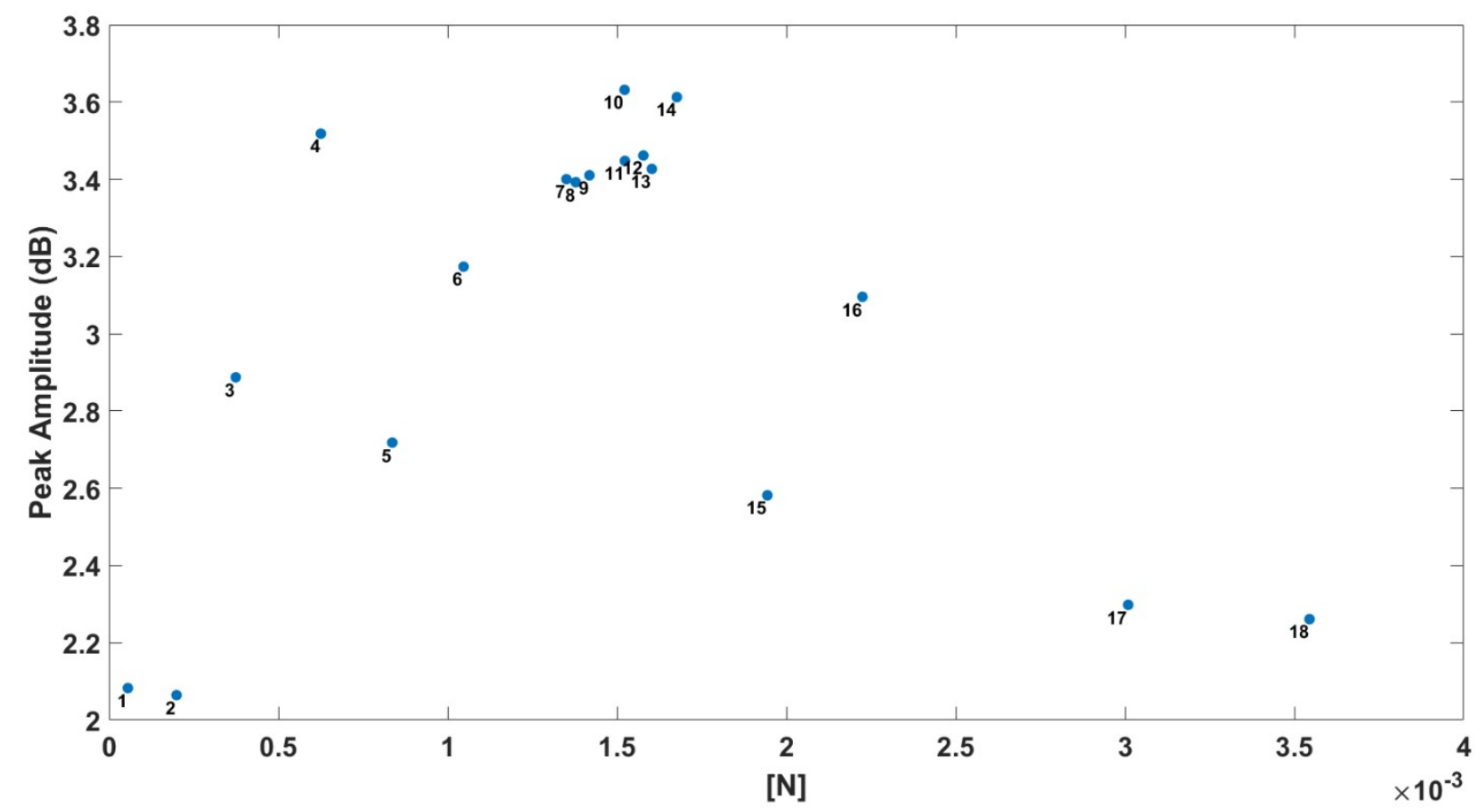

Fig S13. Sensor response to the nitrogen level of a panel of agricultural samples collected from both BHL and Field 5.

Table S13. Information of panel of agricultural samples collected from both BHL and Field 5.

\begin{tabular}{|c|c|c|c|c|c|c|}
\hline $\begin{array}{c}\text { Test } \\
\#\end{array}$ & Sample ID & Projec & Sample Date & $\begin{array}{c}\text { Nitrate+Nitrit } \\
\mathbf{t}\end{array}$ & [N] & $\begin{array}{c}\text { Phosphate } \\
\text { (mg P/L) }\end{array}$ \\
\hline $\mathbf{1}$ & IS8-W & BHL & $9 / 9 / 2019$ & 0.781 & $5.5759 E-05$ & 0.002 \\
\hline $\mathbf{2}$ & IS8-W & BHL & $9 / 25 / 2019$ & 2.793 & 0.00019940 & 0.11 \\
\hline
\end{tabular}




\begin{tabular}{|c|c|c|c|c|c|c|}
\hline 3 & T8-12 tile-G & $\mathrm{BHL}$ & 9/9/2019 & 5.242 & $\begin{array}{c}0.00037424 \\
9\end{array}$ & 0.013 \\
\hline 4 & S12-G & $\mathrm{BHL}$ & $11 / 13 / 2019$ & 8.762 & $\begin{array}{c}0.00062555 \\
8\end{array}$ & 0.004 \\
\hline 5 & Plot 11 & Field 5 & $7 / 11 / 2019$ & 11.716 & $\begin{array}{c}0.00083645 \\
7\end{array}$ & 0.017 \\
\hline 6 & IS8-W & $\mathrm{BHL}$ & 10/9/2019 & 14.664 & $\begin{array}{c}0.00104692 \\
8\end{array}$ & 0.064 \\
\hline 7 & T8-W & $\mathrm{BHL}$ & 10/9/2019 & 18.919 & $\begin{array}{c}0.00135071 \\
1\end{array}$ & 0.51 \\
\hline 8 & S11-E60 & $\mathrm{BHL}$ & 10/9/2019 & 19.307 & $\begin{array}{c}0.00137841 \\
2\end{array}$ & 0.004 \\
\hline 9 & IS8-E60 & $\mathrm{BHL}$ & 10/9/2019 & 19.869 & $\begin{array}{c}0.00141853 \\
5\end{array}$ & 0.003 \\
\hline 10 & IS8-G & $\mathrm{BHL}$ & 10/9/2019 & 21.325 & $\begin{array}{c}0.00152248 \\
6\end{array}$ & 0.027 \\
\hline 11 & T8-E60 & $\mathrm{BHL}$ & 10/9/2019 & 21.338 & $\begin{array}{c}0.00152341 \\
4\end{array}$ & 0.027 \\
\hline 12 & T8-G & $\mathrm{BHL}$ & 10/9/2019 & 22.101 & $\begin{array}{c}0.00157788 \\
8\end{array}$ & 0.03 \\
\hline 13 & S11-W & $\mathrm{BHL}$ & 10/9/2019 & 22.45 & $\begin{array}{c}0.00160280 \\
4\end{array}$ & 0.004 \\
\hline 14 & S11-G & $\mathrm{BHL}$ & 10/9/2019 & 23.484 & $\begin{array}{c}0.00167662 \\
6\end{array}$ & 0.025 \\
\hline 15 & Plot 1 & Field 5 & $5 / 29 / 2019$ & 27.23 & 0.00194407 & 0.135 \\
\hline 16 & S11-G & $\mathrm{BHL}$ & 9/9/2019 & 31.161 & $\begin{array}{c}0.00222472 \\
1\end{array}$ & 0.038 \\
\hline 17 & Plot 7 & Field 5 & $7 / 11 / 2019$ & 42.15 & $\begin{array}{c}0.00300927 \\
4\end{array}$ & 0.019 \\
\hline 18 & Plot 3 & Field 5 & $7 / 11 / 2019$ & 49.653 & $\begin{array}{c}0.00354494 \\
6\end{array}$ & 0.012 \\
\hline
\end{tabular}

\section{Concentrations of Ternary Mixtures}

In order to study the ion-specific response of the resonant sensors in the presence of other ions, 21 samples containing different concentrations of $\mathrm{KNO}_{3}, \mathrm{NH}_{4} \mathrm{NO}_{3}$, and $\mathrm{NH}_{4} \mathrm{H}_{2} \mathrm{PO}_{4}$ were prepared (Table S14). The total concentration of these mixtures was kept constant at $1 \mathrm{mM}$ in order to eliminate the effect of total concentration of the solution on the sensor response. 
Table S14. Concentration of ternary mixtures containing $\mathrm{KNO}_{3}, \mathrm{NH}_{4} \mathrm{NO}_{3}$, and $\mathrm{NH}_{4} \mathrm{H}_{2} \mathrm{PO}_{4}$.

\begin{tabular}{|c|c|c|c|}
\hline Sample \# & $\mathbf{K N O}_{3}(\boldsymbol{\mu m})$ & $\mathbf{N H}_{4} \mathbf{H}_{\mathbf{2}} \mathbf{P \mathbf { O } _ { 4 }}(\boldsymbol{\mu m})$ & $\mathbf{N H}_{\mathbf{4}} \mathbf{N O}_{\mathbf{3}}(\boldsymbol{\mu m})$ \\
\hline $\mathbf{1}$ & 1000 & 0 & 0 \\
\hline $\mathbf{2}$ & 0 & 1000 & 0 \\
\hline $\mathbf{4}$ & 0 & 0 & 1000 \\
\hline $\mathbf{5}$ & 600 & 200 & 0 \\
\hline $\mathbf{6}$ & 400 & 400 & 0 \\
\hline $\mathbf{7}$ & 200 & 600 & 0 \\
\hline $\mathbf{8}$ & 800 & 800 & 0 \\
\hline $\mathbf{9}$ & 600 & 0 & 200 \\
\hline $\mathbf{1 0}$ & 400 & 0 & 400 \\
\hline $\mathbf{1 1}$ & 200 & 0 & 600 \\
\hline $\mathbf{1 2}$ & 0 & 0 & 800 \\
\hline $\mathbf{1 3}$ & 0 & 800 & 200 \\
\hline $\mathbf{1 4}$ & 0 & 600 & 400 \\
\hline $\mathbf{1 5}$ & 0 & 400 & 600 \\
\hline $\mathbf{1 6}$ & 600 & 200 & 800 \\
\hline $\mathbf{1 7}$ & 400 & 200 & 200 \\
\hline $\mathbf{1 8}$ & 400 & 200 & 400 \\
\hline $\mathbf{1 9}$ & 200 & 400 & 200 \\
\hline $\mathbf{2 0}$ & 200 & 200 & 600 \\
\hline $\mathbf{2 1}$ & 200 & 400 & 400 \\
\hline $\mathbf{2 2}$ & 650 & 600 & 200 \\
\hline $\mathbf{2 3}$ & 300 & 250 & 100 \\
\hline $\mathbf{2 4}$ & 250 & 350 & 350 \\
\hline $\mathbf{2 5}$ & 150 & 250 & 525 \\
\hline & & 150 & 700 \\
\hline
\end{tabular}

\section{MATLAB Code for Ternary Plots}

The following MATLAB codes (Code S15) were used for plotting the $\left|S_{11}\right|,\left|S_{21}\right|$, and $S_{21}\left(^{\circ}\right.$ ) values of three resonators exposed to different solutions containing $\mathrm{KNO}_{3}, \mathrm{NH}_{4} \mathrm{NO}_{3}$, and $\mathrm{NH}_{4} \mathrm{H}_{2} \mathrm{PO}_{4}$.

\%Source for the code: https://github.com/alchemyst/ternplot 


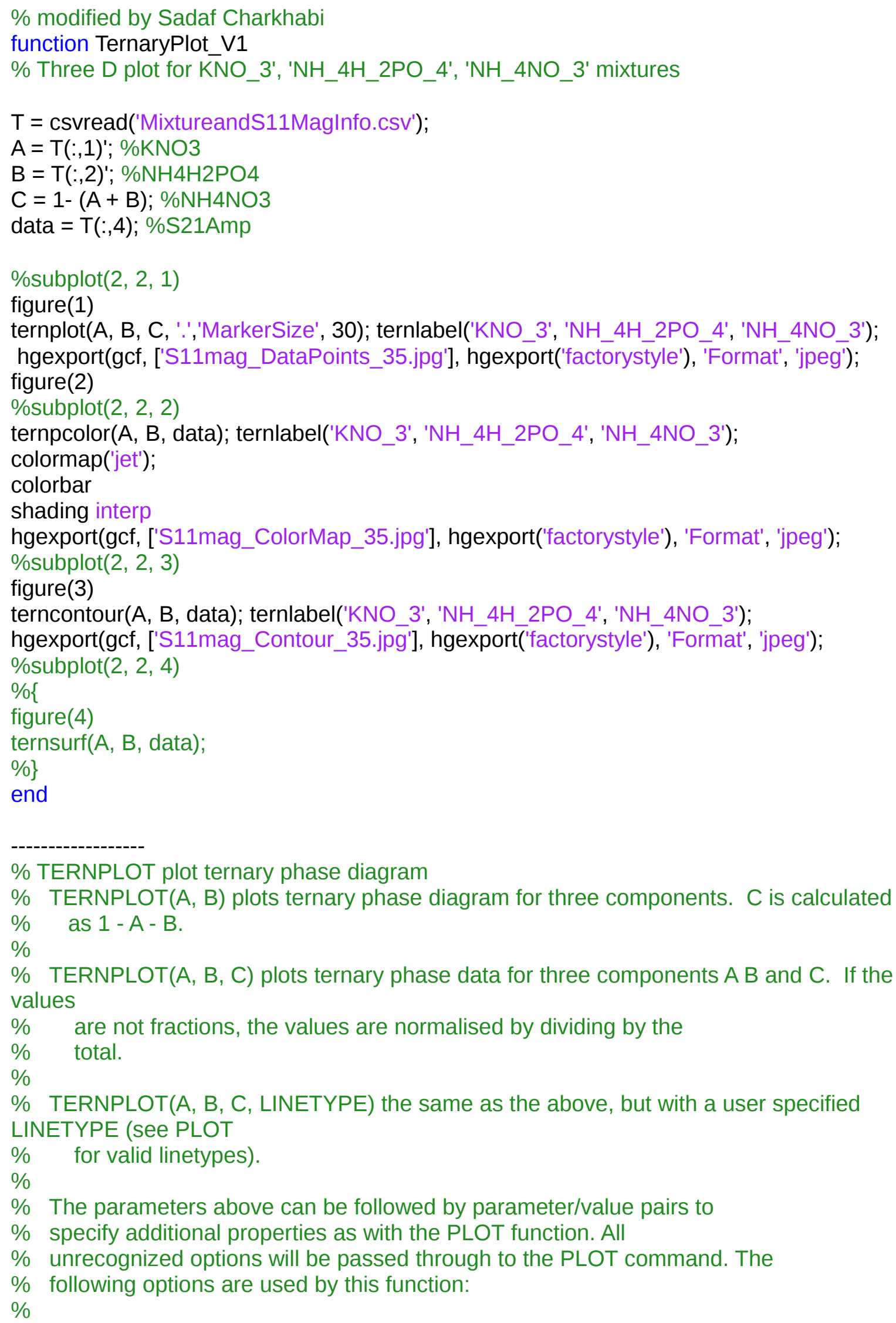


$\%$ majors 10 The number of major intervals to divide the plot grid into.

$\%$ sortpoints false Sort points in $\mathrm{x}$ order before plotting

$\%$

$\%$ Example

$\%$

$\% \quad \operatorname{plot}(\mathrm{x}, \mathrm{y}$, 'majors', 10)

$\%$

$\%$ NOTES

$\%$ - An attempt is made to keep the plot close to the default plot type. The code has been based largely on the

$\%$ code for POLAR.

$\%$ - The regular TITLE and LEGEND commands work with the plot from this function, as well as incrimental plotting

$\% \quad$ using HOLD. Labels can be placed on the axes using TERNLABEL

$\%$

$\%$ See also TERNLABEL PLOT POLAR

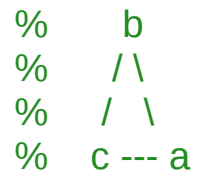

\% Author: Carl Sandrock 20020827

$\%$ To do

$\%$ Modifications

\% 20160405 (SA) Added an input argument 'major'

$\%$ Modifiers

$\%$ CS Carl Sandrock

$\%$ SA Shahab Afshari

function handles $=$ ternplot(A, B, C, varargin)

if nargin $<3$

$C=1-(A+B)$

end;

[varargin, majors] = extractpositional(varargin, 'majors', 10);

[varargin, sortpoints] = extractpositional(varargin, 'sortpoints', false);

$[f A, f B, f C]=$ fractions $(A, B, C)$;

$[x, y]=$ terncoords $(f A, f B, f C)$;

$\%$ Sort data points in $\mathrm{x}$ order

if sortpoints 


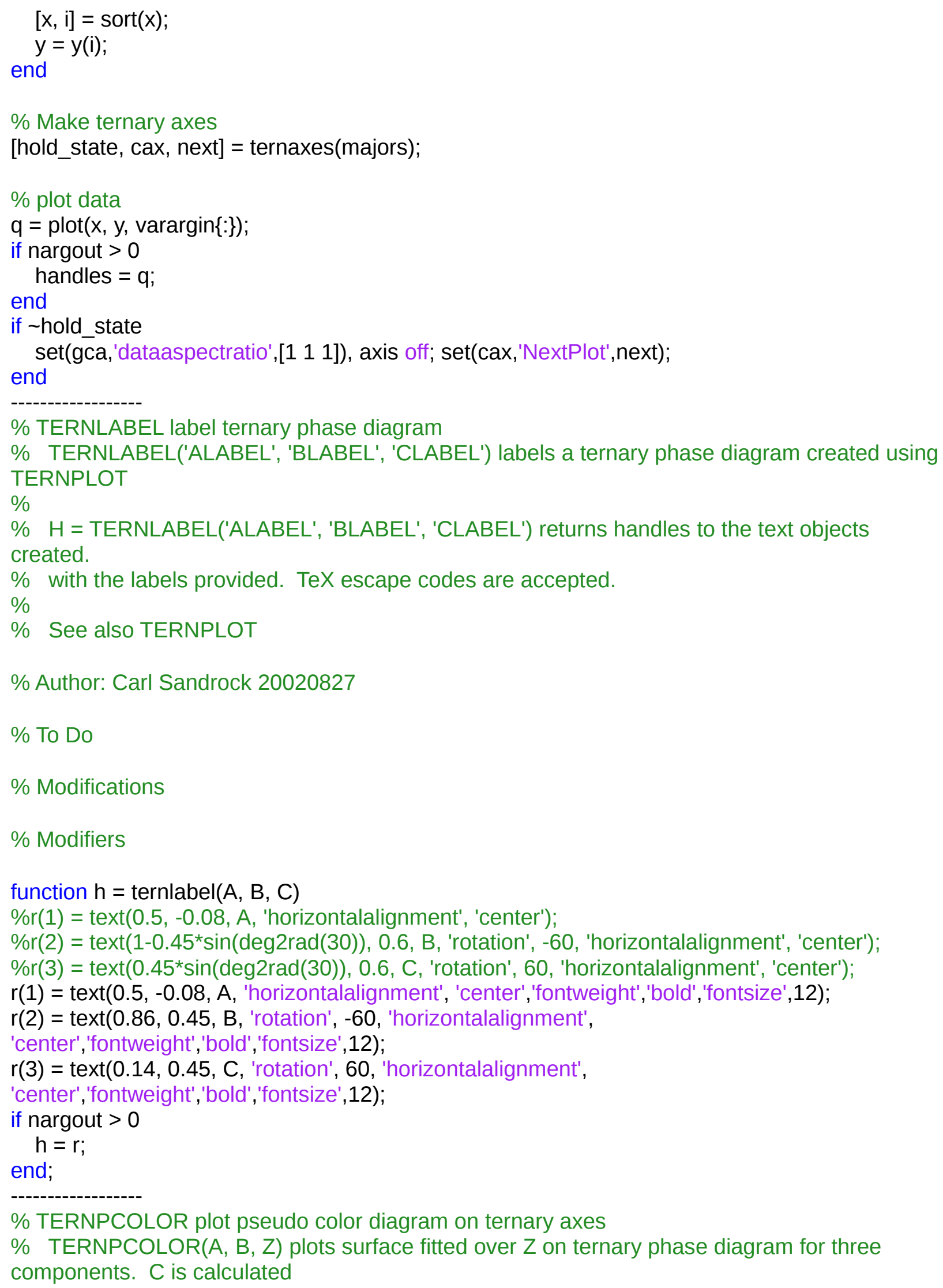


as $1-A-B$.

$\%$

$\%$ TERNPCOLOR(A, B, C, Z) plots surface of $Z$ on ternary phase data for three components $A$ $B$ and $C$. If the values

$\% \quad$ are not fractions, the values are normalised by dividing by the total.

$\%$

$\%$ NOTES

$\%$ - An attempt is made to keep the plot close to the default trisurf type. The code has been based largely on the

$\%$ code for TERNPLOT.

$\%$ - The regular TITLE and LEGEND commands work with the plot from this function, as well as incrimental plotting

$\% \quad$ using HOLD. Labels can be placed on the axes using TERNLABEL

$\%$

$\%$ See also TERNSURF TERNCONTOUR

\% Author : Carl Sandrock 20070107

\% To do: Better error checking

function ternpcolor(varargin)

ternsurf(varargin $\{:\})$;

$\operatorname{view}(0,90)$;

$\%$ TERNSURF plot surface diagram for ternary phase diagram

$\%$ TERNSURF(A, B, Z) plots surface fitted over Z on ternary phase diagram for three components. $\mathrm{C}$ is calculated

$\% \quad$ as 1 - A - B. Number of steps in axes will be enter by user as MAJORS

$\%$

$\%$ TERNSURF $(A, B, C, Z)$ plots surface of $Z$ on ternary phase data for three components $A B$ and $\mathrm{C}$. If the values

$\% \quad$ are not fractions, the values are normalised by dividing by the total. Number of steps in axes will be enter by user as MAJORS

$\%$

$\%$ NOTES

$\%$ - An attempt is made to keep the plot close to the default trisurf type. The code has been based largely on the

$\%$ code for TERNPLOT.

$\%$ - The regular TITLE and LEGEND commands work with the plot from this function, as well as incrimental plotting

$\% \quad$ using HOLD. Labels can be placed on the axes using TERNLABEL $\%$

$\%$ See also TERNCONTOURF TERNPLOT TERNLABEL PLOT POLAR CONTOUR CONTOURF

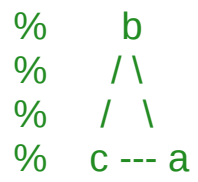


\% Author: Peter Selkin 20030507 based on TERNPLOT by Carl Sandrock 20020827 $\%$ Modified heavily by Carl Sandrock on resubmission

$\%$ To do

\% Make TERNCONTOURF and TERNSURF

$\%$ Modifications

$\% 20031006$ (CS) Added call to SIMPLETRI to plot triangular surface

$\% 20070107$ (CS) Modified to use new structure (more subroutines)

$\% 20160405$ (SA) Added an input argument 'major', and an output argument 'handle'

$\%$ Modifiers

$\%$ CS Carl Sandrock

$\%$ SA Shahab Afshari

function handle $=$ ternsurf(A, B, C, Z, varargin)

if nargin $<4$

$Z=C$;

$C=1-(A+B)$

end;

[varargin, majors] = extractpositional(varargin, 'majors', 10);

$[f A, f B, f C]=$ fractions $(A, B, C)$;

$[x, y]=$ terncoords $(f A, f B, f C)$;

$\%$ Sort data points in $x$ order

$[\mathrm{x}, \mathrm{i}]=\operatorname{sort}(\mathrm{x})$;

$y=y(i)$;

$\mathrm{Z}=\mathrm{Z}(\mathrm{i})$;

$\%$ The matrixes we work with should be square for the triangulation to work

$\mathrm{N}=$ majors +1

$\%$ Now we have $X, Y, Z$ as vectors.

$\%$ use meshgrid to generate a grid

$A r=$ linspace $(\min (f A), \max (f A), N)$;

$\mathrm{Br}=$ linspace $(\min (\mathrm{fB}), \max (\mathrm{fB}), \mathrm{N})$;

$[\mathrm{Ag}, \mathrm{Bg}]=$ meshgrid $(\mathrm{Ar}, \mathrm{Br})$;

$[\mathrm{xg}, \mathrm{yg}]=$ terncoords $(\mathrm{Ag}, \mathrm{Bg})$;

$\%$...then use griddata to get a plottable array

$\mathrm{zg}=\operatorname{griddata}\left(\mathrm{x}, \mathrm{y}, \mathrm{Z}, \mathrm{xg}, \mathrm{yg},^{\mathrm{N}} \mathrm{\prime}\right)$;

$\mathrm{Zg}(\mathrm{Ag}+\mathrm{Bg}>1)=\mathrm{nan}$;

$\%$ Make ternary axes

[hold_state, cax, next] = ternaxes(majors);

$\%$ plot data

tri = simpletri $(\mathrm{N})$;

$\%$ tri = delaunay $(x g, y g, z g)$;

handle = trisurf(tri, $x g, y g, z g)$;

$\%$ h = trimesh (tri, $x g, y g, z g) ;$

view([-37.5, 30]);

if $\sim$ hold_state

set(gca,'dataaspectratio',[1 111$]$ ), axis off; set(cax,'NextPlot',next); end 
$\%$ TERNCOORDS calculate rectangular coordinates of fractions on a ternary plot

$\%[\mathrm{X}, \mathrm{Y}]=\mathrm{TERNCOORDS(FA,} \mathrm{FB}$ ) returns the rectangular $\mathrm{X}$ and $\mathrm{Y}$ coordinates

$\%$ for the point with a fraction defined by FA and FB. It is assumed that

$\% \quad \mathrm{FA}$ and $\mathrm{FB}$ are sensible fractions.

$\%$

$\%[\mathrm{X}, \mathrm{Y}]=\mathrm{TERNCOORDS}(\mathrm{FA}, \mathrm{FB}, \mathrm{FC})$ returns the same. $\mathrm{FC}$ is assumed to be

$\%$ the remainder when subtracting FA and FB from 1.

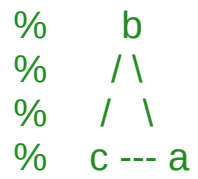

\% Author: Carl Sandrock 20050211

$\%$ Modifications

$\% 20160405$ (SA) rotation of the ternary axes in clockwise/counter-clockwise order

$\% \quad$ (User must directly switch to either options via

$\% \quad$ commenting/uncommenting the associated lines.

$\% \quad$ Moreover, any modification on terncoords must be adjusted

$\% \quad$ with associated lines on ternaxes)

$\%$ Modifiers

$\%$ SA Shahab Afshari

function $[x, y]=$ terncoords $(f A, f B, f C)$

if nargin $<3$

$f C=1-(f A+f B) ;$

end

direction = 'clockwise';

if $\sim$ strcmp(direction, 'clockwise')

$y=f B^{*} \sin (\operatorname{deg} 2 \operatorname{rad}(60))$;

$x=f A+y^{\star} \cot (\operatorname{deg} 2 \operatorname{rad}(60))$;

else

$y=f C * \sin (\operatorname{deg} 2 \operatorname{rad}(60))$

$x=1-f A-y^{\star} \cot (\operatorname{deg} 2 \operatorname{rad}(60))$;

end

16. Definition of Scattering Parameters Used in Ternary Plots

As mentioned earlier, 21 mixtures with different concentrations of $\mathrm{KNO}_{3}, \mathrm{NH}_{4} \mathrm{NO}_{3}$, and $\mathrm{NH}_{4} \mathrm{H}_{2} \mathrm{PO}_{4}$ were tested on three resonators having different spiral length. For each test, the $\left|\mathrm{S}_{11}\right|$, $\left|S_{21}\right|$, and $S_{21}\left({ }^{\circ}\right)$ signal were monitored and their values were captured at the resonant frequency of the sensor. For $\left|S_{21}\right|$, the sensor response was defined as the difference of $\left|S_{21}\right|$ for the 
resonant (peak) and trough (anti-resonant) of the resonant feature of the response (Fig S16b). For $\left|S_{11}\right|$ and $S_{21}\left({ }^{\circ}\right)$ however, the sensor response was defined with respect to the control solution (DI water). Therefore, the values observed on the ternary plot for these two parameters are the differences between the trough of the control resonant peak and the sample (Fig S16a and $\mathrm{c}$ ). 

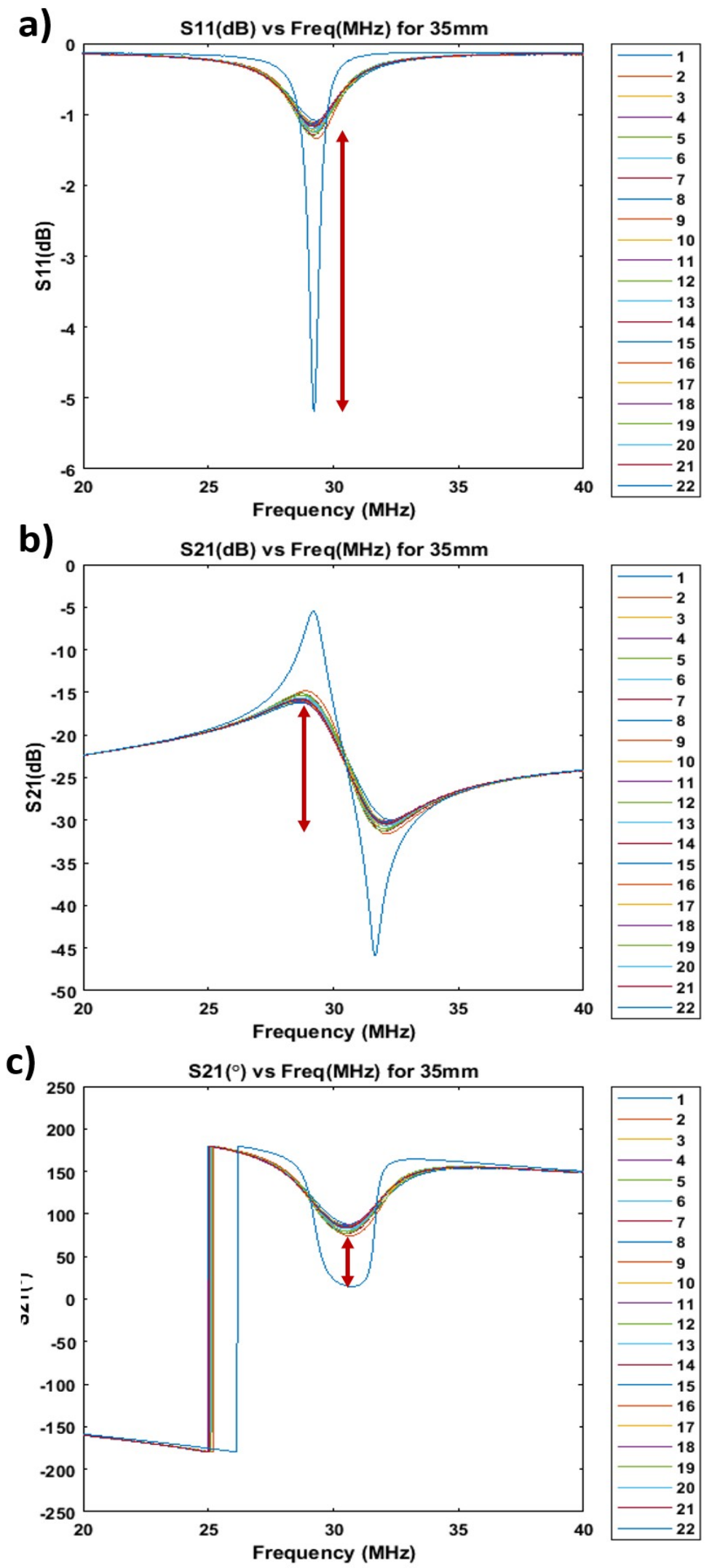

Figure S16. Definition of $\left|S_{11}\right|,\left|S_{21}\right|$, and $S_{21}\left({ }^{\circ}\right)$ values on the ternary plots. 


\section{Repeatability Ternary}

The samples used in the ternary mixture test were remade and tested again on the same resonators in order to study the repeatability of the resonant sensors in response to the ionic mixture of these solutions.

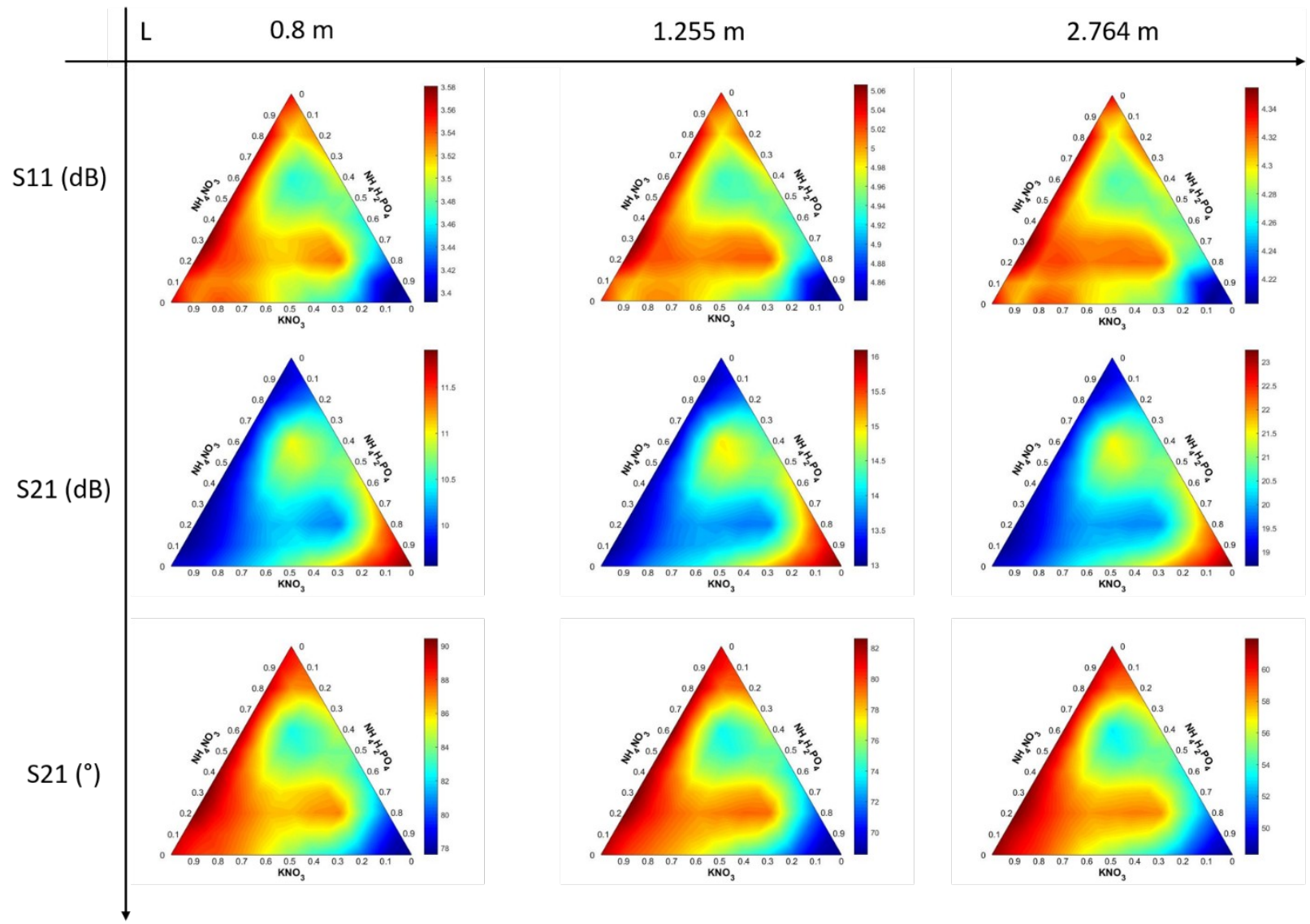

Figure S17. $\left|S_{11}\right|,\left|S_{21}\right|$, and $S_{21}\left(^{\circ}\right)$ values of ternary mixtures in the second test. 
18. Concentrations of Solutions with Known (1-21) Unknown Mixture of Salts

For this step, the ability of the resonant sensor to determine the concentrations of salts in a solution containing unknown concentrations of $\mathrm{KNO}_{3}, \mathrm{NH}_{4} \mathrm{NO}_{3}$, and $\mathrm{NH}_{4} \mathrm{H}_{2} \mathrm{PO}_{4}$ was tested. For this purpose, four "unknown" solutions having the following concentrations were prepared.

Table S18. Concentrations of ternary mixtures unknown solutions.

\begin{tabular}{|c|c|c|c|}
\hline Sample \# & $\mathbf{K N O}_{3}(\boldsymbol{\mu m})$ & $\mathbf{N H}_{4} \mathbf{H}_{\mathbf{2}} \mathbf{P O}_{\mathbf{4}}(\boldsymbol{\mu m})$ & $\mathbf{N H}_{4} \mathbf{N O}_{3}(\boldsymbol{\mu m})$ \\
\hline b & 650 & 100 & 250 \\
\hline c & 300 & 350 & 350 \\
\hline d & 250 & 550 & 200 \\
\hline e & 150 & 700 & 150 \\
\hline
\end{tabular}


19. MATLAB Code for Prediction Algorithm

The following MATLAB code (Code S19) was used to predict the concentration of individual salts in a mixture of $\mathrm{KNO}_{3}, \mathrm{NH}_{4} \mathrm{NO}_{3}$, and $\mathrm{NH}_{4} \mathrm{H}_{2} \mathrm{PO}_{4}$ and plot the ternary plots for sensor response.

Alchemyst/Ternary - C. Sandrock

function ternsurf_ARC(majors)

\% Written by Carl Sandrock 12 Aug 2017

$\%$ Source for the code: https://github.com/alchemyst/ternplot

\%Edited by Adam Carr 27 Dec 2018

$\%$

\%\%\%\%\%\%\%\%\%\%\%\%\%\%\%\%\%\%\%\%\%\%\%\%\%\%\%\%\%\%\%\%\%\%\%\%\%\%\%\%\%\%\%\%\%\%\% $\% \% \% \% \% \% \% \%$

$\%$ Read in the S parameters taken for the ternary diagram

$\mathrm{D}=$ csvread('S_Parameters.csv',1);

$\mathrm{A}=\mathrm{D}(:, 2) ; \% \mathrm{Cl}-\mathrm{M}$

$\mathrm{B}=\mathrm{D}(:, 3) ; \% \mathrm{NO}-\mathrm{M}$

$\mathrm{C}=\mathrm{D}(:, 4) ; \% \mathrm{H} 2 \mathrm{PO} 4-\mathrm{M}$

for $\mathrm{j}=5: 13$

$Z=D(:, j) ; \% S$ parameter to be interoplated

$[\mathrm{fA}, \mathrm{fB}, \mathrm{fC}]=$ fractions $(\mathrm{A}, \mathrm{B}, \mathrm{C})$;

$[x, y]=$ terncoords $(f A, f B, f C)$;

$\%$ Sort data points in $\mathrm{x}$ order

$[\mathrm{x}, \mathrm{i}]=\operatorname{sort}(\mathrm{x})$;

$y=y(i)$;

$\mathrm{Z}=\mathrm{Z}(\mathrm{i})$;

$\%$ majors = 50;

$\%$ The matrixes we work with should be square for the triangulation to work

$\mathrm{N}=$ majors +1

$\%$ Now we have $X, Y, Z$ as vectors.

$\%$ use meshgrid to generate a grid

$\mathrm{Ar}=$ linspace $(\min (\mathrm{f} A), \max (\mathrm{f} A), N)$;

$\mathrm{Br}=$ linspace $(\min (\mathrm{fB}), \max (\mathrm{fB}), \mathrm{N})$;

$[\mathrm{Ag}, \mathrm{Bg}]=$ meshgrid $(\mathrm{Ar}, \mathrm{Br})$;

$[\mathrm{xg}, \mathrm{yg}]=$ terncoords $(\mathrm{Ag}, \mathrm{Bg}) ; \%$ Concentrations in terms of meshgrid

$\mathrm{Cg}=1$ - Ag - Bg;

$\%$...then use griddata to get a plottable array

$\mathrm{zg}=\operatorname{griddata}\left(\mathrm{x}, \mathrm{y}, \mathrm{Z}, \mathrm{xg}, \mathrm{yg},^{\mathrm{N}}\right.$ ');

$\mathrm{Zg}(\mathrm{Ag}+\mathrm{Bg}>1)=\mathrm{nan} ;$

csvwrite([int2str(j-4),'.csv'],zg);\%Make file for triangular matrix of parameter

figure(j-4) 
ternpcolor(A, B, Z); ternlabel('KNO3', 'NH4NO3', 'NH4H2PO4');

shading flat; colormap jet; colorbar;

end

\%Make traingular matrices of each of the species

csvwrite('10.csv',Ag);

csvwrite('11.csv',Bg);

csvwrite('12.csv',Cg);

end

$\%$ FRACTIONS normalise ternary data

$\% \quad[f A, f B, f C]=$ FRACTIONS $(A, B, C)$ calculates fractional values for

function $[f A, f B, f C]=$ fractions $(A, B, C)$

Total $=(A+B+C)$

$\mathrm{fA}=\mathrm{A} . /$ Total;

$\mathrm{fB}=\mathrm{B} . /$ Total;

$f C=1-(f A+f B)$;

$\%$ TERNCOORDS calculate rectangular coordinates of fractions on a ternary plot

$\% \quad[\mathrm{X}, \mathrm{Y}]=\mathrm{TERNCOORDS}(\mathrm{FA}, \mathrm{FB})$ returns the rectangular $\mathrm{X}$ and $\mathrm{Y}$ coordinates

$\%$ for the point with a fraction defined by FA and FB. It is assumed that

$\% \quad F A$ and $F B$ are sensible fractions.

$\%$

$\%[\mathrm{X}, \mathrm{Y}]=$ TERNCOORDS(FA, FB, FC) returns the same. $\mathrm{FC}$ is assumed to be

$\%$ the remainder when subtracting FA and FB from 1.

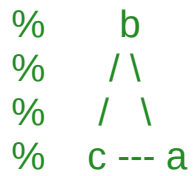

\% Author: Carl Sandrock 20050211

$\%$ Modifications

$\% 20160405$ (SA) rotation of the ternary axes in clockwise/counter-clockwise order

$\% \quad$ (User must directly switch to either options via

$\% \quad$ commenting/uncommenting the associated lines.

$\% \quad$ Moreover, any modification on terncoords must be adjusted

$\% \quad$ with associated lines on ternaxes)

$\%$ Modifiers

$\%$ SA Shahab Afshari

function $[x, y]=$ terncoords $(f A, f B, f C)$

if nargin $<3$

$f C=1-(f A+f B) ;$ 


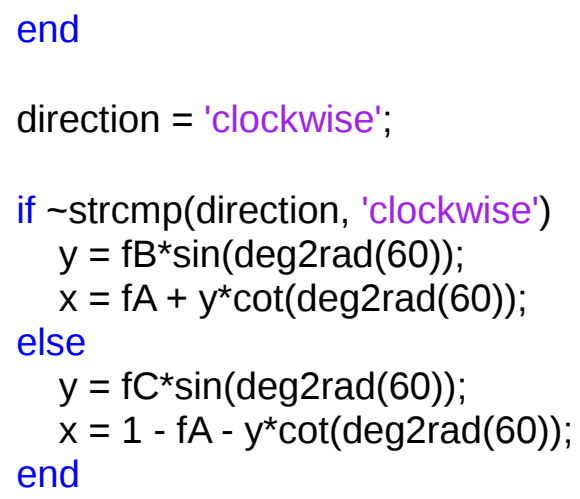

$\%$ TERNSURF plot surface diagram for ternary phase diagram

$\%$ TERNSURF(A, B, Z) plots surface fitted over $Z$ on ternary phase diagram for three components. $C$ is calculated

$\%$ as 1 - A - B. Number of steps in axes will be enter by user as MAJORS

$\%$

$\%$ TERNSURF(A, B, C, Z) plots surface of $Z$ on ternary phase data for three components A B and $C$. If the values

$\% \quad$ are not fractions, the values are normalised by dividing by the total. Number of steps in axes will be enter by user as MAJORS

$\%$ 
$\%$ NOTES

$\%$ - An attempt is made to keep the plot close to the default trisurf type. The code has been based largely on the

$\%$ code for TERNPLOT.

$\%$ - The regular TITLE and LEGEND commands work with the plot from this function, as well as incrimental plotting

$\% \quad$ using HOLD. Labels can be placed on the axes using TERNLABEL

$\%$

$\%$ See also TERNCONTOURF TERNPLOT TERNLABEL PLOT POLAR CONTOUR CONTOURF

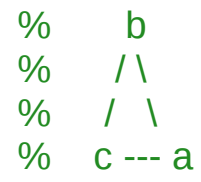

\% Author: Peter Selkin 20030507 based on TERNPLOT by Carl Sandrock 20020827

$\%$ Modified heavily by Carl Sandrock on resubmission

$\%$ To do

$\%$ Make TERNCONTOURF and TERNSURF

$\%$ Modifications

$\% 20031006$ (CS) Added call to SIMPLETRI to plot triangular surface

$\% 20070107$ (CS) Modified to use new structure (more subroutines)

\% 20160405 (SA) Added an input argument 'major', and an output argument 'handle'

$\%$ Modifiers

$\%$ CS Carl Sandrock

$\%$ SA Shahab Afshari

function handle $=$ ternsurf(A, B, C, Z, varargin)

if nargin $<4$

$Z=C$

$C=1-(A+B)$

end;

[varargin, majors] = extractpositional(varargin, 'majors', 100);

$[f A, f B, f C]=$ fractions $(A, B, C)$;

$[x, y]=$ terncoords $(f A, f B, f C)$;

$\%$ Sort data points in $x$ order

$[x, i]=\operatorname{sort}(x)$;

$y=y(i)$;

$\mathrm{Z}=\mathrm{Z}(\mathrm{i})$;

$\%$ The matrixes we work with should be square for the triangulation to work $\mathrm{N}=$ majors +1 
$\%$ Now we have $X, Y, Z$ as vectors.

$\%$ use meshgrid to generate a grid

$A r=$ linspace $(\min (f A), \max (f A), N)$;

$\mathrm{Br}=$ linspace $(\min (\mathrm{fB}), \max (\mathrm{fB}), \mathrm{N})$;

$[\mathrm{Ag}, \mathrm{Bg}]=$ meshgrid $(\mathrm{Ar}, \mathrm{Br})$;

$[\mathrm{xg}, \mathrm{yg}]=$ terncoords $(\mathrm{Ag}, \mathrm{Bg})$;

$\%$...then use griddata to get a plottable array

$\mathrm{zg}=\operatorname{griddata}\left(\mathrm{x}, \mathrm{y}, \mathrm{Z}, \mathrm{xg}, \mathrm{yg}, \mathrm{v}^{\prime}\right)$;

$z g(A g+B g>1)=$ nan;

$\%$ Make ternary axes

[hold_state, cax, next] = ternaxes(majors);

$\%$ plot data

tri = simpletri(N);

\%tri = delaunay $(\mathrm{xg}, \mathrm{yg}, \mathrm{zg})$;

handle = trisurf(tri, $x g, y g, z g)$;

$\% \mathrm{~h}=$ trimesh(tri, $\mathrm{xg}, \mathrm{yg}, \mathrm{zg})$;

view([-37.5, 30]);

if $\sim$ hold_state

set(gca,'dataaspectratio',[[ 111 1]), axis off; set(cax,'NextPlot',next);

end

$\%$ TERNLABEL label ternary phase diagram

$\%$ TERNLABEL('ALABEL', 'BLABEL', 'CLABEL') labels a ternary phase diagram created using TERNPLOT

$\%$

$\% \quad H=$ TERNLABEL('ALABEL', 'BLABEL', 'CLABEL') returns handles to the text objects created.

$\%$ with the labels provided. TeX escape codes are accepted.

$\%$

$\%$ See also TERNPLOT

\% Author: Carl Sandrock 20020827

\% To Do

$\%$ Modifications

$\%$ Modifiers

function $\mathrm{h}=$ ternlabel $(\mathrm{A}, \mathrm{B}, \mathrm{C})$

$\% r(1)=\operatorname{text}(0.5,-0.08, A$, 'horizontalalignment', 'center');

$\% r(2)=\operatorname{text}\left(1-0.45^{\star} \sin (\right.$ deg2rad(30)), 0.6, B, 'rotation', -60, 'horizontalalignment', 'center');

$\% \mathrm{r}(3)=\operatorname{text}\left(0.45^{\star} \sin (\operatorname{deg} 2 \mathrm{rad}(30)), 0.6, \mathrm{C}\right.$, 'rotation', 60, 'horizontalalignment', 'center'); 


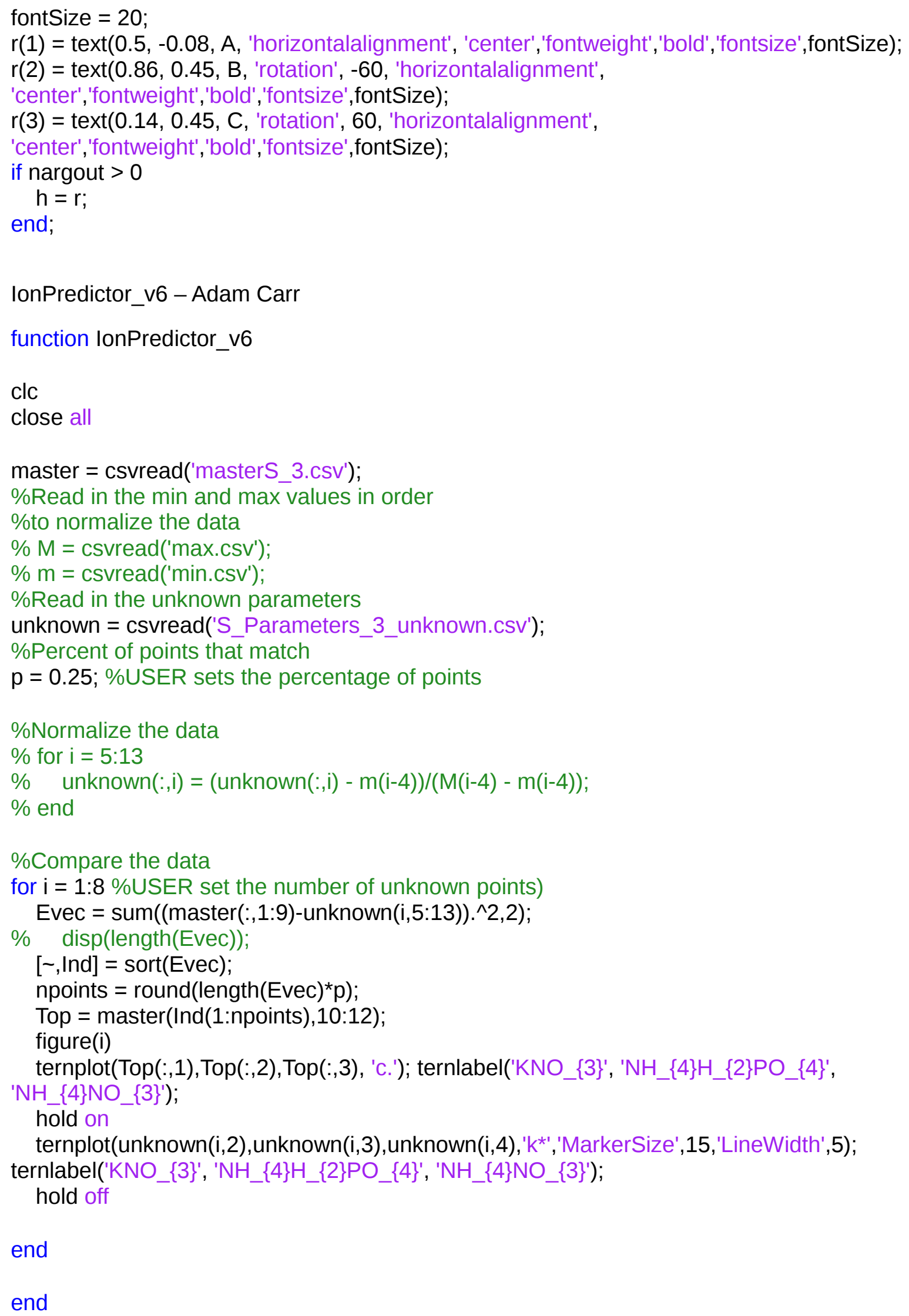




\section{References}

(1) Andringa, M. M.; Neikirk, D. P.; Dickerson, N. P.; Wood, S. L. Unpowered Wireless Corrosion Sensor for Steel Reinforced Concrete. In SENSORS, 2005 IEEE; IEEE, 2005; p. 4-pp.

(2) Anand, R. Wireless Communications: For Students of BE/B. Tech. of All Technical Universities of India; New Delhi: S. chand \& company LTD, 2012.

(3) Roy, S.; Neihart, N. M.; Bowler, N. Coaxial Microwave Resonant Sensor Design for Monitoring Ionic Concentration in Aqueous Solutions. In 2018 IEEE International Instrumentation and Measurement Technology Conference (I2MTC); 2018; pp. 1-6.

(4) Roy, S. Microwave Resonant Sensor for Measurement of Ionic Concentration in Aqueous Solutions. 2017.

(5) Seyfi, S.; Brown, C. S. Apparatus and Method for Measuring Salinity of a Fluid by Inductance, 2009.

(6) Little, V. I. The Dielectric Constant of Aqueous Ionic Solutions. Proc. Phys. Soc. Sect. B $1955,68,357$.

(7) Chen, T.; Hefter, G.; Buchner, R. Dielectric Spectroscopy of Aqueous Solutions of KCl and CsCl. J. Phys. Chem. A 2003, 107, 4025-4031.

(8) Levy, A.; Andelman, D.; Orland, H. Dielectric Constant of Ionic Solutions: A Field-Theory Approach. Phys. Rev. Lett. 2012, 108, 227801.

(9) Hasted, J. B.; Ritson, D. M.; Collie, C. H. Dielectric Properties of Aqueous Ionic Solutions. Parts I and II. J. Chem. Phys. 1948, 16, 1-21.

(10) Furth, R. Dielektrizitatskonstanten Guter Leiter. Phys. Zeit. 1924, 25, 676-679.

(11) Pechhold, R. Untersuchung Einiger Wäßriger Elektrolytlösungen Nach Der Fürthschen Ellipsoidmethode. Ann. Phys. 1927, 388, 427-456.

(12) Bockris, J. O.; Bowler-Reed, J. The Measurement of Dielectric Constants of Conducting Liquids. Br. J. Appl. Phys. 1951, 2, 74.

(13) Anderson, J. E. The Debye-Falkenhagen Effect: Experimental Fact or Friction? J. Non. Cryst. Solids 1994, 172, 1190-1194.

(14) Falkenhagen, H. The Principal Ideas in the Interionic Attraction Theory of Strong Electrolytes. Rev. Mod. Phys. 1931, 3, 412.

(15) Dunning, W. J.; Shutt, W. J. The Dielectric Properties of Aqueous Solutions of Salts. Trans. Faraday Soc. 1938, 34, 467-479.

(16) Hemmer, P. C. The Collected Works of Lars Onsager; World scientific series in 20th century physics; World Scientific, 1996.

(17) Mollerup, J. M.; Breil, M. P. Modeling the Permittivity of Electrolyte Solutions. AIChE J. 2015, 61, 2854-2860. 
(18) Wang, C.-C.; Bruner, L. J. Dielectric Saturation of the Aqueous Boundary Layers Adjacent to Charged Bilayer Membranes. J. Membr. Biol. 1978, 38, 311-331.

(19) Little, V. I.; Smith, V. The Ionic Conductivity of Dilute Potassium Chloride Solutions at Centimetric Wavelengths. Proc. Phys. Soc. Sect. B 1955, 68, 65.

(20) Allison, S.; Wu, H.; Twahir, U.; Pei, H. Conductivity and Electrophoretic Mobility of Dilute Ionic Solutions. J. Colloid Interface Sci. 2010, 352, 1-10.

(21) https://medicalsciences.med.unsw.edu.au/research/researchservices/ies/ionicmobilitytables 
